\author{
UNIVERSIDADE DE SÃO PAULO \\ ESCOLA DE ENFERMAGEM DE RIBEIRÃO PRETO
}

A visão dos gerentes das Unidades Básicas de Saúde sobre a Tuberculose na Agenda Municipal, em um município do Estado de São Paulo 


\section{A visão dos gerentes das Unidades Básicas de Saúde sobre a Tuberculose na Agenda Municipal, em um município do Estado de São Paulo}

Tese apresentada à Escola de Enfermagem de Ribeirão Preto da Universidade de São Paulo para obtenção do título de Doutor em Enfermagem em Saúde Pública.

Área de Concentração: Enfermagem em Saúde Pública. Inserida na linha de pesquisa: Práticas, Saberes e Políticas de Saúde.

Orientador: Prof. Dr. Pedro Fredemir Palha

Ribeirão Preto 
AUTORIZO A REPRODUÇÃO E DIVULGAÇÃO TOTAL E PARCIAL DESTE TRABALHO, POR QUALQUER MEIO CONVENCIONAL OU ELETRÔNICO, PARA FINS DE ESTUDO E PESQUISA, DESDE QUE CITADA A FONTE.

FICHA CATALOGRÁFICA

\section{Protti, Simone Teresinha}

A visão dos gerentes das Unidades Básicas de Saúde sobre a Tuberculose na Agenda Municipal, em um município do Estado de São Paulo

120 p. : il.; $30 \mathrm{~cm}$

Tese de Doutorado, apresentada à Escola de Enfermagem de Ribeirão Preto/USP - Área de concentração: Enfermagem em Saúde Pública.

Orientador: Palha, Pedro Fredemir.

1. Tuberculose. 2. Gerência. 3. Planejamento em Saúde. 4. Sistemas de saúde. 


\section{FOLHA DE APROVAÇÃO}

Simone Teresinha Protti

A visão dos gerentes das Unidades Básicas de Saúde sobre a Tuberculose na Agenda Municipal, em um município do Estado de São Paulo

Tese apresentada à Escola de Enfermagem de Ribeirão Preto da Universidade de São Paulo para obtenção do título de Doutor em Enfermagem em Saúde Pública.

Área de Concentração: Enfermagem em Saúde Pública.

Aprovado em:

\section{BANCA EXAMINADORA}

Prof. Dr.

Instituição: Assinatura:

Prof. Dr.

Instituição: Assinatura:

Prof. Dr. Instituição: Assinatura:

Prof. Dr.

Instituição: Assinatura:

Prof. Dr. Instituição: Assinatura: 


\section{LISTA DE ILUSTRAÇÕES}

GRÁFICO 1 A TB como doença prioritária no quadro sanitário do município

GRÁFICO 2 Participação na discussão e definição de ações de saúde para o controle da TB

GRÁFICO 3 Número de anos como gerente de Unidade Básica de Saúde

GRÁFICO 4 Participação na discussão e definição de aplicação de 77 recursos para o PCT

GRÁFICO 5 Definição de linhas específicas para TB no repasse de 81 recursos para o município

GRÁFICO 6 Distribuição de recursos realizada de acordo com as 88 necessidades da população a ser atendida 


\section{RESUMO}

PROTTI, S. T. A visão dos gerentes das Unidades Básicas de Saúde sobre a Tuberculose na Agenda Municipal, em um município do Estado de São Paulo. 2008.120f.Tese (Doutorado) - Escola de Enfermagem de Ribeirão Preto, Universidade de São Paulo, 2008.

Nesta investigação analisamos a visão dos gerentes das Unidades Básicas de Saúde (UBS) a cerca da problemática da Tuberculose (TB) em um município do interior do Estado de São Paulo. Participaram do estudo 14 gerentes de UBS, sendo a coleta dos dados realizada por meio de entrevista que enfocava "a TB na agenda municipal", foi aplicado um questionário fechado e ao final deste uma questão aberta, que permitiu aos sujeitos manifestarem livremente as dificuldades no controle da TB no âmbito da gerência local. A entrevista se deu após o consentimento livre e esclarecido. Para o tratamento dos dados utilizamos o Programa Statística 8.0 da Statsoft, e, por meio deste, elaboramos tabelas de freqüência simples e para os dados qualitativos, utilizamos a técnica de análise de conteúdo, modalidade temática, surgindo três categorias temáticas: 1) A gerência da UBS no controle da TB: um campo de desafios; 2) Ações gerenciais do controle da TB na Atenção Básica (AB): potencialidades e limites; 3) O Controle da TB na AB: a visão gerencial. Os sujeitos do estudo atuam a mais de cinco anos na função de gerentes e a maioria deles toma a TB como uma doença prioritária no quadro sanitário local, de forma que, $81,3 \%$ deles a considera como doença prioritária no quadro sanitário do município, e apenas 12,5\% expõem que, às vezes, a consideram prioritária. Quanto à participação deles na discussão e definição de ações para o controle da TB no município mais de 50\% participam às vezes ou quase nunca, nos permitindo refletir o quão estes gerentes estão imbuídos desta temática. Observamos que há pontualidade do enfoque da TB na $A B$, ou seja, nas campanhas e semana da $T B$. Essa característica de "focalização" das ações, presente nas falas dos sujeitos remete a cultura presente na organização dos sistemas locais de saúde, refletindo no campo do planejamento. A demora no diagnóstico foi relatada pelos gerentes, fazendo com que o doente retorne várias vezes à unidade de saúde em busca de uma solução para seus sintomas. Somado à demora o estigma é algo aparece na fala dos sujeitos e necessita ser trabalhado, uma vez que ambos implicam diretamente no planejamento e organização das ações do controle da TB na AB. Os dados nos mostram que $50 \%$ dos gestores não participam e/ou não sabem em relação à definição de linhas específicas para a $T B$, no repasse de recursos para o município. A subnotificação é uma preocupação apontada pelos gerentes que possuem pouco conhecimento do Programa de Controle da Tuberculose (PCT), bem como, dos casos de TB de sua área de abrangência. Nos seus depoimentos fica explícito uma gerência técnico-burocrática, com debilidades nas dimensões do planejamento e na organização das atividades da UBS que gerenciam. Assim, os gerentes assistenciais do contexto sanitário estudado necessitam recompor aspectos da gerência, como o planejamento e a organização como formas de viabilizar a política de controle da TB, de acordo com os preceitos jurídico-legais e as normatizações inerentes ao PCT.

Palavras-chave: Tuberculose. Gerência. Planejamento em Saúde. Sistemas de saúde. 


\begin{abstract}
PROTTI, S. T. The view of Basic Health Unit managers about Tuberculosis in the Municipal Agenda of a city in the state of São Paulo. 2008. 120 p. Dissertation (Doctorate) - Ribeirão Preto College of Nursing at University of São Paulo, 2008.
\end{abstract}

In this study we analyzed the view of Basic Health Unit (BHU) managers about the Tuberculosis (TB) issue in a city in the interior of São Paulo state. Fourteen BHU managers participated in the study. Data collection took place through interviews that focused on "TB in the municipal agenda". A closed questionnaire was administered, and, at the end, an open question was also applied, which allowed for subjects to freely express the difficulties to control TB in the scope of local management. The interview was carried out after obtaining free and informed consent. Data analysis was performed using the Statsoft software Statística 8.0, which was also used to create simple frequency tables, and thematic content analysis was used for the qualitative data. Thus, three thematic categories emerged: 1) Managing the $B H U$ in TB control: a field of challenges; 2) Managerial actions for TB control in Primary Care (PC); strengths and limits; 3) TB Control in PC: the managerial view. The study subjects have worked as managers for over five years and most consider TB a priority disease in the local health setting. In fact, $81.3 \%$ of them consider it a priority disease in the municipal health setting, and only $12.5 \%$ state that they sometimes consider it a priority. As to their participation in the discussion and definition oft TB control actions in the city, over $50 \%$ sometimes or almost never participate. This shows how deep these managers are imbued with this theme. We observed that TB is strongly focused in PC, i.e., in the campaigns and TB week. This characteristic of "focusing" on actions, present in the subjects' statements, recalls the present culture of the local health system organization, having an effect on the field of planning. Managers reported there is a delay in diagnosis, which implies that the patient comes back several times to the health unit searching for a solution to his or her symptoms. In addition to that delay, subjects also state the stigma, which also needs to be solved since both have a direct effect on the planning and organization of TB control actions in PC. The data show that $50 \%$ of the managers do not participate and/or do not know about the definition of specific lines for TB, in terms of transferring resources in the municipality. Underreported cases are a concern pointed out by managers who have little knowledge about the Tuberculosis Control Program (TCP), as well as TB cases in their area. Their statements clearly state a technicalbureaucratic management, deficient in the activity planning and organization dimensions at the BHU they manage. Hence, health care managers in the studied context need to recompose management aspects like planning and organization as ways to make the TB control policy feasible according to the legal precepts and regulations inherent in the TCP.

Keywords: Tuberculosis. Management. Health planning. Health systems. 


\section{SUMÁRIO}

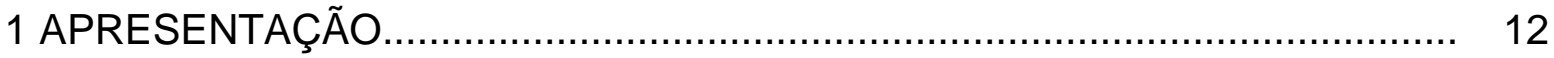

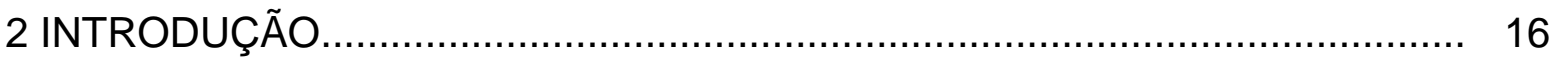

2.1 O Contexto da Tuberculose no Cenário Mundial....................................... 16

2.2 A Tuberculose no Brasil................................................................. 19

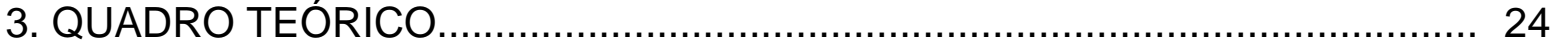

3.1 A Descentralização do Setor Saúde no Brasil......................................... 24

3.2 A Descentralização das Ações de Tuberculose no Brasil......................... 27

3.3 A Gerência nos Serviços de Saúde.............................................. 30

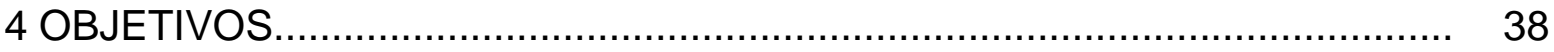

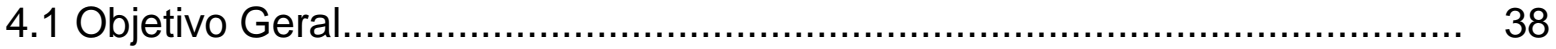

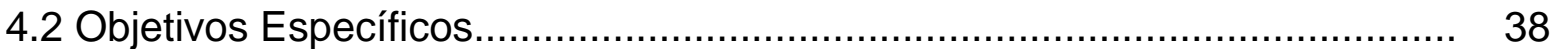

5 PERCURSO METODOLÓGICO............................................................. 40

5.1 Cenário do Estudo............................................................................ 40

5.1.1 A Rede de Atenção à Saúde no Município do Estudo .................... 43

5.1 .2 Sujeitos do Estudo.............................................................. 44

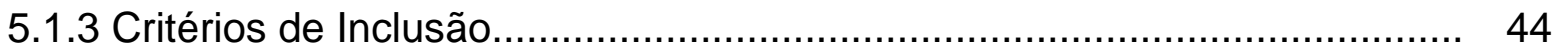

5.1.4 Critérios de Exclusão................................................................. 44

5.1 .5 Instrumento de Coleta dos Dados................................................... 44

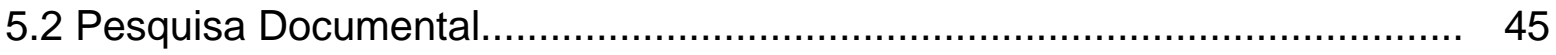

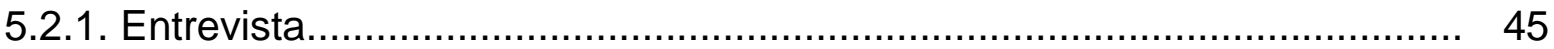

5.2.2 A Coleta dos Dados................................................................... 46

5.3 Análise dos Dados........................................................................ 48

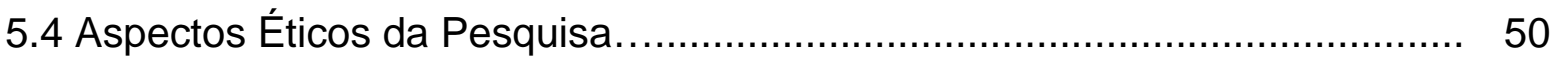

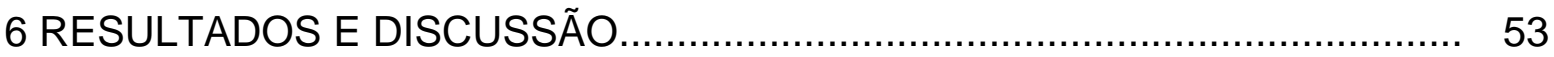


6.1.1 A Gerência da Unidade Básica de Saúde no Controle da Tuberculose: um campo de desafios

6.1.2 O Controle da Tuberculose na Atenção Básica: a visão gerencial.

6.1.3 Ações Gerenciais do Controle da Tuberculose na Atenção Básica:

potencialidades e limites

7 CONSIDERAÇÕES FINAIS

REFERÊNCIAS.

APÊNDICE.

ANEXOS 


\section{APRESENTAÇÃO}

O interesse pela Tuberculose (TB) emergiu em 2005 em decorrência, principalmente, de minha inserção no Grupo de Estudos EpidemiológicoOperacionais em Tuberculose (GEOTB). Este grupo é cadastrado e certificado no diretório de grupos do Conselho Nacional de Desenvolvimento Científico e Tecnológico (CNPq) desde 2002, está inserido na Rede Brasileira de Pesquisa em Tuberculose (REDE-TB). O grupo é coordenado pelo Prof. Dr. Antonio Ruffino Netto da Faculdade de Medicina de Ribeirão Preto da Universidade de São Paulo (FMRPUSP) e pela Profa. Dra. Tereza Cristina Scatena Villa da Escola de Enfermagem de Ribeirão Preto da Universidade de São Paulo (EERP-USP).

Participar do GEOTB tem sido para mim uma oportunidade de ampliar e aprofundar questões, teorias e conceitos em relação à problemática da TB no Brasil e no mundo. O grupo propicia ainda a integração com pesquisadores de diversos campos científicos contribuindo, assim, para o aprofundamento teórico-metodológico na temática, bem como, capacita constantemente seus membros.

Este estudo faz parte de uma série de estudos realizados em diferentes regiões do Brasil a partir do projeto multicêntrico desenvolvido pela Área de Pesquisa Operacional da Rede Brasileira de Pesquisa em Tuberculose - REDE-TB "Avaliação das dimensões organizacionais e de desempenho dos serviços de atenção básica no controle da TB em centros urbanos de diferentes regiões do Brasil". Este projeto tem a aprovação e o financiamento do CNPq/MS-SCTIE-DECIT 
- nº 25/2006 409035/2006-8 e contemplou municípios prioritários da região Sudeste, como as cidades de São Paulo e Rio de Janeiro; a região Nordeste é representada pelos estados da Paraíba e da Bahia. O critério de inclusão utilizado foi a implantação do Tratamento Diretamente Observado de Curta Duração (DOTS) há pelo menos cinco anos.

Cabe salientar ainda que o estudo envolveu cinco municípios e está sendo desenvolvido por pesquisadores da REDE/TB, Escola de Enfermagem e Faculdade de Medicina de Ribeirão Preto, da Universidade de São Paulo; Faculdade de Medicina de São José do Rio Preto; Universidade Federal do Rio de Janeiro; Universidade Estadual da Paraíba, Universidade Federal da Paraíba e Universidade Estadual de Feira de Santana. Sendo assim, para esta investigação, contemplamos o município de Ribeirão Preto/SP como cenário de investigação.

Sabemos que a TB se consolida como um problema de Saúde Pública no Brasil durante todo o século $X X$, sendo conhecida como a "calamidade negligenciada" (RUFFINO-NETTO, 2002). Esta doença ocupa, atualmente, o $16^{\circ}$ lugar entre os 22 países com a mais alta carga de TB notificada no mundo. No ano de 2005, estimativas globais apontavam a existência de aproximadamente 8,8 milhões de casos novos de TB, como 136/100.000 habitantes (WORLD HEALTH ORGANIZATION [WHO], 2007).

Com o processo de descentralização das ações de atenção à TB, no qual a doença passa a ser de responsabilidade de todos os municípios brasileiros, devemos reconhecer a necessidade e a importância de estudos que contemplem o envolvimento dos gestores em saúde nas ações de controle da TB, bem como da estratégia DOTS. 
Nesse sentido, Monroe (2007), contemplou em seu estudo "o envolvimento de atores-chave com o controle da TB no contexto de sistemas municipais de saúde do Estado de São Paulo". A autora afirma que a prioridade dada à TB na agenda municipal de saúde, a adequada gestão do Programa de Controle da Tuberculose (PCT) e o adequado preparo e envolvimento das equipes de saúde que lidam com a TB, principalmente aquelas que atuam na Atenção Básica, são elementos essenciais para o êxito no controle da doença, bem como o alcance de metas pactuadas nacional e internacionalmente.

Como conseqüência deste processo de discussão, firmou-se o meu interesse em aprofundar conhecimentos nessa temática e, assim, direcionar meu objeto de investigação que é o desempenho dos gerentes das Unidades Básicas de Saúde (UBS) no controle da tuberculose no município de Ribeirão Preto/SP.

Convém apontar que os gerentes das UBSs se constituem como gestores locais de saúde, cabendo a estes a gestão dos programas da sua unidade objetivando um adequado desempenho dos serviços de saúde no manejo da doença nos diversos contextos locais em que a mesma se apresenta.

Dessa forma, o presente estudo aborda a visão destes gerentes/gestores em relação à problemática da $\mathrm{TB}$, bem como o seu papel enquanto gestor de políticas de saúde e facilitador das ações em saúde no seu campo de atuação. Com esta investigação pretendemos colaborar na produção de conhecimentos teóricos e operacionais que possibilitem (re)pensar ações e intervenções locais na atenção à TB, bem como seus indicadores epidemiológicos. 


\section{INTRODUÇÃO}

\subsection{O Contexto da Tuberculose no Cenário Mundial}

A Tuberculose é uma calamidade que preocupa as autoridades da saúde no mundo todo. Em 1993, a Organização Mundial da Saúde (OMS) declarou a TB como estado de urgência e criou o programa STOP TB que reúne instituições de alto nível científico e/ou poder econômico: OMS, Banco Mundial, Centers for Disease Control (CDC)-Atlanta, International Union Against Tuberculosis and Lung Disease (IUATLD), Royal Netherlands Tuberculosis Association (RNTA) e American Thoracic Association (ATA) (RUFFINO-NETTO, 2002).

A TB ainda ocupa em nossos dias a liderança mundial como causa de morte por doença infecciosa entre adultos, apesar dos avanços tecnológicos e de ações de saúde disponíveis para controlá-la e até mesmo erradicá-la (TEIXEIRA, 2004). Segundo a OMS um terço da população mundial está infectada com a TB sendo dois bilhões de infectados, oito milhões que desenvolverão a doença e 1,8 milhões morrerão dela (BRASIL,2004).

Representa um grave problema de aspecto sócio-econômico, pois é uma doença que atinge as camadas menos favorecidas da população; isso exige envolvimento dos profissionais da saúde e da sociedade em prol de estratágia/ações inovadoras para o controle, tendo como foco a diminuição da morbimortalidade pela TB (AMSTERDAM DECLARATION TO STOP TB,2000). 
A falta de conhecimento em relação à transmissão e cura, e a discriminação aos doentes têm contribuído para a permanência do estigma da TB, aliado ao fato de que se evidenciam poucas informações sobre temas relativos à doença junto aos meios de comunicação. Por outro lado, os Programas de Controle da Tuberculose (PCT) não têm obtido capacidade de vocalização junto à imprensa (SANTOS FILHO,2006).

Para Ogden; Walt; Lush (2003) outro fator que culminou para a TB estar entre um dos importantes problemas de saúde pública foi o advento do HIV nas décadas de 80 e 90 juntamente com seu impacto nos países desenvolvidos. Somase a isso o surgimento da multidrogarresistente (MDR). Dessa forma, a Aids, a MDR, as pressões populares, acadêmicas e da mídia propiciaram com que decisores políticos voltassem seus olhares para a TB, contribuindo, assim, para o retorno desta como prioridade nas organizações internacionais.

Diante disso, a Assembléia Mundial de Saúde considerou, em 1991, a TB como problema de saúde pública e apontou para a necessidade do seu controle, estabeleceu também, as metas globais de detecção de casos - 70\% dos casos novos de TB com a baciloscopia positiva, e a cura da doença - 85\% dos casos detectados com baciloscopia positiva. Essas metas deveriam ser atingidas até o ano de 2000 (BLANC; MARTINEZ, 2006).

É importante ressaltar que tais metas globais, pactuadas em 1991 para a detecção e cura da TB não conseguiram ser atingidas no ano de 2005 e obteve-se, neste mesmo ano, $62 \%$ de detecção de casos e $84 \%$ de sucesso no tratamento (WORLD HEALTH ORGANIZATION, 2007).

Desde o ano de 1993, vem se criando e adotando novas diretrizes de trabalho e estratégias globais no controle da TB dada a emergência do quadro sanitário 
mundial (BRASIL, 1997. Em 2000, FRENTE À Declaração DE Amsterdã, os governos dos países com altas taxas de TB assumiram compromissos políticos globais como ampliar o acesso, garantir recursos financeiros e humanos, monitorar e avaliar os programas nacionais de TB segundo os padrões estabelecidos pela OMS, transparência, distribuição de medicamentos e apoiar parcerias com as Organizações Não-Governamentais (ONG) no controle da doença (AMSTERDAM DECLARATION TO STOP TB, 2000).

Em 1998 a TB passa a ser prioridade na agenda de saúde do cenário internacional. Neste mesmo ano foi criado o Stop TB Iniciative, legitimado pela OMS. O intuito deste movimento era o controle e a eliminação dessa doença como um grave problema de saúde pública (WHO, 2000; VÉRON et al, 2004).

Com a publicação da Amsterdam Declaration, em 2000, reiterou-se o compromisso dos países envolvidos em priorizar esforços para o controle da TB, privilegiando a estratégia DOTS, bem como, salientando a necessidade de se estabelecer parcerias com Organizações não-governamentais (ONGs) para atingir os objetivos propostos. E, nesse sentido, as metas globais estabelecidas para o controle da TB em 1991 na 44ª Assembléia Mundial de Saúde foram reafirmadas, com um novo prazo projetado para o ano de 2005 (AMSTERDAM DECLARATION TO STOP TB, 2000).

Com a criação das Metas para o Desenvolvimento do Milênio (MDM) pelas Nações Unidas, a TB passou a ser privilegiada juntamente com outras doenças como a malária e o HIV, até 2015. Cabe ressaltar que algumas destas MDM estão diretamente relacionadas com a TB sendo: em 2005, detecção de $70 \%$ dos casos novos bacilíferos e sucesso no tratamento de $85 \%$ dos casos; para o período de 1990 a 2015 reduzir pela metade as taxas de prevalência e de mortalidade por TB; 
para 2015 controlar e iniciar a redução da incidência da doença. Para atingir essas metas propostas a OMS salienta a importância da implementação da estratégia DOTS (WHO, 2005).

\subsection{A Tuberculose no Brasil}

No ranking dos países com maior incidência de tuberculose, 22 destes merecem atenção especial, pois são responsáveis por $80 \%$ dos casos estimados de TB no mundo, ressaltando que o Brasil ocupa a $16^{a}$ posição entre esses países (WHO, 2006).

Teixeira (2002) ressalta que, no Brasil, semelhante aos países que apresentam um perfil social similar, a TB teve uma redução que foi acelerada nos primeiros anos pós-quimioterapia e, posteriormente, se fez de forma lenta, embora sustentada. Um estudo realizado nas capitais brasileiras mostrou que no período de 1954 a 1980 ocorreu uma redução de 93\% (3,57\% ao ano) nas taxas de mortalidade e de 65\% (2,5\% ao ano) na notificação de casos. Já no período de 1981 a 2000 a taxa de mortalidade teve uma redução de $37,45 \%$ o equivalente a 1,97\% ao ano e a de notificação de casos apresentou uma redução de 33,33\%, ou 1,58\% anual. Chama a atenção o fato de que neste mesmo período, países como Cuba, Chile, Uruguai, Venezuela e Argentina apresentaram taxas de notificação de casos muito inferiores às apontadas no Brasil.

Os relatórios sobre políticas de controle da tuberculose realizados em Bangladesh, Brasil, Nigéria, Tanzânia e Tailândia ressaltam três questões relevantes 
a serem discutidas. A primeira diz respeito à atenção inadequada da relação entre a TB e a pobreza, a qual resultou em medidas pouco eficazes por parte do governo considerando custos ocultos do tratamento, os quais sobrecarregam o orçamento de pessoas de baixa renda e de populações vulneráveis, inclusive mulheres. A segunda questão diz respeito à freqüência com que os pacientes com TB utilizam o serviço privado de saúde levando a um acesso desigual a serviços de qualidade, diminuindo a capacidade do governo de monitorar a evolução da epidemia e gerando, assim, preocupações em relação ao aumento da resistência aos medicamentos de primeira linha contra a TB. A terceira questão infere que as abordagens específicas ao controle de tuberculose que têm a participação popular vêm demonstrando resultados positivos, porém há necessidade de maior apoio e de financiamento de fontes nacionais e internacionais (SANTOS FILHO, 2006).

Segundo dados do Sistema de Informação de Agravos de Notificação (SINAN/MS) foram notificados no Brasil 81.432 casos novos correspondendo a um coeficiente de incidência de 47,2/100.000 habitantes. Em relação ao término do tratamento, $72,2 \%$ receberam alta por cura, $11,7 \%$ abandonaram o tratamento, $7,0 \%$ foram a óbito e 9,1\% foram transferidos, sendo que as metas internacionais estabelecidas pela OMS e pactuadas pelo governo brasileiro são de $70 \%$ de detecção de casos de TB e 85\% de cura. A Organização Mundial da Saúde estimou em 2004 que a detecção de casos novos de TB com baciloscopia positiva foi de $89 \%$ e o sucesso de tratamento sob o DOTS no mesmo ano foi de $83 \%$ (BRASIL, 2000; WHO, 2006).

Em 1990 ocorreu a desestruturação do PCT no âmbito federal, não sendo mais prioridade o programa de controle da TB, enfraquecendo as coordenações estaduais, diminuindo os recursos financeiros e as supervisões do programa, 
contribuindo para a disseminação da Aids, para a queda da cobertura, para a diminuição da busca de casos novos e piora nos resultados de tratamento, aumentando os casos de abandono (RUFFINO-NETTO, 2002).

O autor expõe ainda que no ano de 1998 o Conselho Nacional de Saúde considera a situação da doença no país, e conclui que o Plano Emergencial necessitava de ajustes e ampliação e que a situação poderia e deveria ser corrigida com recursos disponíveis, decidindo por fim que a TB passaria a ser prioridade na saúde pública no Brasil, sugerindo estratégias para um novo plano.

Assim, neste mesmo ano, a Coordenação Nacional de Pneumologia Sanitária (CNPS) voltou ao controle do Ministério da Saúde (MS), vinculada à Secretaria de Políticas de Saúde (SPS), e ainda, foi lançado o Programa Nacional de Controle da TB (PNCT) seguindo as diretrizes de que: o MS é responsável pelo estabelecimento das normas, aquisição e abastecimento de medicamentos; referência laboratorial e de tratamento; coordenação do sistema de informações, apoio aos Estados e Municípios e articulação intersetorial visando maximizar os resultados de políticas públicas (BRASIL,1999).

Com o lançamento do PNCT, caberia aos municípios o desenvolvimento de seus programas de controle da TB baseando-se nas normas e orientações do PNCT em vigor. Para tanto, é enfatizada a necessidade de adequações frente às diversidades locais existentes, principalmente em relação ao Tratamento Supervisionado (TS) (BRASIL, 1999).

Para somar-se ao PNCT, o MS instituiu em 2000 o "Plano Estratégico para a Implementação do Plano de Controle da Tuberculose no Brasil para o período de 2001 a 2005"; o mesmo incluía parcerias com os serviços de atenção básica, principalmente com o Programa de Agentes Comunitários de Saúde (PACS) e 
Programa de Saúde da Família (PSF), objetivando a expansão das ações no controle da TB com a finalidade de obter maior detecção e cura de casos da doença (BRASIL, 2000).

Cabe ressaltar que os PNCT são elaborados sob o contexto da descentralização das ações em saúde do país, que seguem as diretrizes traçadas pela OMS que é inserir a TB no sistema de saúde pública no que tange à atenção primária buscando articular os níveis de gestão municipal, estadual e federal (RUFFINO-NETTO, 2002).

Dessa forma, acreditamos que a TB sendo vista como prioridade na $A B$ juntamente com uma gerência que possua adequado preparo e envolvimento local são essenciais para o êxito no controle das ações desta doença, bem como o alcance das metas pactuadas nacional e internacionalmente. 


\section{OBJETIVOS}

\subsection{Objetivo Geral}

- Compreender a visão dos gerentes das Unidades Básicas de Saúde sobre o Programa de Controle da Tuberculose na Atenção Básica.

\subsection{Objetivos Específicos}

- Identificar e analisar a visão dos gerentes das Unidades Básicas de Saúde a partir da dimensão: a Tuberculose na agenda municipal;

- Identificar e analisar a visão dos gerentes das Unidades Básicas de Saúde sobre as ações da Tuberculose na Atenção Básica. 


\section{QUADRO TEÓRICO}

\subsection{A Descentralização do Setor Saúde no Brasil}

A descentralização, de acordo com Silva et al. (2007), introduz componentes essenciais e centrais para a análise dos desenhos das políticas sociais, que é a transferência de poder e decisão para o âmbito local, reservando ao governo central a tarefa de realizar o monitoramento das diretrizes gerais, ou seja, das políticas públicas. Quando falamos de descentralização não devemos esquecer que ela está intimamente relacionada às peculiaridades geográficas, econômicas, sociais, culturais, sanitárias, étnicas e demográficas do país.

No Brasil, a descentralização do sistema de serviços de saúde ocorre numa combinação das formas de devolução e privatização. No sistema público, pela devolução municipalizada, expressa no movimento da municipalização da saúde, e, nos sistemas privados, pela expansão, via privatização, dos sistemas de assistência médica supletiva e desembolso direto.

Após anos de descentralização dos sistemas de saúde, a experiência internacional indica que há áreas em que a descentralização do processo decisório não deve ocorrer: na definição de macropolíticas de saúde, nas decisões referentes aos recursos estratégicos, na regulação de setores como de medicamentos e de equipamentos de alta densidade tecnológica e a macro análise de situação e tendências de saúde (MENDES, 2001).

O autor aponta que a descentralização dos sistemas de serviços de saúde possui como fortalezas maior eficiência alocativa pela influência dos usuários locais, 
inovação e adaptação às condições locais, maior qualidade/transparência, responsabilidade e legitimidade, devido à participação da população no processo de tomada de decisão e maior integração entre agências governamentais e nãogovernamentais. Em contrapartida as principais debilidades da descentralização são: enfraquecimento das estruturas locais, dificuldades de coordenação, incremento dos custos de transação, aumento das desigualdades, ineficiência por perda de escala e de escopo, fragmentação dos serviços, escassez de recursos gerenciais, clientelismo local, aumento do emprego estatal e desestruturação de programas verticais de saúde pública (MENDES, 2001).

Autores como Barata, Tanaka e Mendes (2004), Viana et al. (2002), Mendes (2001), Cordeiro (2001), Costa e Pinto (2002), Luchese (2003) e Monnerat, Senna e Souza (2002) referem que a Constituição Federal de 1988, através dos princípios doutrinários e organizacionais, Leis Orgânicas infraconstitucionais, Normas Operacionais e portarias ministeriais têm sido as diretrizes determinantes no processo de descentralização das políticas de saúde no Sistema Único de Saúde (SUS).

Monnerat Senna e Souza (2002) lembra que com o aprofundamento da descentralização em direção à municipalização da saúde em meados dos anos 90 se potencializou inúmeros projetos inovadores que corroboraram para o incremento da eficácia e eficiência da gestão do sistema local.

Sendo assim, tendo o município como produtor e gestor local das políticas de atenção à saúde, cabe um destaque antecipado do fator benéfico que a descentralização da saúde reserva à população e, nesse sentido, Yunes (1999) aponta que transferir competências, no caso da saúde, não deve ser visto como uma emulação do pragmatismo característico da rede privada, que tem a lógica do lucro, 
mas deve ser vista pela busca da eficiência da aplicação dos recursos públicos, por parte dos gestores, tendo como eixo a ética e a satisfação dos usuários.

Barata,Tanaka e Mendes (2004); Monnerat, Senna e Souza (2002) comentam que o processo de descentralização, opondo-se justamente à tradição centralizadora da assistência à saúde, traz o conceito de que o município é o melhor cenário para o gerenciamento da atenção à saúde, dada a proximidade com a realidade da população e, sob este aspecto, Merhy e Queiroz (1993) chamavam a atenção de que a municipalização dos serviços de saúde, desde meados da década de 70 , passava a ser entendida como o único meio que permitiria, ao mesmo tempo, uma racionalidade administrativa, controle financeiro e participação democrática da comunidade no gerenciamento do sistema.

Em nosso país, a descentralização vem se constituindo como um forte componente no processo de Reforma Sanitária, onde as diretrizes foram aprovadas na $8^{a}$ Conferência Nacional de Saúde no ano de 1986. Estudos apontam que o processo de descentralização contribui na organização do sistema de saúde, bem como na gestão em saúde (SILVA et al, 2007).

Em que pese às dificuldades e potencialidades discutidas pelos autores em relação ao processo de descentralização na área da saúde com relação à tuberculose, a questão da transferência de responsabilidades para o nível local vem sendo objeto de intensa discussão a partir das últimas décadas, em especial pela responsabilidade assumida pelos governos locais em relação à estratégia do DOTS, como uma das políticas públicas que passaram a ser objeto de trabalho pela rede de Atenção Básica.

\subsection{A Descentralização das Ações de Tuberculose no Brasil}


É possível verificar que no início dos anos 80 algumas propostas de reorganização dos serviços de saúde, por meio da descentralização, passam a ser operados entre algumas instituições no Brasil a exemplo do INAMPS/MS/SES, com a transferência da execução do controle da Tuberculose para as secretarias estaduais de saúde. Esta transferência ocorre por meio da celebração de convênios onde as atribuições, recursos financeiros, profissionais de saúde e estrutura física são objetos de gestão a partir de então dos entes federados estaduais e municipais (VILLA et al. 2007).

$\mathrm{Na}$ década de 90 ocorreu a desestruturação do Programa Nacional de Controle da Tuberculose junto ao Ministério da Saúde o que acarretou em péssimos scores nos indicadores da Tuberculose no Brasil, especificamente com relação às taxas de cobertura, busca de sintomáticos respiratórios, efetividade do tratamento resultado do abandono ao mesmo, descontinuidade na produção de drogas antituberculosas, assim como na compra destas no mercado internacional (VILLA et al. 2007). Estes fatores, associados à gestão pouco pró-ativa das coordenações estaduais, provocaram um quadro epidemiológico pouco promissor no controle da Tuberculose do Estado brasileiro.

Estes são os elementos que determinam o ingresso do Brasil em novas parcerias no controle da Tuberculose e uma delas parte da Organização Mundial da Saúde a propor aos países com franca expansão da Tuberculose, a adotar a estratégia DOTS (Directly Observed Treatment Short-course) em 1993 (VILLA et al. 2007). 
No Brasil, no ano de 1998, o DOTS começou a se instalar como uma estratégia efetiva para o controle da TB, juntamente com o Programa de Controle da Tuberculose (PCT) sendo que as metas são: atingir $85 \%$ das taxas de cura, $70 \%$ de detecção de casos e reduzir o abandono do tratamento 5\%. A conformação do DOTS compreende a combinação de cinco componentes principais, recomendados pela OMS:

1) Comprometimento dos governos no suporte financeiro das atividades de controle;

2) Detecção de casos por baciloscopia de todos os pacientes sintomáticos respiratórios que procurarem os serviços de saúde;

3) Gratuidade no regime de tratamento padronizado de seis a oito meses para todos os casos confirmados a partir dos testes positivos de secreção com tratamento diretamente observado (DOT) ou por pelo menos três dias nos dois meses iniciais e dois dias nos meses subseqüentes;

4) Fornecer regularmente os medicamentos essenciais anti-tuberculose;

5) Sistema padronizado de registro e notificação permitindo conclusões seguras sobre o resultado do tratamento para cada paciente e do PCT de uma forma geral (WHO,2005).

Teixeira (1998) expõe que a estratégia DOTS possibilita uma reorganização das ações em saúde, contribuindo para a redução das internações hospitalares, tornando assim o tratamento menos oneroso e de mais fácil acesso. Outro fator positivo é que o DOTS diminui o risco de abandono ao tratamento e, em conseqüência, o desenvolvimento de resistência às drogas convencionais.

Constata-se que a partir da implantação do DOTS, no Brasil, a curva de busca de sintomáticos respiratórios começou a crescer a partir do final da década de 90, bem como a taxa de abandono (VILLA et al. 2007). 
Estes são alguns elementos que trazem à tona aspectos inerentes à problemática do controle da TB no Brasil, especialmente pelo fato que segundo as Normas Operacionais de Assistência a Saúde - (NOAS) a partir das edições de 2001 e 2002 preconizam que Tuberculose é uma patologia que deve ser diagnosticada e tratada no âmbito da atenção básica (ARCÊNCIO; OLIVEIRA; VILLA, 2007).

E é justamente neste contexto que se inclui a Tuberculose na Atenção Básica, por meio da expansão de cobertura dos Programas Saúde da Família (PSF) e Programa de Agentes Comunitários da Saúde (PACS), se constituindo em potencialidades de acesso aos sujeitos acometidos por esta patologia (ARCÊNCIO; OLIVEIRA; VILLA, 2007).

Entende-se que para a integração da Tuberculose com as ações de atenção básica é necessária uma maior aproximação das equipes de saúde que trabalham diretamente na assistência aos doentes, no entanto, existem muitas dificuldades para que isso ocorra, pois tanto os profissionais de saúde quanto os gestores locais não têm tido sensibilidade suficiente para tornar prioritária essa doença (ARCÊNCIO; OLIVEIRA; VILLA, 2007).

\subsection{A Gerência nos Serviços de Saúde}


Como já discutido anteriormente, a descentralização das ações em saúde desencadeada pelo Sistema Único de Saúde (SUS), nos remete a refletir o processo de municipalização da saúde, sendo esta parte do movimento da reforma administrativa do Estado brasileiro. Para os municípios, essas "inovações" são a possibilidade, a partir da área da saúde, de reorganizar e reestruturar a gestão local tendo como eixo norteador uma gestão democrática, participativa, tecnicamente competente e gerencialmente eficiente (ERMEL; FRACOLLI, 2003).

Nesse sentido, chamamos a atenção para a questão da tecnologia gerencial, pois é a partir desta que podemos pensar e agir em saúde, ou seja, vislumbrar a implementação de um sistema de saúde hierarquizado, regionalizado e com uma participação social efetiva. Cabe ressaltar que a municipalização da saúde contribui para o fortalecimento da autonomia político-gerencial dos municípios aumentando, assim, sua capacidade técnico-operacional de planejamento, programação, controle gerencial e operacional de ações voltadas ao enfrentamento dos problemas de saúde em territórios específicos (ERMEL; FRACOLLI, 2003). É pensando em uma gerência eficiente e competente do ponto de vista administrativo que acreditamos serem primordiais estes predicados para o desenvolvimento de ações adequadas para o controle da TB, ações estas que não podem ser desenvolvidas individualmente, mas sim, pensando sempre no caráter coletivo, trabalhando em equipe com uma gerência imbuída de conhecimento local, ou seja, conhecimento das necessidades de saúde da população e, além disso, uma gerência que seja participativa no conselho gestor, nas tomadas de decisões.

Campos, Merhy e Nunes (1994) afirmam que o trabalho de gerência da produção de serviços de saúde é um importante instrumento na efetivação de políticas públicas, pois este é ao mesmo tempo "condicionante" e "condicionado" 
pela forma como se organiza a produção dos serviços de saúde e conseqüentemente o modelo tecno-assistencial vigente.

Para Merhy e Onocko (1997) gerenciar serviços de saúde é atuar no limite entre a prática e o autogoverno dos sujeitos do trabalho em saúde. O autor afirma que gerenciar é construir, formar sujeitos que possam ser criativos, éticos, tecnicamente competentes e que trabalhem em prol da vida dos cidadãos.

Somado ao que nos aponta Merhy e Onocko (1997), alguns autores nos expõem ainda que, atualmente, o que se espera de uma gerência local é que esta possua bagagem de conhecimentos, capacidade de análise, capacidade de ação, aprimoramento de práticas e determinação em alcançar resultados em favor da saúde da população (BARBOSA; LIMA, 1996). Assim, torna-se indispensável a reorientação do perfil gerencial, para que, dessa forma, melhore o cenário e o funcionamento dos serviços de saúde (SANTANA, 1996).

É evidente que investir na melhoria do gerenciamento das Unidades Básicas de Saúde e também nas Unidades de Referência contribui para uma assistência de maior qualidade na Atenção Primária, assistência essa que reflete diretamente na atenção à saúde da população e comunidade (RAMIRES; LOURENÇÃO; SANTOS, 2004).

Quando elencamos o tema da gerência para pautar a discussão desta investigação, o fizemos pensando na perspectiva de compreendê-la como um instrumento do trabalho em saúde capaz de contribuir para a transformação da prática assistencial no que concerne à melhoria da atenção à TB, e dessa forma, nos voltando para um modelo usuário centrado que produza mudanças e seja compromissado com a saúde da população. 
Cabe ressaltar que a gerência dos serviços de saúde se apresentava como uma figura normativa e tradicional. Dessa forma, a gerência é exposta como uma atividade burocrática, ou seja, centrada na manipulação de papéis, no trabalho rotinizado, pré-determinado, com poucas chances de criação, onde se tem a padronização das ações e a inflexibilidade frente às normas colocadas. Com este quadro torna-se difícil desenvolver um trabalho mais amplo, pois o perfil que aparece na prática é extremamente burocrático-administrativo e pouco se volta para as questões técnicas ou relacionadas às políticas de saúde (MISHIMA, 1995).

Pensando a gerência como potencial para transformação, podemos percebêla como um espaço instituinte, na qual há a possibilidade de maior participação da equipe dos trabalhadores da saúde, ou seja, repensar sua forma de produção e reprodução em relação ao gerenciamento dos serviços locais de saúde (VANDERLEI; ALMEIDA, 2007).

As autoras afirmam que a gerência dos serviços de saúde deve ser um instrumento capaz de possibilitar o compartilhar de poder no interior das unidades e equipes de saúde e, assim, poderá se constituir como importante ferramenta na efetivação de políticas. A gerência que lança mão de tecnologias leves e considera os profissionais da saúde e os usuários como sujeitos potenciais para a produção de ações em saúde, compreendendo-os como co-responsáveis no trabalho em saúde, se contrapõe à racionalidade gerencial: burocrática, normativa e tradicionalista.

É pertinente mostrar que as discussões ocorridas na área da saúde sobre a temática gerencial e o conjunto de intervenções de vários grupos sociais envolvidos interessados nesse tema destacam a necessidade de operar mudanças no modo de trabalhar em gerência, em todos os níveis das organizações de saúde (FRACOLLI; EGRY, 2001). As autoras apontam ainda que muitos dos debates que têm a 
gerência como protagonista fazem referências às dimensões macro-estruturais do trabalho de gerência em saúde, sendo que poucos destacam pretensões de mudanças, a partir da aquisição de capacidade teórica e operacional de ação sobre os aspectos micro-políticos desse processo de trabalho.

Monroe (2008) destaca em sua investigação que as discussões sobre a problemática da TB podem permear tanto as macro-políticas, de forma que a doença incide fundamentalmente a área social (geração de emprego/renda, educação, habitação, dentre outros), como as micro-políticas, relacionadas à organização e gestão dos programas para o adequado desempenho dos serviços de saúde no manejo da doença nos diversos locais.

Assim, o presente estudo tem como foco as micro-políticas uma vez que discute a participação da gerência da Unidade Básica de Saúde na gestão da atenção à TB no município de Ribeirão Preto/SP.

O trabalho de gerência em UBS envolve, de um lado, a execução de práticas gerenciais que tomam como campo de ação a formulação e decisão política e, de outro lado, o campo de práticas gerenciais que enfrentam o fabricar "bens" do trabalho em saúde. A gerência em UBS torna-se um lugar de possíveis intervenções impactantes na política e no modelo de atenção à saúde (MERHY, 1997).

Estudo realizado por Fracolli e Egry (2001) nos mostra que os saberes utilizados pelos gerentes reforçavam a burocracia, a divisão do trabalho, o produtivismo e a alienação do trabalhador do seu produto final, e ainda enfatizavam ações de supervisão e controle deixando para segundo plano o planejamento e a avaliação dos profissionais e das práticas de saúde. As autoras salientam ainda que a tensão entre assistir e gerenciar aparecia como pólos de oposição e não como ações intercessoras e intercomplementares. 
Segundo Barbieri e Hortale (2005) a eficiência e a eficácia são categorias adotadas e aceitas por todas as escolas da administração para medir o desempenho gerencial. A eficiência e a eficácia entram para o debate da saúde pública incluindo os elementos técnico e racional, e também as dimensões de política e de poder e suas decorrências.

Nesse sentido, as categorias de eficiência e eficácia foram repensadas tendo como variáveis as funções clássicas da administração como: o planejamento, a organização, a direção e o controle e, assim, adaptadas para a área da saúde de nível local (BARBIERI; HORTALE, 2005) A eficácia pensando na área da saúde, fica definida como a capacidade dos gerentes obterem resultados nas atividades de planejamento, organização, direção e controle, sem perder de vista a finalidade maior que é resolver os problemas de saúde da clientela (CAMPOS, 1994).

Campos (1994) define ainda que a eficiência no campo da saúde é o conhecimento da realidade e meios selecionados pelos gerentes para o alcance dos resultados (planejamento); práticas individuais e coletivas realizadas pela equipe subordinada à gerência para a produção da assistência (direção); uso ótimo dos recursos materiais e humanos disponíveis (organização); e instrumentos desenvolvidos para a verificação do desempenho individual e coletivo (controle).

O planejamento, a organização, a direção e o controle compõem o processo gerencial no sentido de que as atividades têm interação dinâmica, são interrelacionadas e interdependentes, acontecem em atitudes cotidianas ao mesmo tempo ou em tempos diferentes (BARBIERI; HORTALE, 2005).

As autoras trazem ainda que o planejamento é a capacidade de prever o futuro a partir da clara compreensão dos limites e possibilidades da realidade e, no caso específico do setor saúde, das necessidades imediatas e mediatas da 
população sob responsabilidade de uma unidade de saúde em particular. A organização compreende a capacidade de relacionar atividades, decisões e pessoas para alcançar resultados; associada à liderança, define estratégias de trabalho. A direção é a capacidade de tomada de decisões e do inter-relacionamento não apenas em uma unidade de trabalho, mas em todos os níveis hierárquicos da organização. O controle pressupõe a capacidade do gerente em utilizar e adaptar sistemas de informação para avaliar o trabalho que the é confiado, demonstra responsabilidade e observância para com os compromissos e resultados institucionais. Barbieri; Hortale (2005) afirmam que o planejamento e o controle dizem respeito à eficácia organizacional, enquanto a organização e a direção se referem à eficiência.

Tomaremos também para este estudo a classificação hierárquica, proposta por Barbieri e Hortale (2005), dos quatro níveis gerenciais: a) gerente superior: gestão global e formulação de políticas; b) gerentes técnicos: coordenação e operacionalização de políticas e programas; c) gerentes de infra-estrutura: responsáveis pelo fornecimento de insumos estratégicos para o funcionamento da organização; d) gerentes assistenciais: ocorre a assistência propriamente dita e principal finalidade da organização.

A partir da descrição do objeto do estudo nos propomos nesta investigação ter na figura dos gerentes das Unidades Básicas de Saúde do município o foco desta investigação. Dessa forma, classificamos os sujeitos desta investigação como gerentes assistenciais e tomaremos como eixo de análise as dimensões gerenciais do planejamento e da organização em saúde. 


\section{PERCURSO METODOLÓGICO}

\subsection{Cenário do Estudo}

\subsubsection{Caracterização do Local do Estudo}

O município possui aproximadamente uma população de 567.917 habitantes, segundo projeções realizadas pelo Censo Demográfico de 2000 e encontra-se entre os maiores municípios do Estado de São Paulo e do Brasil (DATASUS,2008).

O intenso crescimento populacional no município, durante as décadas de setenta e oitenta, pode ser explicado pelo fato de que, nesta época, foi pólo de atração populacional, sendo uma das poucas regiões do Estado a apresentar um fluxo migratório positivo. No entanto, a taxa média de crescimento populacional teve uma redução significativa no período de 1991 a 2000, permanecendo abaixo da taxa média de crescimento do Estado (DATASUS,2008).

Esta tendência é confirmada pelo DATASUS, porém, seus dados diferem em números absolutos quanto à população total do município, pois a distribuição mostra um aumento populacional e sua concentração em algumas faixas etárias, enquanto que, em outras, há uma diminuição da população de forma não esperada, apontando para o envelhecimento populacional e afluxo de migrantes para o município.

No geral, a população do município estudado cresceu $17,20 \%$ no período de 1991 a 2000. Para o ano de 2005, a Fundação Sistema Estadual de Análise de 
Dados - SEAD/SP previu para o município um crescimento anual de 1,53\% abaixo da previsão para o Estado de São Paulo no mesmo período. Mesmo com o crescimento populacional este ainda sofre influência do processo migratório, observa-se que em grande parte, uma diminuição desta tendência e um crescimento equilibrado de sua população, o que possibilita um melhor dimensionamento dos serviços públicos (DATASUS,2008).

Em relação às condições de vida, o município está classificado como a $6^{a}$ cidade do Estado de São Paulo em relação ao Índice de Desenvolvimento Humano Municipal (IDH-M). Este, além de espelhar a renda associa a longevidade de uma população, que é expressa pela esperança de vida ao nascer e o grau de maturidade educacional, avaliado pela taxa de alfabetização de adultos e pela taxa combinada de matrícula nos três níveis de ensino. A renda é calculada através do PIB real per capita, expresso em dólares e ajustado para refletir a paridade do poder de compra entre países.

O IDH-M é semelhante ao IDH, pois inclui as três dimensões mencionadas (renda, longevidade e educação, com pesos iguais), porém, com algumas adaptações para adequar o índice ao município.

Considerada como uma das cidades mais ricas do Estado de São Paulo, apresenta elevado padrão de vida (renda, consumo, longevidade), com bons indicadores sociais (saúde, educação e saneamento), próxima de importantes centros consumidores, com adequada infra-estrutura de transportes e comunicação.

Nesse sentido, o município se constitui num pólo de atração das atividades relacionadas à agricultura, comércio e prestação de serviços. A área de influência extrapola os limites da própria região de governo, estendendo-se às regiões de 
Franca, Barretos, São Carlos, São João da Boa Vista e outras do Estado de São Paulo e de outros Estados.

De acordo com o Instituto Brasileiro de Geografia e Estatística (IBGE) de 2003, o município possui 96,3\% dos domicílios com saneamento básico, o maior percentual entre as cidades com mais de 500 mil habitantes do Estado de São Paulo. Isso significa que 141.310 casas (incluindo favelas) possuem água encanada, sistema de coleta de lixo e de esgoto, além do importante manejo dos resíduos sólidos urbanos.

Em relação à atenção à saúde a cidade apresenta indicadores que apontam uma boa qualidade de vida da sua população. A proporção de óbitos de indivíduos com cinqüenta anos ou mais é indicador do nível de vida das populações, ou seja, quanto melhor a qualidade de vida, maior a proporção de pessoas que atingem idades avançadas. No ano de 2004, este indicador para o município, foi de $77,8 \%$, que é classificado como nível característico de regiões desenvolvidas. As principais causas de mortalidade, para o mesmo a ano, estão relacionadas às doenças do aparelho circulatório seguido pelas neoplasias e doenças respiratórias.

Segundo informações da Divisão de Vigilância Epidemiológica (DVE) do município, as doenças de notificação compulsória que apresentam maior número de casos são: a Aids, a Dengue, a Hepatite C, a Hepatite B, a Tuberculose e a Meningite, seguida da Hanseníase, a Teníase e a Esquistossomose.

\subsubsection{A Rede de Atenção à Saúde no Município do Estudo}


O município é considerado como pólo de atenção à saúde, possui uma situação privilegiada na oferta de ações e serviços de saúde pela rede pública municipal, por serviços filantrópicos e particulares. O município divide-se em cinco regiões administrativas que compõem os cinco Distritos Sanitários: Distrito Central com 107.936 habitantes, Distrito Sul com 86.583 habitantes, Distrito Leste com 128.969 habitantes, Distrito Norte com 101.218 habitantes e Distrito Oeste com 143.211 habitantes (DATASUS, 2008).

Atualmente o município possui 34 Unidades Básicas de Saúde (UBSs), 24 Equipes de Saúde da Família (ESF), algumas destas ainda em fase de implantação, 01 Ambulatório Regional de Especialidades (NGA-59), 01 Ambulatório Geral de Especialidades Pediátricas (PAM II), 02 Centros de Referência de Moléstias Infectocontagiosas, 01 Núcleo de Atenção à Pessoa Deficiente (NADEF), 01 Centro de Referência em Saúde do Trabalhador, 01 Centro de Atenção Psicossocial (CAPS), 01 Centro de Atenção Psicossocial Álcool e Droga (CAPS-ad), 03 Ambulatórios de Saúde Mental (SECRETARIA DE SAÚDE, 2008).

De acordo com a Secretaria Municipal de Saúde - SMS (2005), existe uma produção insatisfatória de consultas básicas (36,56\%), contribuindo para um elevado número de consultas especializadas $(34,15 \%)$ e de urgência - pronto atendimento (30,29\%). Assim, segundo a SMS, em 2004, a cobertura da atenção básica ficou em torno de 58\%, o que reforça a necessidade de maior investimento e reestruturação nesta área por meio da ampliação do número das ESF, ações voltadas à Vigilância em Saúde, Avaliação, Regulação, Controle e Auditoria da oferta de serviços, Infraestrutura e Financiamento dentre outras. 


\subsubsection{Sujeitos do Estudo}

Os sujeitos do estudo foram 14 gerentes das Unidades Básicas de Saúde.

\subsubsection{Critérios de Inclusão}

- Ser gerente de uma Unidade Básica de Saúde;

- Ser gerente de uma Unidade Básica Distrital de Saúde;

- Aceitar participar da pesquisa;

- Responder o instrumento de coleta de dados;

- Assinar o Termo de Consentimento Livre e Esclarecido.

\subsubsection{Critérios de Exclusão}

- Não aceitar participar da pesquisa;

- Aceitar participar da pesquisa, porém recusar-se a responder o instrumento de coleta de dados;

- Recusar-se a assinar o Termo de Consentimento Livre e Esclarecido;

\subsection{Instrumentos de Coleta dos Dados}

\subsubsection{Pesquisa Documental}


A pesquisa documental, nesse estudo, teve como objetivo reunir documentos não editados como: livros, periódicos, materiais como Plano Municipal de Saúde, site da Secretaria Municipal de Saúde que pudessem evidenciar achados referentes às discussões sobre a problemática da tuberculose no cenário do município. Segundo Martins (2006:46) "buscas sistemáticas por documentos relevantes são importantes em qualquer planejamento para a coleta de dados e evidências"; ainda afirma o autor que

Um dos grandes desafios da prática da pesquisa
documental é o grau de confiança sobre a
veracidade dos documentos, fato que poderá ser
atenuado através de análises cruzadas e
triangulação com resultados de outras fontes
(MARTINS, 2006; p.46).

Nesse estudo a busca pela pesquisa documental ocorreu desde a fase do planejamento da pesquisa, intensificando-se no período da aplicação do instrumento de coleta (questionário) e da análise dos dados.

\subsubsection{Entrevista}

Para coleta de dados deste estudo utilizamos a entrevista para "entender e compreender o significado que os entrevistados atribuem às questões e situações" (MARTINS, 2006 p.27). A entrevista foi realizada por meio de um questionário fechado ${ }^{1}$, o qual faz parte do projeto multicêntrico de pesquisa: "Avaliação das dimensões organizacionais e de desempenho dos serviços de atenção básica no

\footnotetext{
${ }^{1}$ Este instrumento é baseado num questionário elaborado por James Macinko (New York University) e Célia Almeida (ENSP-FIOCRUZ), norteado por Barbara Starfield, MD, MPH, FRPCGP e James Macinko, PHD.D, Dept. of Health Policy \& Management, Jhons Hopkins, Bloomberg School of Public Health, Baltimore, MD. USA. Adaptado para a atenção à tuberculose por Tereza Cristina Scatena Villa (EERP-USP)/Área Operacional REDETB) e Antonio Ruffino Netto (FMRP/REDE-TB).
} 
controle da Tuberculose em centros urbanos de diferentes regiões do Brasil", Edital MCT-CNPq/ MS - SCTIE - DECIT no. 25/2006, que se insere nas regiões Nordeste e Sudeste.

Este instrumento foi direcionado aos seguintes sujeitos: doentes de tuberculose, profissionais da saúde e gestores municipais; é composto por 104 questões e abrange nove dimensões, sendo elas: a) A tuberculose na agenda municipal; b) Porta de entrada; c) Acesso; d) Vínculo; e) Elenco de serviços; f) Coordenação; g) Enfoque na família; h) Orientação para comunidade; i) Formação profissional.

Para esse estudo foi utilizado o instrumento direcionado aos gerentes municipais com enfoque para a dimensão: "A TB na agenda municipal", a qual abrange as questões enumeradas de 11 a 22. Ao final da entrevista incluímos também uma questão norteadora: "Quais as dificuldades que você, gerente de uma Unidade Básica de Saúde, enfrenta no dia-a-dia para desenvolver as ações de controle da tuberculose?" (Apêndice A)

\subsection{A Coleta dos Dados}

Passamos a descrever a trajetória da fase de coleta de dados por meio das entrevistas. O período que antecedeu a coleta de dados propriamente dita foi precedido de reuniões periódicas com todos os pesquisadores do grupo GEO-TB dos diferentes cenários de investigações. A finalidade desses encontros era treinar os pesquisadores e auxiliares de pesquisa para a aplicabilidade do instrumento. 
A coleta de dados compreendeu os meses de agosto de 2007 a janeiro de 2008. Para a realização das entrevistas, contamos com o auxílio de uma graduanda de enfermagem, bolsista PIBIC/CNPq 2007-2008.

Para o agendamento das entrevistas junto aos gerentes das Unidades Básicas de Saúde, foram realizados contatos prévios via telefone e, por meio deste, agendados data e hora para a aplicação do instrumento. Todos os gerentes das 34 Unidades Básicas de Saúde (UBS) foram contactados e convidados a participarem da pesquisa, porém destes 02 recusaram-se a participar do estudo alegando falta de tempo para conceder a entrevista.

Dois gerentes, por ocasião do agendamento, optaram por preencher o instrumento para posterior entrega ao pesquisador, no entanto, no prazo estabelecido para a entrega dos questionários preenchidos comunicaram o extravio do documento. Nessa ocasião, disponibilizamos novamente o instrumento, porém, a oferta foi recusada.

Com os demais gerentes, foram realizadas várias tentativas para marcar a entrevista via telefone e até mesmo indo pessoalmente em algumas unidades, em horários e dias da semana alternados. Nessas tentativas era difícil encontrá-los na unidade e, quando era possível agendar a data e horário para a aplicação do instrumento, ao chegar no local designado pelo entrevistado, estes remarcavam alegando falta de tempo para o preenchimento. Em novas tentativas de agendamento as alegações supracitadas perduravam ou então solicitavam a possibilidade da enfermeira da unidade de saúde responder. Para esta situação era argüido pelo pesquisador a impossibilidade da enfermeira responder, dado que as informações do instrumento correspondiam às funções inerentes ao gerente. 
Dessa forma, optamos por finalizar a amostra com 14 gerentes depoentes. Dentre as facilidades para o agendamento das entrevistas, esteve a aceitabilidade do projeto de pesquisa junto à Secretaria Municipal de Saúde, com a disponibilidade de uma enfermeira do órgão central em viabilizar o contato com alguns gerentes de unidade. Houve também, por parte do médico responsável pela Atenção Básica na SMS, disponibilização de endereços, telefones, nome das UBS e respectivos gerentes, bem como de mapas geográficos do município. Outro fator que contribuiu positivamente para o andamento das entrevistas foi a boa recepção dos profissionais que atuam nos serviços de saúde. Com relação aos sujeitos que aceitaram participar do estudo, quando agendados eles atenderam o pesquisador com presteza, solicitude, demonstrando interesse pela temática investigada, assim como, alguns, se colocaram à disposição para auxiliar no agendamento de novas entrevistas com seus pares.

\subsection{Análise dos Dados}

A análise dos dados foi realizada em duas etapas. Na primeira, elaboramos, através do Programa Statistica 8.0 da Statsoft, tabelas de freqüência simples e por meio destas pode-se obter um panorama geral deste estudo. 
Na segunda etapa para o tratamento dos dados empíricos trabalhamos com análise de conteúdo que pode ser definida como:

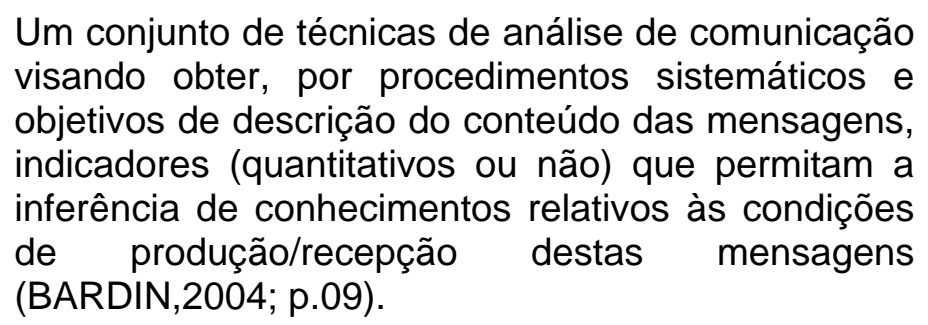

Para Minayo (2004) a análise de conteúdo parte de uma leitura prévia para depois atingir maior profundidade, ou seja, ultrapassar os significados manifestados. Assim, a análise de conteúdo busca relacionar estruturas semânticas (significantes) com estruturas sociológicas (significados) dos enunciados. Articula o texto descrito com os fatores que determinam suas características: variáveis psicossociais, contexto e processo de produção da mensagem.

Martins (2006) define a análise de conteúdo como uma técnica para se estudar e analisar a comunicação de forma objetiva, sistemática e quantitativa. Por meio desta técnica, buscam-se inferências confiáveis de dados e informações em relação a determinado contexto, a partir das falas escritas ou orais de seus sujeitos.

A autora comenta ainda que para atingir os significados manifestos e latentes do material qualitativo há várias técnicas; neste estudo, para melhor exploração dos dados, utilizamos a técnica de Análise Temática.

Esta técnica consiste em descobrir os núcleos de sentido que compõem uma comunicação cuja presença ou freqüência signifiquem alguma coisa para o objetivo analítico visado. A análise temática expõe qualitativamente a presença de determinados temas, denota os valores de referência e os modelos de comportamento presentes no discurso (MINAYO, 2004).

Para a autora, a análise temática é constituída em três etapas: a) Pré Análise: onde é realizada a escolha dos documentos que serão analisados, retomam-se as 
hipóteses e objetivos do estudo, reformulando-os diante do material coletado, e elaborando indicadores que orientem a interpretação final - Leitura Flutuante: manter contato exaustivo com o material coletado deixando-se impregnar pelo seu conteúdo - Constituição do Corpus: organizar o material obedecendo certas normas como a exaustividade contemplando os aspectos levantados no roteiro - Representatividade: deve conter a representação do universo pretendido - Homogeneidade: deve obedecer critérios precisos de escolha em termos de temas, técnicas e interlocutores - Pertinência: o material analisado deve ser adequado ao objetivo do trabalho Formulação de hipóteses ou objetivos; b) Exploração do Material: nesta fase ocorre a transformação dos dados em sua íntegra objetivando alcançar o núcleo de compreensão do texto; c) Tratamento dos Resultados Obtidos e Interpretação: os resultados brutos são submetidos a operações estatísticas simples ou complexas permitindo, dessa forma, colocar em destaque as informações obtidas. A partir daí o pesquisador realiza interpretações de acordo com seu quadro teórico ou abre pistas em torno de dimensões teóricas elucidadas com a leitura do material.

Podemos afirmar que a análise temática é uma técnica de análise dos dados empíricos que mantém sua crença na significação da regularidade, trabalha com o significado dos dados obtidos em substituição às inferências estatísticas (MINAYO, 2004).

\subsection{Aspectos Éticos da Pesquisa}

Projeto de Pesquisa aprovado pelo Comitê de Ética da Escola de Enfermagem de Ribeirão Preto da Universidade de São Paulo (EERP/USP) em 
reunião do dia 22 de março de 2007. O grupo de informantes foi constituído por 14 gerentes das Unidades Básicas de Saúde que aceitaram participar da pesquisa e assinaram o Termo de Consentimento Livre e Esclarecido, respeitando os preceitos éticos para pesquisa envolvendo seres humanos de acordo com a Resolução 196/96 do CNS. 


\section{RESULTADOS E DISCUSSÃO}

\subsection{A Tuberculose na Agenda Municipal}

\subsubsection{A Gerência da UBS no Controle da Tuberculose: um campo de desafios}

Esta temática foi construída a partir dos depoimentos dos gerentes na qual destacamos os seguintes aspectos: a TB no quadro sanitário do município, o planejamento em saúde e as ações de controle da doença, a participação na discussão e definição das ações para o controle da TB e a assistência técnicoburocrática da administração no controle da TB.

Quando da pesquisa de campo, uma das questões presentes no questionário era se a TB se constituía como prioridade no contexto sanitário municipal.

Das respostas dos gerentes obtivemos o seguinte cenário observando o Gráfico 1. 


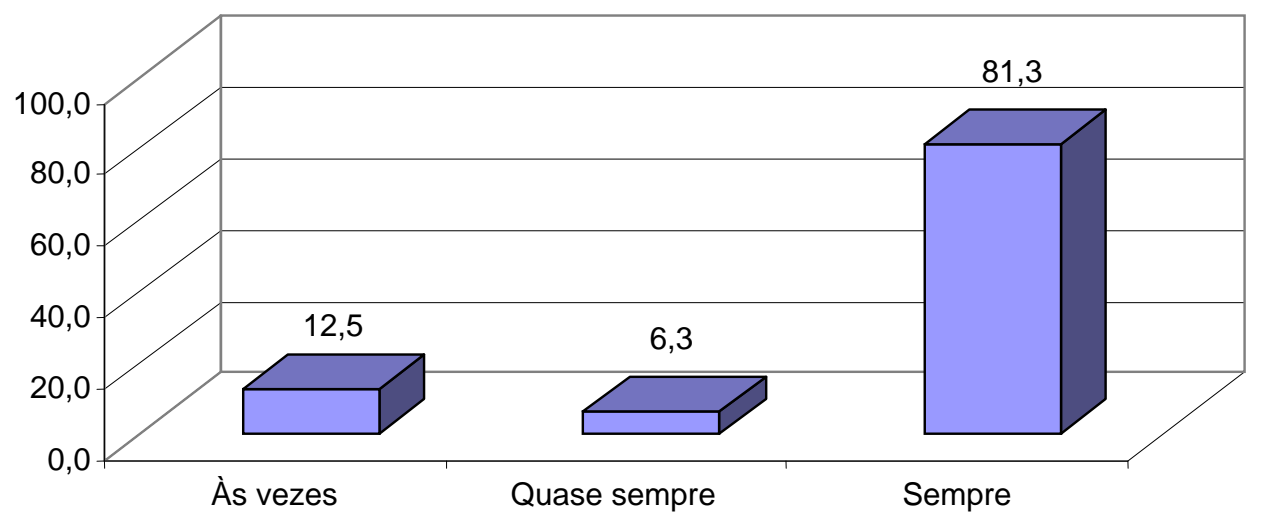

Gráfico 1 A TB como doença prioritária no quadro sanitário do município

Para a maioria dos gerentes entrevistados, $81,3 \%$, a TB é sempre considerada como uma doença prioritária no quadro sanitário do município;12,5\% responderam que a TB, às vezes, é considerada como uma doença prioritária em Ribeirão Preto. Assim, do ponto de vista dos gerentes entrevistados, a TB se constitui em uma doença que tem visibilidade na rede pública de saúde.

A TB na agenda municipal é uma das ações resultante do processo de descentralização ocorrido entre as esferas de governo: Federal, Estadual e Municipal. Esta estratégia teve como objetivo garantir prioridade ao atendimento básico em saúde a partir de um vasto conjunto de Leis Orgânicas constitucionais e infra-constitucionais que vem se consolidando desde o final da década de 80. Cabe destacar que é com a introdução do Piso de Atenção Básica (PAB), criado por meio da Portaria GM/MS n.1882, de 18/12/97, que se regulamenta o repasse de recursos federais para os entes subnacionais (BODSTEIN, 2002).

Com o Piso de Atenção Básica amplia-se a diversidade de experiências na gestão municipal no setor saúde, cada uma com suas especificidades, dados os 
distintos graus de dependência com outras esferas de governo em termos financeiros, técnicos e de disponibilidade de equipamentos (COHN; WESTPHAL; ELIAS, 2005). Dessa forma, o município se torna palco para a gestão da atenção à saúde no sistema local.

Corroborando nessa discussão, Arcêncio, Oliveira e Villa (2007) discutem que em relação a TB, é a partir da edição das Normas Operacionais de Assistência (NOAS) à Saúde 2001 e 2002 que as responsabilidades pelo controle das ações dessa patologia são colocadas na arena da Atenção Básica.

Frente a esse contexto, a gerência das Unidades Básicas de Saúde passa a incorporar várias ações sob sua responsabilidade tanto no plano gerencial quanto assistencial. Essas duas dimensões possibilitam traçar planos e estratégias que viabilizem ações conjuntas da equipe de saúde da UBS e Secretaria Municipal de Saúde (SMS).

Segundo Fracolli e Egry (2001), esse processo de descentralização administrativa tem encontrado barreiras para sua operacionalização, tais como a falta de preparo técnico dos profissionais de saúde e capacidade fiscal dos municípios para assumirem tais responsabilidades, entre outros.

Nesse estudo, quando abordamos a discussão das ações da TB na Agenda Municipal evidenciamos aspectos inerentes ao controle da TB na Atenção Básica, especialmente em relação à continuidade de programas verticalizados na área de saúde, como se segue na fala do depoente.

Deve-se considerar também a forma verticalizada que muitos programas começaram o trabalho e continuam. Podendo trabalhar com outras estratégias, considero que a forma implantada de alguns serviços dificultam a instalação de 
vínculo e a organização dos serviços de saúde. Penso que a atenção básica proporciona outro caráter visando outras formas de construção do trabalho (Entrevista Gerente [EG]1).

A fala expressa que ainda existem programas na área da saúde que são implantados de forma vertical, bem como nos indicam potencialidades para o trabalho na Atenção Básica. O entrevistado comenta os limites encontrados para o desenvolvimento das ações, de forma a atender os princípios estabelecidos pelo Sistema Único de Saúde (SUS) e que podem comprometer resultados das ações em saúde. Embora não entre na discussão direta da TB, o sujeito entrevistado deixa explícito que a Atenção Básica tem potencialidades no tocante à reconstrução do trabalho em saúde.

Essa discussão sobre as ações de controle da TB na AB nos remete a refletir acerca do planejamento das políticas públicas de saúde. Sob esta perspectiva há que se considerar que o planejamento estratégico aparece no campo da saúde como uma resposta ao insucesso do planejamento normativo comumente presente em países com dependência econômica (TESTA, 1995).

Corroborando acerca do planejamento normativo e as suas conseqüências no planejamento das políticas públicas e programas, Cohn; Westphal; Elias (2005) comentam que os programas quando não elaborados pelos espaços locais não contemplam as especificidades dos cenários a que são dirigidos. Esses são os chamados programas clássicos, elaborados de forma vertical pelo Ministério da Saúde, tal qual o PCT, permanecendo, portanto, o predomínio de outra esfera na definição das políticas locais de saúde.

Assim, as reflexões dos autores supracitados nos dão indícios dos limites concretos dos gestores locais em relação as suas responsabilidades no campo do 
planejamento em saúde no âmbito local. Schraiber et al. (1999) comentam que o gestor público defronta-se constantemente com uma prática de grande complexidade que é resultante deste novo espaço de produção social em saúde. De um lado necessita garantir os princípios organizativos e doutrinários do SUS via programas e ações de saúde, e de outro deve buscar incessantemente a resolutividade e qualidade técnico-científica das ações sob sua jurisdição.

Assim, para os autores, não existe dúvidas de que as mudanças exigidas no campo do planejamento e da administração em saúde são constantemente mutáveis e neste ínterim renova as problemáticas e as técnicas de organização, gestão e avaliação, cenário que deve ser revisitado com muita freqüência pelo gestor local.

Esse cenário de mudanças não se faz diferente na atenção à $T B$, pois na década de 90 a responsabilidade pela gestão das ações do PCT foi transferida aos municípios, e em 2006 foi reafirmado o compromisso político e financeiro para o controle da doença entre Municípios, Estados e União por meio do Pacto pela Saúde (BRASIL, 2007). Essas transferências de responsabilidades criam e criaram para os municípios importantes desafios no que concerne ao controle da TB.

Nesse sentido, cabe ao PCT definir metas como: cura, busca de sintomáticos respiratórios e cobertura do Tratamento Diretamente Observado (DOT) que se alinhe com as críticas em relação à normatização do planejamento em saúde, em especial ao desenvolvido por outras esferas federativas. Assim, parece que ao se tomar a gerência como responsável pela operacionalização das ações de saúde no âmbito local, a ela não é possibilitado proposituras inovadoras no campo do planejamento em saúde (Mishima,1995), quando os programas são gestados em outras esferas governamentais. 
Estudo desenvolvido por Nogueira et al (2007) já indicava que havia limites em relação ao processo de descentralização de algumas ações da TB para a $A B$, especificamente ao analisar as ações de busca ativa de sintomáticos respiratórios onde a autora revelou que as mesmas não estavam sendo incorporadas de forma contínua e rotineira nos serviços locais de saúde.

Estas discussões sobre os limites na operacionalização das ações de controle da TB nos levam a refletir sobre a capacidade gerencial instituída no campo da AB. O não seguimento das normatizações preconizadas pelo PCT conforme descrito por Nogueira et al (2007) parece revelar as dificuldades que a gerência local tem para operar processos de transformação das práticas instituídas.

Nesse sentido, Campos (1994), ao analisar o campo do planejamento em saúde comenta que as instituições assistenciais da saúde têm profunda relação com o modelo assistencial vigente e, sob esse prisma, há necessidade de analisar as tecnologias do planejamento buscando recuperar as articulações e inter-relações para que ocorram processos inovadores ou de mudanças no interior daquelas instituições. Estes aspectos demandam novos realinhamentos no campo da atenção à $T B$, requerendo maior envolvimento das equipes locais de saúde, de forma participativa para repensar a produção e reprodução dos aspectos do gerenciamento dos serviços locais de saúde (VANDERLEl; ALMEIDA, 2007).

Um dos aspectos que tem relação direta com o planejamento local pode estar relacionado ao processo e participação dos gerentes em relação às discussões acerca das ações de controle da TB no cenário local. Nesse sentido, no gráfico 2, podemos observar esse processo. 


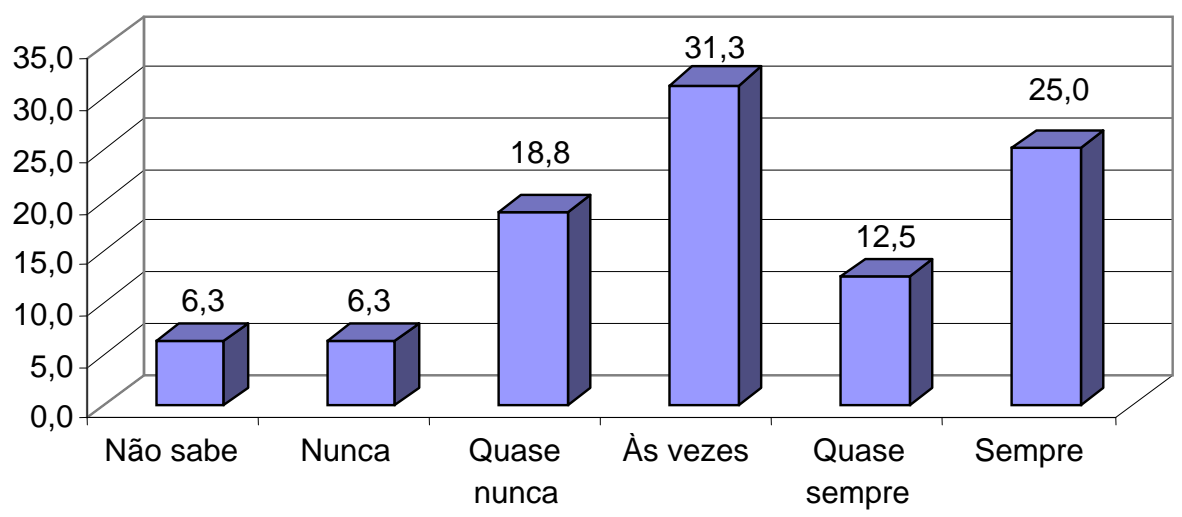

Gráfico 2. Participação na discussão e definição de ações de saúde para o controle da TB

No que se refere à participação dos gerentes na discussão e definição de ações para o controle da TB no município, 31,3\% deles revelaram participar às vezes, enquanto $18,8 \%$ responderam quase nunca participar, ao passo que $12,5 \%$ disseram quase sempre participar e 25\% referiram sempre participar das discussões.

Se entendermos que o planejamento é uma das dimensões do espaço da gerência, devemos então concordar que um dos elementos fundamentais para essa incorporação é o da participação efetiva nos aspectos gerais que concerne uma dada política local, no caso, o PCT. Os resultados revelam certa preocupação nessa linha, visto que mais de $50 \%$ se situam entre as respostas as vezes e nunca e apenas 37,5\% afirmaram participar destas discussões. A participação nas discussões e definição das ações de saúde para o controle da TB nos permite analisar o quanto estes gerentes estão imbuídos dessa temática.

Esse cenário parece ser preocupante na medida em que nem todos os gerentes convergem para uma mesma ação, que é a participação nas discussões de 
programas desta natureza, havendo alguns, inclusive, que desconhecem tal sistemática.

Essas formas de participação ou não participação nos permitem identificar que o "pensar" a operacionalização das ações locais de controle da TB podem estar comprometidas na medida em que, de fato, esses gerentes têm dificuldades de serem porta vozes para o desenvolvimento dessas ações, dada a sua pouca inferência nestas discussões, o que compromete o planejamento sob sua responsabilidade.

Nesse sentido, a falta da participação nas discussões dessa política local, aliada ao desenvolvimento de um planejamento normativo pode minimizar o processo de responsabilização tanto do gerente local quanto da equipe responsável pelas ações de controle da TB na AB.

A falta de uma participação ativa junto à política de atenção à TB parece direcioná-la para uma gerência centrada em tarefas burocráticas e administrativas comumente incorporada no cotidiano de trabalho dos gerentes assistenciais.

Tal situação parece responder às questões trazidas por Muniz; et al (2005) quando problematiza a falta de adesão às ações de busca de sintomáticos respiratórios no âmbito local, indicando pouco compromisso político na manutenção e continuidade destas ações na AB.

Outra situação que corrobora nessa discussão acerca do planejamento das ações de controle da TB, refere-se à necessidade de pensar que esta doença demanda o estabelecimento de parcerias setoriais. Estas parcerias podem estar vinculadas a outros setores sociais presentes no cenário local ou mesmo articuladas à economia, como remete a fala do gerente. 
Deveria acontecer (aqui) a mesma coisa que aconteceu em Campinas, pois a chegada de indústrias traz mais dinheiro e tenta melhorar as condições de vida da população, já que a TB é uma doença de cunho social que afeta as camadas desfavorecidas da população (EG6).

O gerente propõe novas tecnologias assistenciais e organização do sistema de saúde, trazendo a responsabilização compartilhada como uma das práticas da gerência e das equipes na atenção à TB (Muniz et al. 2005), dado seu caráter social que exige organização do trabalho, participação social e incorporação das organizações não governamentais (ONG) (HIJAR, GERHARDT e TEIXEIRA, 2007; DUCATI, RUFFINO NETTO BASSO e SANTOS, 2006). Essas questões se coadunam com a política de descentralização das ações de TB, bem como com o trabalho da gerência na formulação, decisão política, postura pró-ativa e inovadora, melhoria do acesso, adesão ao tratamento e vínculo com os profissionais de saúde VILLA et al (2006).

Nesse sentido, parece revelar a importância da busca de parcerias institucionais para sustentar e controlar as ações da Tuberculose. Segundo Villa et AL (2006), o Plano Nacional de Controle da Tuberculose (PNCT) de 1998 já previa a necessidade da participação social e da incorporação das organizações não governamentais (ONGs) no controle da mesma.

A incorporação de novas tecnologias assistenciais alinha-se com a descentralização do setor saúde e segundo Mendes, (1996) a intersetorialidade reconhece os múltiplos olhares sob uma dada realidade multiforme, portanto seu pressuposto está no fato de que a ação completa não ocorre apenas num setor singular, mas toma a solidariedade a partir de distintos setores, configurando uma nova tecnologia assistencial. 
Nessa perspectiva, entendemos que ao incorporar as ações de TB na $A B, 0$ Ministério da Saúde buscou aproximar e redirecionar o modelo assistencial, promovendo benefícios no que tange à melhoria do acesso, adesão ao tratamento e vínculo com os profissionais de saúde. Assim, ao considerar doenças com caráter crônico, a exemplo da TB, considera a necessidade da incorporação de novas tecnologias na organização da assistência à saúde, por meio de parcerias com outros setores sociais, como um dos elementos que deve acompanhar as práticas da gerência e das equipes na fase do planejamento em saúde (MUNIZ et al 2005).

Sob o aspecto, da intersetorialidade, Merhy (1997) lembra que o trabalho da gerência local deve ser um campo de ação, formulação e decisão política e, nesse sentido, produzir intervenções que possam propiciar resultados na política e no modelo assistencial. Dessa forma, entendemos, assim como os gerentes, que o controle da TB não pode prescindir de ações ampliadas neste campo de atenção tendo em vista que envolve uma série de questões que extrapolam a área setorial, demandando do planejamento em saúde uma postura pró-ativa e inovadora. As ações intersetoriais no campo da atenção à TB não deixam de garantir a singularidade do fazer setorial, ao contrário, reconhece os domínios temáticos na busca de uma síntese para o foco em questão (MENDES, 1996).

O campo da gerência parece de fato um espaço de contradições e de desafios, na medida em que, de um lado, encontramos gerentes que apontam as potencialidades da $A B$ no desenvolvimento do planejamento em saúde e de outro nos deparamos com falas que fazem outras leituras deste cenário direcionando para outros aspectos nesta discussão. Os depoimentos abaixo ilustram aspectos no que diz respeito à focalização das ações. 
Quando eu era gerente no Jardim Aeroporto nós dávamos ênfase à semana de TB, depois ficavam os cartazes (na Unidade de Saúde), aí se o paciente tinha algum sintoma, quando chegava ao posto lia os cartazes, e então, procurava a enfermeira e falava (dos sintomas da TB) (EG2).

Ribeirão dá mais ênfase à Dengue, por exemplo, e deixa as outras doenças de lado, não vê os problemas reais da população, tais como a TB e HIV. Deveria investir mais na busca de sintomáticos, realizar campanhas de conscientização da população (EG6).

O problema maior é que nas campanhas de TB todos se envolvem, funcionários, até a faxineira. Mas depois que passa parece que todo mundo esquece. Tanto que se você olhar os gráficos de maior coleta é porque é campanha, é baixo é porque está fora de campanha. Isso é muito complicado (EG10).

$\mathrm{Na}$ fala dos depoentes observamos que existe referência em relação à visibilidade da TB na Atenção Básica de uma forma restritiva, o que se contrapõe as respostas obtidas no questionário (gráfico 1), quando a grande maioria dos gerentes afirmou que a TB era prioridade no cenário sanitário do município. Neste sentido, os depoentes apontam exatamente o contrário, especialmente porque se refere a "pontualidade" do enfoque dessa doença na $A B$, ou seja, a "valorização" da TB somente por ocasião das campanhas, onde neste período, todos "pensam" na doença e se envolvem na busca de sintomáticos respiratórios.

Nesse sentido, quando identificamos a pouca participação dos gerentes nas questões da TB, as preocupações com a articulação setorial e a visão focalizada da TB na $A B$, entendemos que há processos interacionais que vão se efetivar quando 
das suas responsabilidades na gerência em saúde, permitindo que sua gestão local esteja permeada por contradições que ora apontam potencialidades ora fragilidades.

Segundo Mendes (2001), essa característica de "focalização" das ações presente nas falas dos sujeitos remete à cultura presente na organização dos sistemas locais de saúde, refletindo, portanto, também no campo do planejamento. A primeira idéia se refere à forma verticalizada dos programas de saúde, do qual se herdou do movimento "campanhista" a idéia da focalização das ações, ou seja, o uso prioritário das "campanhas" no desenvolvimento das ações de saúde. A segunda idéia faz referência à fragmentação dos sistemas de saúde no qual se observa uma atenção descontínua e ausência de integração entre os diferentes programas de saúde, tomando como foco a priorização por atividades preventivas e pontuais, portanto, com baixo impacto sobre a saúde dos usuários.

Corroborando nessa discussão, Passos e Ciosak (2006) comentam que as ações presentes nos diferentes níveis de atenção à saúde, ou seja, promoção, proteção, cura e recuperação devem estar integradas e articuladas entre si possibilitando uma ampla cobertura e acesso da população com vista à produção social em saúde.

Nesse sentido, a focalização das ações pode comprometer a integralidade da assistência, uma vez que essa visa resgatar aspectos perdidos na assistência à saúde do indivíduo e coletividade presente em modelos fragmentados de saúde. Assim, o atendimento integral vai além de uma estrutura organizacional hierarquizada e regionalizada da atenção em saúde, perpassa pela qualidade da atenção resgatando o compromisso com a educação em saúde e a prática multiprofissional (MACHADO et al., 2007). 
Dessa forma, foi possível identificar na fala dos gerentes uma permeabilidade por culturas e práticas históricas e pouca ação pró-ativa no sentido da mudança e das inovações, ao contrário, parece permanecer a idéia da responsabilidade individual do usuário em relação ao seu autocuidado em saúde, quando reafirma a necessidade de conscientização da população.

$\mathrm{Na}$ coleta de dados, percebemos uma gerência preocupada com atribuições de "cuidar" dos informes vindos da SMS, enviar relatórios, entre outras. Quanto aos demais profissionais, acumulam a tarefa de executar suas funções com a prática das atividades voltadas à população, de acordo com a demanda da unidade.

Nesse sentido, Schraiber et al. (1999) evidenciam que o gerente de unidade de saúde deve otimizar a produtividade, manejar os problemas e os conflitos cotidianos para a produção de serviços assistenciais oferecidos ao consumo individual e de mercado, envolvendo a eficácia e a eficiência em seu cotidiano de trabalho. E, além disso, enquanto gestor local deve garantir a universalidade e a equidade na prestação de serviços, possibilitar a participação popular e profissional nos processos decisórios correlatos à organização da produção e execução do cuidado em saúde, trabalhar com a integralidade das ações, criando espaços e formas de interação no trabalho cotidiano e gerenciando conflitos, como é da competência desta esfera pública.

Ao entendermos que o planejamento em saúde deve compreender as necessidades mediatas e imediatas, observamos que no campo da atenção local este é ainda deficitário. Corroborando nessa discussão, Barbieri e Hortale (2005) identificaram que os gerentes assistenciais têm pouca participação no planejamento de ações em suas próprias unidades de saúde, o que também foi possível perceber nessa investigação. 
Outro aspecto que poderíamos questionar é se a participação no planejamento das ações, sob a responsabilidade do gerente, estaria vinculada à experiência no sistema gerencial, ou seja, o tempo no cargo da gerência.

Neste sentido, observamos o Gráfico 3. 


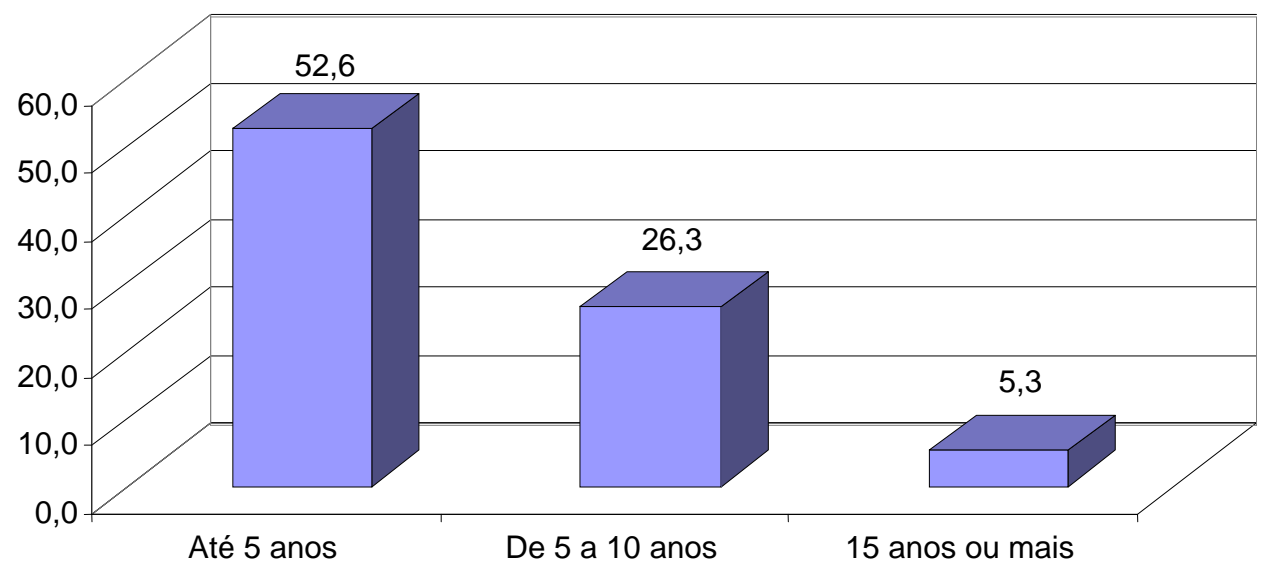

Gráfico 3 Número de anos como gerente de Unidade Básica de Saúde

O gráfico 3 nos revela que 52,6\%. dos gerentes entrevistados responderam atuar há cinco anos no cargo de gerência, 26,3\% atuam de cinco a dez anos e 5,3\% acima de quinze anos. Este cenário indica que o cargo da gerência nas UBS não é recente para a maioria dos entrevistados há, portanto, acúmulo de experiência nesta função.

A pouca participação nas discussões do planejamento das ações em saúde e especificamente em relação às da TB, nesse estudo, parece não ter relação com o tempo de ocupação neste cargo pelo gerente.

Acreditamos que a pouca participação no planejamento das ações, refletida neste estudo, nos leva a pensar qual seria o real papel do gerente da unidade de saúde, pois este além de ser um ator protagonista de mudanças locais, é também o principal interlocutor entre a UBS e a SMS.

Quando reconhecemos a TB como uma doença negligenciada, segundo Ruffino-Netto (2002), nos deparamos com um contexto complexo que envolve 
aspectos sociais e econômicos que permeiam esta patologia, além dos aspectos da organização dos serviços de saúde e do despreparo de recursos humanos para a atenção à TB.

Sabemos que algumas das ações de BSR são descentralizadas, porém os depoimentos revelam que a maioria das UBS tem os Centros de Referência como os responsáveis pelo desenvolvimento de ações em TB, como o diagnóstico, tratamento e acompanhamento.

A reorganização da rede de serviços locais de saúde torna-se condição imprescindível e acompanha as variações no desempenho gerencial, tendo implicações nos resultados e impactos na saúde da população. Estudos envolvendo aspectos gerenciais têm evidenciado o despreparo da esfera municipal e a deficiência de sua estrutura técnico-administrativa voltada para a prestação de serviços, no processo de descentralização da saúde (BODSTEIN, 2002). Nesse sentido, com relação à TB, o relatório da OMS (2004) apontou que um dos seis obstáculos para o avanço nos programas de controle da mesma foi a descentralização incompleta (WHO, 2004).

Assim, esta parece ser um dos motivos que contribui para que a doença permaneça em segundo plano, e isso traz implicações importantes para a própria valorização do planejamento das ações de controle da TB no cenário local.

Na fala dos entrevistados percebemos que há uma preocupação em relação à demora para o diagnóstico da TB, fazendo com que o doente retorne várias vezes à unidade de saúde em busca de uma solução para seus sintomas.

Teve um usuário aqui que levou 09 meses até descobrir que era TB, vinha com queixa de tosse, passava no médico, receitava xarope, vinha novamente e, assim foi até que ao 
final de vários meses o pneumologista diagnosticou TB. Os profissionais da saúde ainda são muito despreparados em relação à $T B$, há casos que o doente chega à unidade com queixas como tosse, escarro com sangue, passa pelo clínico e este apenas encaminha para o pneumologista, então demora muito para ser diagnosticado (EG4).

Pode ser que "passam" alguns casos que a gente não diagnostique, mas quando tem o diagnóstico nós acompanhamos, pedimos para a família vir até o posto, os comunicantes (EG5).

Lucca (2008) comenta que o tempo decorrido entre os primeiros sintomas respiratórios e o início do tratamento tem um campo específico para registro na ficha de investigação de TB (CVE-ESP), porém a autora verificou que este dado foi informado em apenas $70 \%$ dos casos novos do município. Nesse sentido, essa informação pode não ser lembrada com exatidão pelo doente; ao mesmo tempo o registro desta informação pode ser objeto de investigação pelo profissional. Do ponto de vista da assistência este fato pode ter conotações distintas: uma decorrente das características individuais e sociais do doente que o levam a procurar o serviço somente a partir do momento em que se percebe doente, ou seja, com sintomatologia avançada; a outra, para os profissionais, pois o não registro pode implicar em inadequabilidade no processo terapêutico.

O tempo de demora depende também da organização dos serviços de saúde, do profissional que faz a primeira abordagem deste indivíduo, do acesso à primeira consulta médica, da demora na suspeita da doença, da disponibilidade de insumos para a solicitação de exames (potes de escarro, impressos, geladeira para guardar material), disponibilidade de outros exames diagnósticos (radiológico), tempo entre a 
coleta de material para exame e a chegada do resultado, do encaminhamento e agendamento do paciente ao serviço que fará o tratamento (LUCCA, 2008; OLIVEIRA, 2006).

Lembram as autoras que este tempo de demora irá depender da chegada do indivíduo ao serviço, ou seja, o acesso à localização do domicílio, condições de transporte até a instituição do tratamento, que também dependerá do vínculo com os profissionais de saúde.

Percebemos que não há uma definição de estratégias de trabalho no que concerne às ações de controle da TB e nem mesmo coordenação dessas atividades; a demora pelo diagnóstico é algo experimentado pelo doente, fazendo com que, muitas vezes, o usuário seja obrigado a retornar à unidade até a comprovação do diagnóstico. Muitas vezes, o usuário retorna várias vezes à unidade até que o diagnóstico seja comprovado.

\subsubsection{O Controle da Tuberculose na Atenção Básica: a visão gerencial}

Nesta temática abordamos os aspectos apontados pelos gerentes quanto à organização para o controle da TB no município em estudo. Dentre os dados expostos alguns aspectos merecem ser abordados: o estigma em relação à coleta de baciloscopia, o planejamento e a organização, como dimensões da gerência, coresponsabilização no cuidado à saúde, a participação dos gerentes nas discussões para a definição de aplicação de recursos para o controle da TB, e ainda quanto ao horário de funcionamento das UBS. 
Os aspectos supracitados mantém relação próxima do cenário onde essas ações são desenvolvidas, ou seja, AB. Para Testa (1995), o cenário de uma ação social é definido como um espaço social que pode conter ou não um espaço físico, mas que não pode ser definido somente a partir desse último. Este espaço social segundo o autor é onde transcorre os processos, discussões, conflitos, decisões e as ações de saúde que se (re)definem permanentemente tanto em termos conjunturais quanto históricos.

Observamos que são vários fatores preditivos que acarretam um resultado negativo no controle da TB, entre eles podemos citar: problemas sócio-econômicos, falta de moradia, desemprego, alcoolismo, tabagismo e o uso de drogas. Além disso, há os agravantes da miséria, desnutrição, más condições de saneamento e distribuição de renda que predispõem os indivíduos a esta doença (VILLA et al 2008).

Diante de tantos entraves que circundam a problemática do controle da TB, acreditamos que esta vai além do ato de diagnosticar e medicar, mas também devem levar em conta as singularidades dos doentes para implementar estratégias de cuidado. Assim, torna-se imprescindível conhecer as condições sociais em que vivem as pessoas acometidas pela TB, pois essas são determinantes para a implementação de novas abordagens assistenciais, bem como, evitar a emissão de juízos de valor sobre aspectos gerais que norteiam o cotidiano do doente.

Frente a essa discussão as práticas de planejamento são dirigidas para a organização das práticas em saúde. Nesse sentido, as práticas do planejamento podem ser condicionadas e determinadas pelas estruturas e meios de organização do trabalho dos dirigentes e trabalhadores e ainda, podem ser determinadas pelos propósitos desses dois atores sociais quanto aos resultados esperados de suas 
práticas, ou seja, de legitimação, manutenção, crescimento, mudança ou transformação. Há que se ressaltar que essas práticas não estão livres de determinações mais amplas, tanto estruturais quanto conjunturais (VILASBÔAS, PAIM, 2008).

Nesse sentido, a dimensão gerencial torna-se importante aliada no que concerne à organização das ações de TB, pois é necessário um planejamento sistematizado e integral para cada doente visando a singularidade e a resolutividade, sempre que possível, das necessidades destes e de suas famílias. Arcêncio (2006) afirma que a organização das ações de TB e BSR têm sido uma das atribuições da AB.

A identificação de sintomáticos respiratórios não é uma tarefa simples; a realização desta atividade requer entendê-la como uma ação complexa, pois não basta apenas perguntar ao indivíduo se ele vem apresentando tosse. O profissional de saúde deve estar apto para desencadear todas as etapas que envolvem este processo, levando em conta os aspectos antropológicos que permeiam esta ação. Essa tarefa implica em uma abordagem ampliada do paciente e passa pelo processo saúde-doença (MUNIZ, 2004).

Sobre essa situação manifesta o gerente:

Mas eu acho que ainda falta mais esclarecimento para os profissionais de saúde, porque às vezes vem aqui com algum sintoma (tosse) e eles não pensam que pode ser TB (EG5)

Muniz (2004) aponta em sua investigação, acerca dos ACS na identificação de sintomáticos respiratórios para o controle da TB, as dificuldades encontradas em 
relação aos usuários que aceitaram fazer o exame de escarro: 30\% não levam o material na unidade; 25\% não têm dificuldade; 22\% não colhem o material; 14\% não conseguem colher o catarro e 9\% referiram não ter catarro.

O estudo de Campinas (1999) revelou que os doentes manifestam aversão em relação à coleta do exame de escarro. Em nosso estudo identificamos que também os profissionais de saúde demonstram repugnância com a amostra para a baciloscopia.

Eu acho que alguns funcionários têm um pouco de "nojo" quando tem que colher o escarro, pegar o pote....mas isso já não era para ter mais. Eu converso com meus funcionários sempre tento orientá-los mas é muito difícil (EG4)

Mazzaia (2000) avaliou a atitude dos profissionais de enfermagem frente à amostra de escarro e a orientação para a técnica da coleta do mesmo. Verificou que 86\% demonstraram atitude desfavorável em relação à coleta da amostra de escarro.

Entendemos que essa é uma das situações que necessitam ser trabalhadas pelos gerentes locais, uma vez que tem implicação direta com o planejamento e a organização das ações do controle da TB na $A B$, especialmente em relação ao diagnóstico precoce desta doença.

Alguns autores como Hurting, Porter e Ogden (1999) comentam que em muitas culturas o estigma social da TB é um dos fatores que contribui para o não controle da doença. Outro fator acrescido ao estigma, segundo os autores, é em relação ao DOT, pois se de um lado é um instrumento que favorece para alcançar as metas de detecção e cura, de outro, interfere na vida privada do doente, na medida 
em que quando o tratamento é realizado no domicílio a privacidade do doente e de sua família é invadida.

A BSR no âmbito do Programa de Agentes Comunitários de Saúde (PACS) tem sido preconizada pelos Planos Nacionais de Controle da TB como uma estratégia de detecção precoce da doença. Um fator positivo que podemos considerar é que o ACS atua predominantemente junto à comunidade e isso pressupõe que este desenvolverá atividades que ampliem o vínculo, bem como as relações com as famílias.

Aqui não vejo dificuldade para desenvolver as ações em TB, Nós somos privilegiados por ter agente comunitário de saúde, eles foram treinados pelo Dr. (...) em relação às ações em TB. Então quando há casos, eles já sabem o que fazer. O bom é que não é só o médico que pode realizar/pedir o exame de escarro e isso facilita muito (EG03).

A fala acima mostra um fato positivo no que concerne à BSR, pois todos os profissionais de saúde da UBS estão aptos para a sua realização, porém desde que haja um adequado treinamento para tal.

Cabe destacar aqui que Muniz (2004) revelou em seu estudo que os agentes apontaram como dificuldade a falta de argumentos para convencer o paciente a colher o escarro. Esta não é uma dificuldade do usuário em realizar o procedimento, mas sim do ACS. Sabemos que a abordagem inicial à família, ou seja, a confiança, o vínculo, tornam-se essenciais para a realização de qualquer intervenção. Esta tarefa requer além de habilidades técnicas, outros conhecimentos que venham somar-se, 
como a sociologia, a filosofia e a psicologia entre outros, corroborando assim, com as discussões de Schraiber et al. (1999).

Sobre esse aspecto, cabe ressaltar que essa associação entre disciplinas que compunham um saber científico articulado com as necessidades dos serviços, servindo de subsídios para o desenvolvimento das ações de controle da TB, devem vir acompanhadas de um planejamento estratégico por parte das lideranças locais das UBS uma vez que a BSR é uma das tarefas dos ACS cuja formação apresenta limitações. Dessa forma, esses sujeitos necessitam apoio para a compreensão dos principais conceitos que norteiam o entorno da assistência e da forma de vida dos sujeitos imbricados com a questão da TB, os doentes.

Todos os profissionais de saúde devem se responsabilizar pela continuidade da atenção, independentemente da categoria profissional e do ponto de atenção em que ele se encontre. Isso inclui todos os envolvidos na prestação de serviço, seja o agente comunitário de saúde, profissionais médicos, de enfermagem, gerência e equipe de apoio (recepção, transporte, limpeza, administração, segurança) (MUNIZ, 2004). Cabe ressaltar que essa articulação multiprofissional é de competência do gerente da UBS a partir da organização das ações de controle da TB.

Percebemos que muitos são os entraves para a realização da busca de sintomáticos e do seguimento do tratamento. Dessa forma, devemos nos imbuir cada vez mais de conhecimentos que possam nortear as ações de controle da TB. Assim, o planejamento em saúde, a organização, a direção e o controle são elementos essenciais para uma gerência efetiva.

Alguns fatores são essenciais para a produção em saúde, tanto da equipe quanto dos usuários e entre eles podemos citar: conhecimento da realidade local, formas de intervenção dos gerentes no alcance dos objetivos e das metas, 
realização de práticas individuais e coletivas pela equipe de saúde, uso adequado de recursos materiais e humanos e instrumentos de avaliação do desempenho dos profissionais.

No cotidiano ainda observamos que a baciloscopia tem pouca credibilidade entre os doentes ao passo que o RX possui grande aceitabilidade. Este apresenta resultado concreto, algo que retrata o corpo internamente onde se encontra o problema. É fato que o estigma quanto ao ato de escarrar é algo que permeia o imaginário dos usuários e dos profissionais de saúde. (SECRETARIA MUNICIPAL DA SAÚDE, 2002).

Assim, a gerência das UBS tem papel fundamental no desenvolvimento das ações de TB, constituindo-se como ferramenta importante na efetivação de políticas locais de saúde. Uma gerência que considera os profissionais de saúde e os usuários como atores em potencial para a produção das ações em saúde, compreendendo-os como co-responsáveis no trabalho em saúde, se contrapõe à racionalidade gerencial burocrática, normativa e tradicional (VANDERLEI; ALMEIDA, 2007).

Dessa forma, para exercer a gerência, faz-se necessário que o gestor amplie seus conhecimentos e habilidades tanto da área da saúde como da administração e ainda ter compromisso social com a comunidade. Este gerente possui a responsabilidade de organizar a produção de bens e serviços de saúde ao indivíduo ou à coletividade (PASSOS; CIOSAK, 2006).

Para as autoras, gerenciar é tomar decisões que, muitas vezes, afetam a estrutura, o desenvolvimento e o produto de um sistema. Numa organização, o gerente se responsabiliza pelo uso efetivo e eficiente dos insumos, de forma a 
traduzi-los em serviços que levam a organização a atingir os resultados que se esperam dela.

Nesse sentido, o gerente, ao somar o seu conhecimento da área da saúde com algumas dimensões da administração, como o planejamento e a organização acreditamos que poderá contribuir no desenvolvimento de ações para o controle da TB.

Assim, nesta investigação entendemos que o gerente da UBS deve tomar o planejamento como ferramenta de gestão, como método que precede e permeia suas ações para o controle da TB. Trabalhar imbuído com as questões do planejamento em saúde é uma forma de orientar a ação humana, organizar as práticas de saúde sendo essa uma das formas de implementar políticas de saúde. O planejamento em saúde deve estar aliado à organização de suas ações , ou seja, às formas como são realizados os trabalhos pelos gestores locais e determinados pelos resultados que este deseja, a partir de suas ações/implementações (VILASBÔAS, PAIM, 2008).

Sabemos que as questões sociais, culturais e operacionais que circundam o cotidiano do doente influenciam fortemente no (des)comprometimento com sua saúde (VILLA et al.; 2008). Observemos a fala abaixo:

Outro fato é que os pacientes, não só em relação à TB, mas outras doenças eles não se responsabilizam pelo cuidado à sua saúde, nós não podemos ficar sempre atrás, deveriam ser responsabilidades compartilhadas(EG14)

Estudo mostra que a relação entre usuário/profissional é baseada na impessoalidade, na qual o paciente se constitui simplesmente como objeto de 
trabalho; dessa forma, as intervenções baseiam-se apenas na eliminação do foco de transmissão da doença, não valorizando os valores, as crenças e as opiniões dos usuários (ARCENCIO, 2006).

Acreditamos que para estreitar a relação entre usuário e profissional o DOT, recomendado pelo Ministério da Saúde desde 1994, é um importante aliado, principalmente para contribuir na redução do número de abandono.

Nesse sentido, Arcêncio (2006) observou que as equipes de saúde desvalorizam a opção dos doentes em relação ao DOT por acreditarem que as ações implementadas na assistência à TB vão ao encontro das crenças profissionais, do bem-estar do indivíduo, independente da sua capacidade decisória ou não. Muito embora um dos objetivos das práticas profissionais é evitar complicações decorrentes do processo saúde/doença, melhorando as condições de saúde do usuário e levar em conta a questão da autonomia do indivíduo.

Acreditamos que trabalhar com a co-responsabilidade exige desafios a serem vencidos, pois envolve além do saber biologicista dos profissionais, conhecer o indivíduo que vem ao serviço de saúde, suas crenças, seu cotidiano, seus hábitos de vida, esclarecer sobre sua doença e tratamento, para dessa forma, ter elementos para compartilhar a responsabilidade no processo terapêutico.

Segundo Breilh (1991), o processo saúde/doença se constitui numa expressão particular da vida social, portanto, corresponde às formas econômicas e estruturais em torno das quais ocorrem processos particulares de reprodução social e, por conseqüência, nos aspectos epidemiológicos particulares entre os quais se situam os indivíduos.

Nesse sentido, acreditamos que na atenção à TB o contexto sócio-culturaleconômico que permeia a vida dos doentes e suas famílias deve ser considerado 
como um dos elementos gerenciais para o planejamento e organização da atenção no processo saúde/doença.

Observamos no Gráfico abaixo como os gerentes se colocam frente à discussão em relação à aplicação dos recursos para o controle da TB. 
68,8

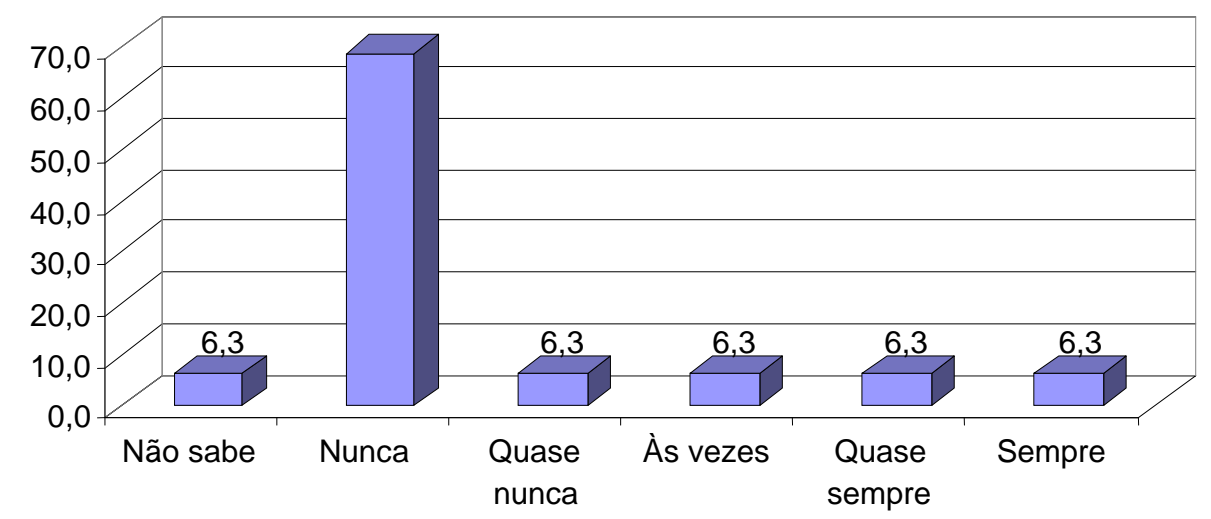

Gráfico 4: Participação na discussão e definição de aplicação de recursos para o PCT.

No gráfico 4, 68,8\% dos entrevistados responderam que nunca participaram das discussões para a definição de aplicação de recursos para o controle da TB. Esses dados são preocupantes na medida em que elementos do processo saúde/ doença, na sua forma mais ampliada, interferem na responsabilização bilateral serviços de saúde e população usuária. Dessa forma, pressupõe-se que uma das funções gerenciais, o planejamento, é componente qualificador para a atenção ao doente com TB. Imprescindível, portanto, o conhecimento da realidade local e do contexto social do doente e/ou sua família.

Para Nemes (2000), uma das finalidades das várias vertentes do planejamento refere-se à dimensão política, que trata da capacidade de priorização em relação à atenção à saúde. Nessa investigação, entendemos que é imprescindível o conhecimento sobre a definição de recursos para o PCT na medida em que mantém uma relação direta com as prioridades elencadas pelo gestor local. 
Assim, teoricamente, o gerente necessita ter um olhar ampliado para as dimensões operativas/técnicas do trabalho em saúde.

Frente ao exposto pelos gerentes, e diante da argüição teórica trazida por Nemes (2000) em relação à operacionalização do planejamento, parece haver um descompasso no nível local, na medida em que os depoentes não participam de fóruns de definição e aplicação de recursos para a temática em questão. É de se esperar, portanto, a baixa vocalização para a defesa dos interesses dos usuários sob sua jurisdição, o que torna a co-responsabilidade um processo débil.

Essa baixa capacidade de advocacy dos gerentes pode refletir diretamente na organização das ações de controle da TB, comprometendo a incorporação de incentivos ou a sua continuidade como parte desta política setorial, interferindo, portanto, nos resultados esperados para o controle da mesma.

Na medida em que há desconhecimento ou minimização da dimensão política presente no planejamento, poderá ocorrer um viés no processo de interação profissional - doente. Esse descompasso mais comumente se apresenta sob a forma da responsabilização unilateral, como pôde ser percebido na fala do gerente.

Sabemos que o controle da TB é um ponto fundamental para a quebra do ciclo de transmissão; para tanto, é necessário que ocorra uma relação harmônica e humanizada entre doente e profissional de saúde, bem como saberes e práticas instituídas para o controle da TB.

Um aspecto abordado pelo gerente diz respeito ao horário de funcionamento da UBS, relacionado com o segmento populacional acometido pela TB. Este é um elemento que pode estar vinculado à visão ampliada do gestor, na medida em que identifica esta população pertencente à classe economicamente ativa. 
A maioria da população adscrita daqui é trabalhadora, então penso que nosso horário de funcionamento possa ser limitante para eles (EG14)

A discussão sobre o horário de atendimento remete ao reconhecimento de uma ritualização presente no planejamento normativo, na medida em que esse processo de burocratização não empreende flexibilidade para o atendimento de usuários em horários alternativos. Segundo Vilasbôas e Paim (2008) a implementação de políticas de saúde parece estar mais coadunada com valores compartilhados entre dirigentes e servidores do que nas necessidades de saúde da população usuária do sistema. Essa articulação responde a uma racionalidade instrumental na orientação do planejamento e da organização dos serviços de saúde.

Essa racionalidade técnico-burocrática presente nos sistemas locais dificulta o acesso dos usuários aos serviços de saúde, no que concerne à atenção à TB; estudo desenvolvido por Villa et al. (2008) identificou que a população masculina é a mais acometida pela TB e se situa entre 20 e 39 anos, portanto, um segmento populacional considerado economicamente ativo.

Dessa forma, a epidemiologia pode contribuir para o planejamento e organização do acesso aos serviços de saúde de segmentos populacionais distintos, buscando novas estratégias para a inserção deles no sistema local, minimizando o insucesso no controle da TB.

Direcionando esta discussão para o planejamento e a organização em saúde, dimensões que compõem o processo gerencial, entendemos que os gerentes, sujeitos do estudo, parecem ter compreensão dos limites e das necessidades da sua 
realidade, porém na dimensão da organização estes demonstram baixa vocalização para a tomada de decisão e definição de estratégias voltadas às ações de TB.

\subsubsection{Ações Gerenciais do Controle da Tuberculose na Atenção Básica: potencialidades e limites}

$\mathrm{Na}$ discussão acerca da TB na $\mathrm{AB}$ abordamos a participação dos gerentes quanto a: definição de linhas específicas para a TB no repasse de recursos para o município, conhecimento em relação aos casos da doença, subnotificação e a distribuição de recursos para a mesma.

Ao estudarmos a gerência local o fizemos pensando ser este um agente de mudanças, mas acima de tudo possuidor de conhecimentos acerca da realidade do município e principalmente da situação da sua área de abrangência.

Quando observamos o gráfico 5 verificamos que 43,8\% dos gerentes afirmaram que sempre participaram da definição de linhas específicas para TB no repasse de recursos para o município, enquanto 37,5\% responderam não saber. 


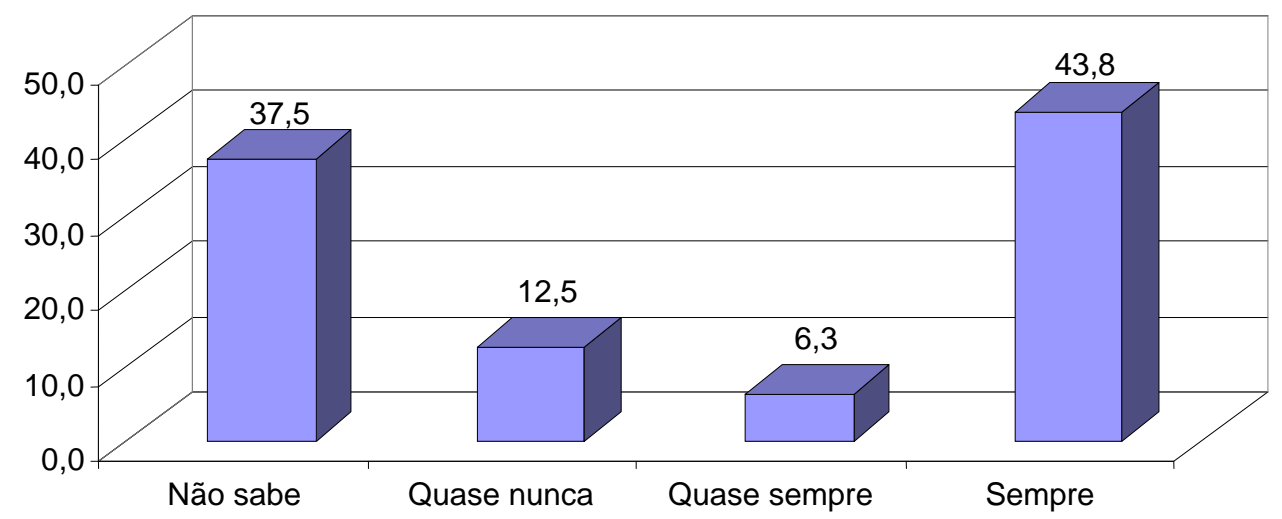

Gráfico 5. Definição de linhas específicas para TB no repasse de recursos para o município.

Apesar do contexto legislativo-normativo que estabelece a descentralização das ações de controle da TB para o município, foi analisado por Monroe (2008), que na prática não existe a valorização da TB na agenda municipal de saúde. Este fato pode se relacionar ao desinteresse pelas políticas e estratégias de controle da TB e também a outras prioridades de saúde de caráter emergencial do município, como a dengue, a exemplo do que foi mencionado anteriormente pelos gestores.

Este contexto pode ser percebido a partir do gráfico 5 no qual $50 \%$ dos gestores não participam e/ou não sabem em relação à definição de linhas específicas para a TB no repasse de recursos para o município. Parece que esse desconhecimento compromete a sua atuação gerencial, na medida em que enquanto gestor deve minimamente ter conhecimento das alíneas de recursos para um dos programas sob sua responsabilidade no âmbito da UBS.

Sob esse aspecto Vilasbôas e Paim (2008) identificaram em seu estudo que quando existe ausência de institucionalização de práticas estruturadas do planejamento e organização, elas fragilizam a capacidade de governabilidade local, 
na medida em que não detêm potencial para sustentar a programação, monitoramento e avaliação das ações em saúde no âmbito local.

Dessa forma, entendemos que a falta de domínio das informações sobre o conjunto de recursos destinados a programas específicos é uma das situações que concorrem para que um dos elementos do processo de gerência, o planejamento, esteja comprometido.

Nos depoimentos que seguem podemos perceber que os gerentes possuem conhecimento dos casos de TB da sua UBS, porém um fato que chama atenção é o de que ao mesmo tempo em que afirmam ter poucos casos da doença, suspeitam da subnotificação, ou seja, dos casos que não são detectados/notificados.

Já trabalhei como enfermeira da vigilância epidemiológica aqui em Ribeirão Preto, atuei em campanhas de tuberculose, participei de representações que tratavam sobre o assunto. Eu não sei responder em relação à busca ativa, porque não temos o programa na unidade (EG12)

Aqui temos poucos casos de TB, que eu lembre apenas 01, porque eles vão no Centro de Referência, são acompanhados lá e não aqui (EG05).

Temos poucos casos de TB aqui, acho que 01 ou 02, porém a meta da coleta de escarros (aproximadamente 10 ao mês) não é atingida, então não sei se há casos que não estamos notificando (EG14).

Outro fato preocupante que emerge das falas aponta para o desconhecimento em relação ao PCT, e ainda as falas denotam a transferência de responsabilidades, 
ou seja, as ações da TB ficam como atributos de maior competência para os Centros de Referência (CR) eximindo, dessa forma, as UBS deste papel.

Oliveira (2006), em seu estudo, mostrou que $40 \%$ da busca de sintomáticos respiratórios no Estado de São Paulo foi realizada como rotina nas UBS e 18\% por meio de mobilizações; observou ainda que a busca ativa é incipiente, sendo que a rotina predominou por demanda espontânea.

Parece que os gerentes locais se mostram alheios à realidade da TB no âmbito da sua jurisdição, pois as dimensões do planejamento, coordenação e supervisão são tomadas como uma atribuição gerencial de ação instrumental.

De acordo com Brasil (2000), em todas as unidades de Programa de Saúde da Família e demais serviços municipais de saúde, a BSR e contatos devem ser atitudes permanentes agregadas à rotina de atividades dos profissionais de todas as equipes de saúde.

A gestão de um serviço de saúde é de competência de cada um dos agentes do trabalho desse serviço, e de todos ao mesmo tempo; gerir é operar num campo de disputas desses distintos agentes mais do que buscar a funcionalidade não cumprida (MERHY, 1997). Para a operacionalização de sua atribuição o gerente necessita utilizar meios de intervenção capazes de atuar no autogoverno dos profissionais para poder alterar a lógica do cuidado e, conseqüentemente, o modelo de atenção a partir do interior dos serviços de saúde (ERMEL; FRACOLLI, 2003).

Podemos observar nas falas a forma inflexível com que alguns gerentes exercem sua função. Na concepção destes o trabalho é permeado de atividades burocráticas e ações relacionadas apenas à unidade de saúde a que pertencem. Em relação ao PCT estes demonstram pouco conhecimento, pois solicitavam a 
permissão para que a enfermeira e outros profissionais de saúde da UBS respondessem algumas questões específicas relacionadas à TB.

Eu não tenho mais nenhum comentário para fazer, vocês devem perguntar para quem trabalha diretamente com a TB (EG07).

Vou pedir para os agentes e a enfermeira me ajudar (responder o questionário), pois eles têm maior contato do que eu com esta realidade (EG13).

A OMS (2003) ressalta que os gestores têm papel fundamental na mudança da forma de pensar sobre os cuidados prestados e nas estratégias de intervenção adotadas nos sistemas de saúde. Sendo assim, os dirigentes devem ser sensibilizados para as necessidades de estratégias de gerenciamento no enfrentamento das condições crônicas, tais como a TB.

O gerente da UBS deve planejar as ações de saúde de sua área de abrangência de acordo com as necessidades de sua população. Schraiber et al., (1999) consideram que a área do planejamento e da administração em saúde tem potencial para mudanças e inovações no processo de organização, gestão e avaliação, as quais o gestor necessita revisitar com freqüência.

Também considera que o campo da saúde coletiva representa o locus da produção técnico-científica de caráter mais aplicado, a qual traduzirá suas ciências e suas tecnologias-base, como por exemplo, a biomedicina, sociologia, antropologia, matemática, estatística e a epidemiologia, em conhecimentos que são de imediato colocados à disposição junto aos serviços de saúde na forma de intervenção. 
Sob essa perspectiva Paim (2003) comenta que a gestão, o planejamento e a organização dos sistemas locais de saúde são processos que não podem abrir mão da disciplina da epidemiologia como saber científico, pois é prática instrumental que qualifica processos de intervenção no âmbito da saúde na sua dimensão coletiva.

Nesse sentido, Teixeira (1999) comenta que o saber epidemiológico poderia compor a racionalidade técnico-sanitária capaz de explicar a realidade da situação de saúde num determinado espaço social. Para esse estudo, entendemos e concordamos com Teixeira (1999), Schraiber et al. (1999) e Paim (2003) que a epidemiologia enquanto uma ação instrumental pode ser concebida como uma tecnologia ou uma ferramenta para o processo da gestão em saúde, que por meio do seu saber tecnológico sirva como instrumento para formulação de políticas públicas locais.

Quando analisamos as respostas referentes à participação dos gerentes na discussão e definição de ações de saúde para o controle da TB (gráfico 2) notamos contradições quando da análise dos depoimentos, pois parece incoerente participar das discussões e não ter dimensão acerca do quadro sanitário-epidemiológico dos aspectos relativos à TB em sua área de abrangência.

Assim, nos parece que em relação à atuação dos gerentes, há uma lacuna de conhecimentos em relação ao PCT. Este fato é preocupante, na medida em que do ponto de vista epidemiológico, a TB atinge anualmente 09 milhões de pessoas e leva a óbito um indivíduo a cada 15 segundos (WHO, 2007), o que deveria servir de alerta para os gestores municipais e gerentes das UBS.

De acordo com Vilasbôas e Paim (2008) quando existe precariedade do método (gestão) e debilidade da organização, no caso UBS e SMS, pode haver restrições na manutenção e oferta dos serviços de saúde. Nesse sentido, estes 
podem ameaçar o propósito de legitimidade do grupo responsável pela administração do sistema local, comprometendo o processo de assistência à TB e os resultados em saúde.

Este estudo aponta para um descompasso do planejamento da gerência da UBS em relação às políticas de TB no município. Nesse sentido, Barbieri e Hortale (2005) já mostravam que o planejamento é pouco desenvolvido pelos gerentes assistenciais, sendo a organização a dimensão mais executada por eles. Assim, de acordo com as autoras, existe déficit de governabilidade pelos gerentes assistenciais com pouca participação nos processos decisórios, percebendo-se apenas como controladores do processo.

Quanto à participação na discussão e definição de aplicação dos recursos para TB, às vezes, os gestores são chamados para ver os recursos, mas esse aspecto é mais direcionado à Secretaria Municipal de Saúde (EG12).

Sou gerente apenas da unidade básica e não tenho conhecimento sobre aspectos relacionados ao gerenciamento de recursos destinados ao programa de controle da TB. Se chegar alguém doente aqui a gente atende e agenda consulta. Eu não vejo porque eu tenho que responder este questionário, vocês deveriam procurar quem trabalha com a TB, aqui nós nem temos muitos casos, e eu não tenho que saber se há ou não recurso para isso, minha competência é gerenciar a unidade básica que estou (EG11). 
Ao nos reportarmos à dimensão da organização, enquanto competência da gerência assistencial para operar atividades e relacionar estas com seu modus operandi, na busca de resultados positivos, entendemos que, a partir dos depoimentos supracitados, os gerentes locais parecem ter dificuldades para responder satisfatoriamente o plano gerencial.

Isto remete à permanência da dimensão da organização ainda pouco articulada à complexidade do objeto em discussão, a TB, dando a idéia de que o paradigma dominante do planejamento predomina em relação à propositura de um conhecimento crítico-reflexivo ancorado na realidade local e de domínio destes gerentes. Assim, tal qual o planejamento, a organização também carece de novos elementos propulsores capazes de tornar exeqüíveis as políticas de atenção à TB em consonância com as necessidades dos doentes e das diretrizes do PNCT.

Esses aspectos parecem estar intrinsecamente ligados ao fato de que os gerentes não se vêem no papel de gestores, responsáveis pela tomada de decisões de sua UBS e também pela necessidade de aprimorar a incorporação e viabilização das ações de TB na AB de acordo com as políticas de controle da doença.

A dimensão do controle ganha evidência neste momento, pois nos revela a capacidade do gerente utilizar e adaptar sistemas de informação para avaliar o trabalho que é de sua competência, demonstrando a responsabilidade na realização e avaliação das tarefas e dos resultados (Barbieri e Hortale, 2005), neste caso, a UBS. Nesse sentido, as falas refletem as limitações destes profissionais nos aspectos relacionados ao planejamento e controle das ações em saúde de sua área de abrangência.

Cabe relembrar que com a NOAS, nas edições de 2001 e 2002, ficou estabelecido que a TB, sendo uma patologia de caráter crônico, deve ser 
diagnosticada e tratada no âmbito da $A B$, porém o que observamos neste estudo é a visão de que algumas ações de controle da doença são de responsabilidade única dos Centros de Referência.

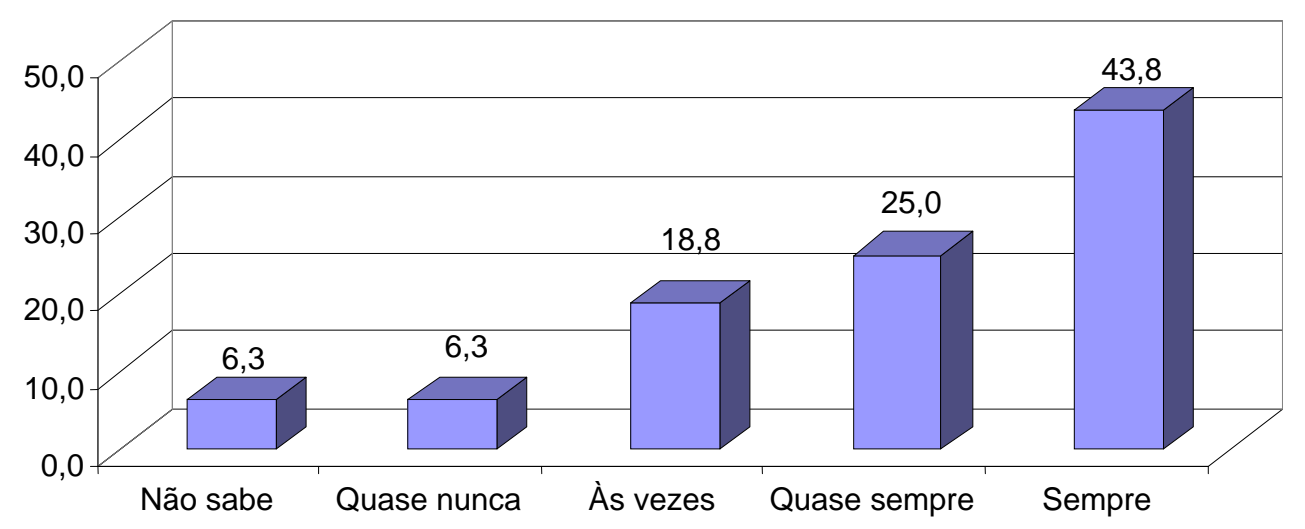

Gráfico 6. Distribuição de recursos realizada de acordo com as necessidades da população a ser atendida.

Quando questionados quanto à distribuição de recursos de acordo com as necessidades da população a ser atendida, 43,8\% dos gerentes responderam que sempre é realizada, enquanto que para $25 \%$ os recursos são distribuídos quase sempre de acordo com as necessidades da população a ser atendida.

O depoimento abaixo nos remete a refletir sobre a participação dos gerentes na definição e aplicação dos recursos destinados à TB.

Em relação aos recursos quando sobra cesta básica no Centro de Referência ou passe de ônibus eles dão para nós, aí é destinado para outros pacientes (EG02). 
Observamos na fala do depoente que este toma as ações voltadas à definição dos recursos como não sendo responsabilidade dos mesmos e, sim da SMS. Dessa forma, conhecem apenas algumas ações pontuais, como por exemplo, o repasse de cestas básicas e vale-transporte.

Segundo Schraiber et al. (1999), se no trabalho em saúde o processo de fragmentação é identificável, este vai exigir, portanto, maior controle de supervisão para a recomposição do conjunto. Nesse sentido, o gestor dos serviços de saúde assumiria o papel de implementador da política de Estado, bem como, supervisor ou controlador técnico da recomposição do trabalho coletivo, portanto, o gerente é um agente não só executor da macro-política mas situa-se como formulador desta no âmbito local.

Essa discussão trazida por Schraiber et al. (1999) corrobora nesse estudo ao conhecermos a distribuição dos recursos versus população atendida, na qual os gerentes na sua maioria afirmaram participar deste fórum, em contradição à afirmação referente ao gráfico 2 no qual 60\% deles diziam ter pouca participação nas discussões e definição de ações de saúde para o controle da TB, assim como 50\% deles admitiram não participarem dos fóruns em relação à definição de linhas específicas para TB (gráfico 5); neste ínterim lembramos que 68,8\% dos gerentes também afirmaram nunca participar das discussões para a definição da aplicação de recursos no controle da TB (gráfico 4).

Assim, entendemos que os gerentes assistenciais do contexto sanitário estudado necessitam recompor aspectos inerentes à gerência, como o planejamento, organização como forma de viabilizar a política de controle da TB de acordo com os preceitos jurídicos-legais e as normatizações inerentes ao PCT. 


\section{CONSIDERAÇÕES FINAIS}

Nesta investigação analisamos a visão dos gerentes das UBS acerca da problemática da Tuberculose em um município do interior do Estado de São Paulo e acoplamos uma questão aberta no questionário que permitiu ao sujeito manifestar-se livremente sobre as dificuldades no controle da TB no âmbito da gerência local.

Os gerentes que aceitaram participar desse estudo revelaram atuar há mais de cinco anos na função de gerência local, portanto, acumulam experiência no processo de gestão da UBS. É interessante também que, a maioria deles toma a TB como uma doença prioritária no quadro sanitário local. No entanto, podemos observar a partir da análise dos dados, que havia divergências entre as respostas dos instrumentos de coleta de dados.

Entendemos que quando tomamos um determinado agravo como componente essencial do quadro nosológico da atenção à saúde, este deve ser acompanhado por informações que nos possibilitem atuar de forma efetiva no controle deste processo. As divergências que apontamos se referem ao fato de que $50 \%$ dos gerentes têm uma atuação esporádica quando responderam que às vezes participam da discussão e definição de ações para o controle da TB e, 68\% nunca participaram das discussões para a definição da aplicação de recursos no controle da doença.

Nesse sentido, é de se estranhar que o acúmulo de experiência na função gerencial não se coaduna com processos decisórios mais amplos em relação ao planejamento dos recursos e sua aplicabilidade no cenário onde desenvolvem suas atividades profissionais como gerentes. 
Outro fato importante que segue nessa mesma linha de pensamento se refere ao fato de que o trabalho de controle da TB é visto como ações pontuais e de certa forma, focalizadas.

Da mesma forma, o diagnóstico tardio da TB é percebido como rotineiro nos serviços de saúde local e a ritualização da procura sistemática dos usuários para o diagnóstico não é motivo de indignação para esses gerentes. Isso, em nossa opinião, poderia ser manifestado pelos gerentes, por ocasião da questão aberta, que possibilitou livre expressão aos depoentes. Nesse sentido, o que foi possível observar é que existe a constatação do fato e não há questionamentos sobre a problemática do diagnóstico tardio e da peregrinação do usuário pelo serviço de saúde até o diagnóstico final.

Por meio dos depoimentos, de ambos os instrumentos, foi possível apreender que o cotidiano da gerência da UBS é permeado por atividades técnico-burocráticas, nas quais busca responder às suas funções com o desenvolvimento de tarefas administrativas e normativas, tendo pouca expressão para a propositura de questões inovadoras no âmbito do planejamento local. O papel de intermediação entre a UBS e a SMS os torna cumpridores dessas responsabilidades administrativas e com pouca interferência no processo de mudanças da gestão local, o que nos leva a supor que esses não se vêem como responsáveis pela gerência das ações de controle da TB.

Identificamos também que há um descompasso no que concerne às alterações inerentes à gerência e o conhecimento da realidade do município, dada a falta de participação em instâncias diretivas onde são discutidos os recursos destinados à programas específicos e a adequabilidade destes para a região de 
pertencimento do gerente e isso, de certa forma, desresponsabiliza o mesmo para as questões de saúde emergentes em sua área de abrangência.

Esse “engessamento' da gerência pode ser um dos fatores que os exime da co-responsabilidade pelo cuidado ampliado em saúde para com a população adscrita a sua UBS.

Preocupa o fato de que para alguns gerentes há algumas ações de controle da TB, como a BSR, que não fazem parte das atividades da UBS e da visão do planejamento local destes gerentes.

Entendemos que ao serem designados para assunção das atividades da gerência, os gerentes deveriam ampliar os horizontes na visão do planejamento e da organização da atenção em saúde, com o intuito de promover espaços de discussão com a equipe de saúde sobre aspectos inerentes a cada área programática, identificando as potencialidades e limites para que o processo do cuidado em saúde seja exeqüível a cada realidade concreta.

Dessa forma, a gerência nas UBS é um campo de desafios que possui potencialidades e limites sendo que estes limites contribuem para uma gerência de baixo poder de vocalização, apresentando dificuldades no planejamento e organização das ações de controle da TB.

A AB tem potencialidades que permitem a incorporação das ações de TB nas UBS, no entanto, os profissionais devem estar capacitados para tal e imbuídos do trabalho interdisciplinar, importante aliado neste processo, pois é preciso conhecer as condições de vida dos doentes de TB, o entorno social ao qual está inserido para planejar e organizar a atenção a essa população de forma a obter a efetividade das ações. 
Uma das ações de competência da Atenção Básica é a BSR, e é um procedimento complexo que exige profícuas articulações dos ACS com toda a equipe de saúde da UBS. A BSR torna-se complexa na medida em que envolve o entorno do indivíduo permeado por: estigma, crenças, valores e culturas; agregado a isto há a dificuldade de acesso aos serviços de saúde, pois muitos dos usuários são trabalhadores e o horário de atendimento não é compatível com o período livre deles.

Contudo, acreditamos que se faz necessário uma gerência com maior envolvimento político que busque saberes da epidemiologia, das dimensões gerenciais do planejamento e organização, para que, dessa forma, estes atores tenham ferramentas que possibilitem o adequado desenvolvimento das ações gerenciais de controle da TB.

Sabemos que novos estudos envolvendo esta temática se fazem necessários, pois é por meio destes que podemos (re)construir novos saberes no âmbito da gerência que possam vir a contribuir para o controle da TB. 


\section{REFERÊNCIAS}

AMSTERDAM Declaration To Stop Tb. A call for accelerated action against tuberculosis. Amsterdam, 2000.

ARCÊNCIO, R. A. A organização do Tratamento Supervisionado nos municípios prioritários do Estado de São Paulo (2005). 2006. 139f. Dissertação (Mestrado) Escola de Enfermagem de Ribeirão Preto, Universidade de São Paulo, Ribeirão Preto, 2006.

ARCÊNCIO, R. A.; OLIVEIRA, M. F.; VILLA, T. C. S. Internações por tuberculose pulmonar no Estado de São Paulo no ano de 2004. Ciência e Saúde Coletiva, Rio de Janeiro, v.12, n. 2, p.409-417, 2007.

BARATA, L. R. B; TANAKA, O. Y; MENDES, J. D. V. Por um processo de descentralização que consolide os princípios do Sistema Único de Saúde. Epidemiol. Serv. Saúde, v.13, n.1, p.15-24, 2004.

BARBIERI, A. R.; HORTALE, V. A. Desempenho gerencial em serviços públicos de saúde: estudo de caso em Mato Grosso do Sul, Brasil. Cad. Saúde Pública, Rio de Janeiro, v.21, n.5, p.1349-1356, 2005

BARBOSA, P. R.; LIMA, S. M. L. Gestão em saúde: bases para maior eficiência e eficácia. Rev. Espaço Saúde. v. 5, n.5, p. 5-12, 1996.

BARDIN, L. Análise de conteúdo. 3. ed. Lisboa: Edições70, 2004. 223 p.

BODSTEIN, R. Atenção básica na agenda da saúde. Ciência e Saúde Coletiva v.7n.3, p.401-412, 2002.

BLANC, L.; MARTINEZ, L. Reaching the targets for TB control: call for papers. Bulletin of the World Health Organization, Geneva, v.86, n.9, p.688, 2006.

BRASIL. Ministério da Saúde. Fundação Nacional de Saúde. Centro Nacional de Epidemiologia. Coordenação Nacional de Pneumologia Sanitária. Programa de controle da tuberculose: diretrizes do plano de ação emergencial para municípios prioritários. Brasília, 1997. 
BRASIL. Ministério da Saúde. Secretaria das Políticas Públicas. Departamento de Atenção Básica. Coordenação Nacional de Pneumologia Sanitária. Plano de Controle da Tuberculose no Brasil no período de 2001-2005. Brasília, 1999.

BRASIL. Ministério da Saúde. Secretaria das Políticas Públicas. Departamento de Atenção Básica. Evolução do credenciamento e implantação da Estratégia Saúde da Família no período de jan.1998 a dez.2006. Brasília, 2000.

BRASIL. Ministério Da Saúde. Secretaria de Vigilância em Saúde. Departamento de Vigilância Epidemiológica. Coordenação geral de Doenças Endêmicas. Área Técnica de Pneumologia Sanitária. Programa Nacional De Controle Da Tuberculose. Brasília: Ministério da Saúde, 2004.

BRASIL, Ministério da Saúde. Departamento de apoio à descentralização, 2007. Disponível em:< www.dtr2001.saude.gov.br/dad/cgalP > acesso em: 20 maio 2007.

BREILH, J. Perspectivas para a crítica dos modelos convencionais. A necessidade de transformar a epidemiologia e redirecionar a clínica. In: BREILH, J. Epidemiologia, economia, política e saúde. São Paulo: Unesp/HUCITEC. 1991, p. 40-70.

CAMPINAS, L. L. S. L. Conhecimentos e opiniões de usuários sobre o valor do exame de escarro, de um serviço de saúde do município de São Paulo visando qualidade das amostras para o diagnóstico da tuberculose pulmonar pelo método bacteriológico. 1999. Dissertação (Mestrado) - Faculdade de Saúde Pública, Universidade de São Paulo, São Paulo, 1999.

CAMPOS, R. O. Análise do planejamento como dispositivo mediador de mudanças institucionais com base em estudo de caso. Cad. Saúde Pública, Rio de Janeiro, v.16, n.4, p. 1021-1030, 2000.

CAMPOS, G. W.S.; MERHY, E. E.; NUNES, E. D. Planejamento sem normas. São Paulo: HUCITEC. 1994.

COHN, A.; WESTPHAL, M. F.; ELIAS, P. E. Informação e decisão política em saúde. Rev. Saúde Pública,São Paulo, v.39, n.1, p. 114-21, 2005.

CORDEIRO, H. Descentralização, universalidade e equidade nas reformas de saúde. Ciência e Saúde Coletiva, Rio de Janeiro, v.6, n.2, p.319-328, 2001. 
COSTA, N. R; PINTO, L. F. Avaliação de programa de atenção à saúde: incentivo à oferta de atenção ambulatorial e a experiência da descentralização no Brasil. Ciência e Saúde Coletiva, Rio de Janeiro, v.7, n.4, p.907-923, 2002.

DATASUS. População residente no Estado de São PAULO. Informações em saúde, 2008 Disponível em: < http:/tabnet.datasus.gov.br>. Acesso em 04 set. 2008.

DUCATI, R. G.; RUFFINO-NETTO, A.; BASSO, L. A.; SANTOS, D. S. The resumption of consumption - A review on tuberculosis. Mem. Inst. Oswaldo Cruz, Rio de Janeiro, v.101, n.7, p.697-714, 2006.

ERMEL, R. C.; FRACOLLI, L. A. Processo de trabalho de gerência: uma revisão de literatura. Rev. Esc. Enferm. USP, São Paulo, v. 37, n. 2, p. 89-96, 2003.

FRACOLLI, L. A; EGRY, E. Y. Processo de trabalho de gerência: instrumento potente para operar mudanças nas práticas de saúde? Rev.Latino-am Enfermagem, Ribeirão Preto, v.9, n.5, p.13-8, 2001.

HIJAR, M. A; GERHARDT, G, TEIXEIRA, G. M, PROCÓPIO, M. J. Retrospecto do controle da tuberculose no Brasil. Revista de Saúde Pública. 41 (Supl 1): p.50-58, 2007

HURTIG, A. K.; PORTER, J. D. H.; OGDEN,J. A. Tuberculosis control and directly observed therapy from the public health/human right perspective. The international Journal of Tuberculosis and Lung Disease, v.3, n.7, p. 553-560, 1999.

LUCCHESE, P. T. R. Equidade na gestão descentralizada do SUS: desafios para a redução de desigualdades em saúde. Ciência e Saúde Coletiva, Rio de Janeiro, v.8, n.2, p.439-448, 2003.

LUCCA, M. E. S. Análise epidemiológica da tuberculose e co-infecção HIV/TB em Ribeirão Preto;SP de 1998-2006. 2008, 133p. Dissertação (Mestrado), Faculdade de Medicina de Ribeirão Preto, Universidade de São Paulo, Ribeirão Preto, 2008.

MACHADO, M. F. A. S.; MONTEIRO, E. M. L. M.; QUEIROZ, D. T.; VIEIRA, N. F. C.; BARROSO, M. G. T. Integralidade, formação de saúde, educação em saúde e as propostas do SUS - uma revisão conceitual. Ciência e Saúde Coletiva,Rio de Janeiro, v.12, n.2, p.335-342, 2007. 
MARTINS, G. A. Estudo de caso, uma estratégia de pesquisa. São Paulo: Atlas, 2006.101p.

MAZZAIA, M. C. Conhecimentos, atitudes e práticas do pessoal de enfermagem visando a qualidade de amostras de escarro para baciloscopia no diagnóstico da tuberculose pulmonar. 2000. Dissertação (Mestrado) Faculdade de Saúde Pública, Universidade de São Paulo, São Paulo, 2000.

MENDES, E. V. Os grandes dilemas do SUS. Salvador: Casa da Qualidade. 2001.Tomo II.

MENDES, E. V. Um novo paradigma sanitário: a produção social da saúde. In: MENDES, E. V. In: Uma agenda para a saúde. São Paulo: HUCITEC; 1996. p.233295.

MERHY, E. E. Em busca de ferramentas analisadoras das tecnologias em saúde: a micropolítica do trabalho vivo em saúde. In: MERHY, E. E.; ONOKO, R.; Orgs. Agir em saúde: um desafio para o público. São Paulo. HUCITEC: 1997. p. 71-112.

MERHY, E. E.; ONOCKO, R.; Orgs. Agir em saúde: um desafio para o público. São Paulo. HUCITEC; 1997.

MERHY, E. E.; QUEIROZ, M. S. Saúde pública, Rede básica e o sistema de saúde Brasileiro. Caderno de Saúde Pública, Rio de Janeiro, v.9, n.2, p.177-184, abr/jun, 1993.

MINAYO, M. C. de S. O desafio do conhecimento. Pesquisa qualitativa em saúde. São Paulo: Hucitec, 2004. 269p.

MISHIMA, S. M. Constituição de gerenciamento local na rede básica de saúde de Ribeirão Preto.1995. 152f. Tese (Doutorado) - Escola de Enfermagem de Ribeirão Preto, Universidade de São Paulo, Ribeirão Preto, 1995.

MONROE, A. A; CARDOZO GONZALES, R. I; PALHA, P. F; SASSAKI, C. M; RUFFINO NETTO, A; VENDRAMINI, S. H; VILLA, T. C. S. Envolvimento de equipes da atenção básica à saúde no controle da Tuberculose.Rev.Esc.Enferm.USP, São Paulo, v.42, n.2, p.262-7.

MONNERAT, G. L; SENNA, M. C. M; SOUZA, R. G. A reorganização dos serviços de saúde no cenário local. Ciência e Saúde Coletiva, Rio de Janeiro, v.7, n.3, p.509-521, 2002. 
MUNIZ, J. N. O programa de agentes comunitários de saúde na identificação de sintomáticos respiratórios no controle da tuberculose em Ribeirão Preto - SP: um desafio para a atenção primária 'saúde. 2004. 148f. Tese (Doutorado) Escola de Enfermagem de Ribeirão Preto, Universidade de São Paulo, Ribeirão Preto, 2004.

MUNIZ J.N., PALHA P.F., MONROE A.A, CARDOZO-GONZALES R.I., RUFFINO NETTO A., VILLA T.C.S. A incorporação da busca ativa de sintomáticos respiratórios para o controle da tuberculose na prática do agente comunitário de saúde. Ciência e Saúde Coletiva, Rio de Janeiro, v.10, n. 2, p.315-321, 2005.

NEMES, M. I. B. Prática programática em saúde. In: SCHRAIBER, L. B. et al. Saúde do adulto: Programas e ações na unidade básica. 2.ed. São Paulo: Hucitec, p. 48-65.

NOGUEIRA, J. de A.; RUFFINO NETTO, A.; MONROE, A. A.; CARDOZO GONZALES, R. I.; VILLA, T. C. S. Busca ativa de sintomáticos respiratórios no controle da tuberculose na percepção do Agente Comunitário de Saúde. Revista Eletrônica de Enfermagem, v.09, p.106-118, 2007.

OLIVEIRA, M. F. A busca de sintomáticos respiratórios para o controle da tuberculose nos municípios prioritários do Estado de São Paulo/SP (2005). 2005. 105f. Dissertação (Mestrado) - Escola de Enfermagem de Ribeirão Preto, Universidade de São Paulo, Ribeirão Preto, 2006.

OGDEN, J.; WALT, G.; LUSH, L. The politics of branding in policy transfer: the case of DOTS for tuberculosis control. Social Science \& Medicine, Leiscester, v.57, p. 179-88, 2003.

PAIM, J. S. Epidemiologia e planejamento: a recomposição das práticas epidemiológicas na gestão do SUS. Ciência e Saúde Coletiva. Rio de Janeiro, v.8, n.2, p. 557-567, 2003.

PASSOS, J. P.; CIOSAK, S. I. A concepção dos enfermeiros no processo gerencial em Unidade Básica de Saúde. Rev Esc Enferm USP, São Paulo, 2006. v.40, n. 4, p. 464-8, 2006

RAMIRES, E. P.; LOURENÇÃO, L. G.; SANTOS, M. R. Gerenciamento em Unidades Básicas de Saúde: conhecendo experiências. Arq. Ciênc. Saúde, v.11, n.4, p.205-9, 2004 
RUFFINO-NETTO, A. Tuberculose: a calamidade negligenciada. Revista da Sociedade Brasileira de Medicina Tropical, Brasília, v.35, n.1, p.51-58, 2002.

SANTANA, J. P. Desenvolvimento gerencial no SUS: demandas e perspectivas. Rev. Espaço Saúde, v.5, n.5, p. 13-22, 1996.

SANTOS, J. Resposta brasileira ao controle da tuberculose. Rev. Saúde Pública. v.41, n.1, p. 89-94, 2007.

SANTOS FILHO, E. T. Política de TB no Brasil: uma perspectiva da sociedade civil. Rio de Janeiro: Public Health Watch, 2006. 85p.

SECRETARIA MUNICIPAL DE SAÚDE. Divisão de tuberculose. Centro de Vigilância Epidemiológica. Manual de orientação para coleta de amostras de escarro e outros materiais para baciloscopia e cultura para diagnóstico e controle da tuberculose. São Paulo, 2002

SILVA, L. M. V; HARTZ, Z. M. A.; CHAVES, S. C. L.; SILVA, G. A. P.; PAIM, J. S. Análise da implantação da gestão descentralizada em saúde: estudo comparado de cinco casos da Bahia, Brasil.Caderno de Saúde Pública, Rio de Janeiro, v.23, n.2, p.355-370, 2007.

SCHRAIBER, L. B.; PEDUZZI, M.; SALA, A.; NEMES, M. I. B.; CASTANHEIRA, E. R. L. COM, R. Planejamento, gestão e avaliação em saúde: identificando problemas. Ciência e Saúde Coletiva, Rio de Janeiro, v.4, n.2, p.221-242, 1999.

TEIXEIRA, C. F. Epidemiologia e planejamento de saúde. Ciência e Saúde Coletiva. v.4, n.2, p.287-303, 1999.

TEIXEIRA, G. DOTS: A RETOMADA DE UMA ESTRATÁGIA. Rio de Janeiro, 1998. 5p. /mimeografado/.

TEIXEIRA, G. Onde estamos e aonde vamos no que toca ao controle da tuberculose. Boletim de Pneumologia Sanitária, Rio de Janeiro, v. 12, n. 1, p. 5-6, 2004.

TEIXEIRA, C. F. Promoção e vigilância da saúde no contexto da regionalização da assistência à saúde no Sistema Único de Saúde. Cadernos de Saúde Pública, Rio de Janeiro, v. 18 (suplemento), p. 153-162, 2002. 
TESTA, M. Pensamento estratégico e lógica de programação o caso da saúde. ed. Hucitec;Abrasco, São Paulo - Rio de Janeiro, p.306, 1995,

VANDERLEI, M. I. G.; ALMEIDA, M. C. P. A concepção e prática dos gestores e gerentes da estratégia de saúde da família. Ciência e Saúde Coletiva. Rio de Janeiro, v. 12, n. 2, p. 443-453, 2007.

VIANA, A. L. A; HEIMANN, L. S; LIMA, L. D; OLIVEIRA, R. G; RODRIGUES, S. H. Mudanças significativas no processo de descentralização do sistema de saúde no Brasil. Cadernos de Saúde Pública, Rio de Janeiro, v.18 (suplemento), p.139-151, 2002.

VILA, A. C. D.; VILA, V. DA S. C. Tendências da produção do conhecimento na educação em saúde no Brasil. Rev. Latino-am Enfermagem, Ribeirão Preto, v.15, n.6, p. 64-79, 2007.

VILASBÔAS, A. L. Q.; PAIM, J. S. Práticas de planejamento e implementação de políticas no âmbito municipal. Cad. Saúde Pública, Rio de Janeiro, v.24, n.6, p.1239-1250, 2008.

VILLA, T. C. S. BRUNELLO, M. E.; F.; ARCÊNCIO, R. A.; SASSAKI, C. M.; ASSIS, E. G.; CARDOZO-GONZALES, R. I.; Fatores preditivos aos resultados desfavoráveis no tratamento da tuberculose: revisão integrativa da literatura (2001-2005). Online Brazilian Journal of Nursing, Disponível em www.uff.br/objnursing/index.php/nursing/article/view/1676-4285.2008.1098/288. 2008. Acesso em: 23 de junho de 2007.

VILLA, T. C. S.; RUFFINO-NETTO, A.; ARCÊNCIO, R. A.; GONZALES-CARDOZO, R. I. As políticas de controle de tuberculose no sistema de saúde no Brasil e implantação da estratégia DOTS (1980-2005). In: RUFFINO NETTO, A.; VILLA, T. C. S. (Orgs.). Tuberculose - Implantação do DOTS em algumas regiões do Brasil. Histórico e peculiaridades regionais. Ribeirão Preto: FMRP/REDE TB-USP, 2006. cap. 2, p. 29-48.

WORLD HEALTH ORGANIZATION. Global tuberculosis control: WHO Report 2000. Geneva: WHO, 2000. 275 p.

WORLD HEALTH ORGANIZATION. An Expanded DOTS Agência Brasil; no dia mundial de luta contra a Tuberculose, Brasil tem pouco a comemorar.Geneva: WHO Report, 2004. 349p. 
WORLD HEALTH ORGANIZATION. Tuberculosis control. surveillance, planning, financing. Geneva: WHO Report, 2005, 316p.

WORLD HEALTH ORGANIZATION. Global tuberculosis control: surveillance, planning, financing: WHO report 2006. Geneva: WHO, 2006.

WORLD HEALTH ORGANIZATION. Global tuberculosis control: surveillance, planning, financing: WHO report 2007. Geneva: WHO, 2007, 267p.

YUNES, J. O SUS na lógica da descentralização. Estudos Avançados. v.13, n.35, p.65-70, 1999. 


\section{APÊNDICE A}

\section{TERMO DE CONSENTIMENTO LIVRE E ESCLARECIDO}

Prezado (a) senhor (a),

Gostaria de convidá-lo (a) para participar de uma pesquisa sobre "Avaliação das dimensões organizacionais e de desempenho dos serviços de atenção básica no controle da TB em centros urbanos de diferentes regiões do Brasil".

Esta pesquisa está sendo realizada por uma equipe de pesquisadores da instituição: Ela tem como objetivo avaliar o atendimento de tuberculose nos serviços de saúde do Estado de São Paulo.

Sua participação consistirá em responder a um questionário, que dura em média 30 minutos, e as informações fornecidas contribuirão com a melhoria dos serviços de saúde na atenção a Tuberculose.

$\mathrm{Eu}$, tendo recebido as informações acima e ciente de meus direitos abaixo relacionados, concordo em participar.

A garantia de receber todos os esclarecimentos sobre as perguntas do questionário antes e durante a entrevista, podendo afastar-me em qualquer momento se assim o desejar, bem como está me assegurado o segredo das informações por mim reveladas;

A segurança de que não serei identificado, assim como está assegurado que a pesquisa não trará prejuízo a mim e a outras pessoas;

A segurança de que não terei nenhuma despesa financeira durante o desenvolvimento da pesquisa,

A garantia de que todas as informações por mim fornecidas serão utilizadas apenas na construção da pesquisa e ficará sob a guarda dos pesquisadores, podendo ser requisitada por mim a todo o momento.

Uma cópia desta declaração deve ficar com o (a) Sr. (a).

$$
\text { Ribeirão Preto, }
$$
, de de 2007

\section{Assinatura do entrevistado}

Telefone:

Certos de estar contribuindo com o conhecimento em Tuberculose para a melhoria da saúde da população contarmos com a sua preciosa colaboração.

Atenciosamente

Prof $^{\mathrm{a}} \mathrm{Dr}^{\mathrm{a}}$ Tereza Cristina Scatena Villa

CONTATO: Escola de Enfermagem de Ribeirão Preto da Universidade de São Paulo. Endereço: Avenida Bandeirantes, 3900 Campus Universitário - Ribeirão Preto - SP; CEP 14049-900 - SP Telefone (0XX16) 36023228

e.mail: tite@eerp.usp.br 


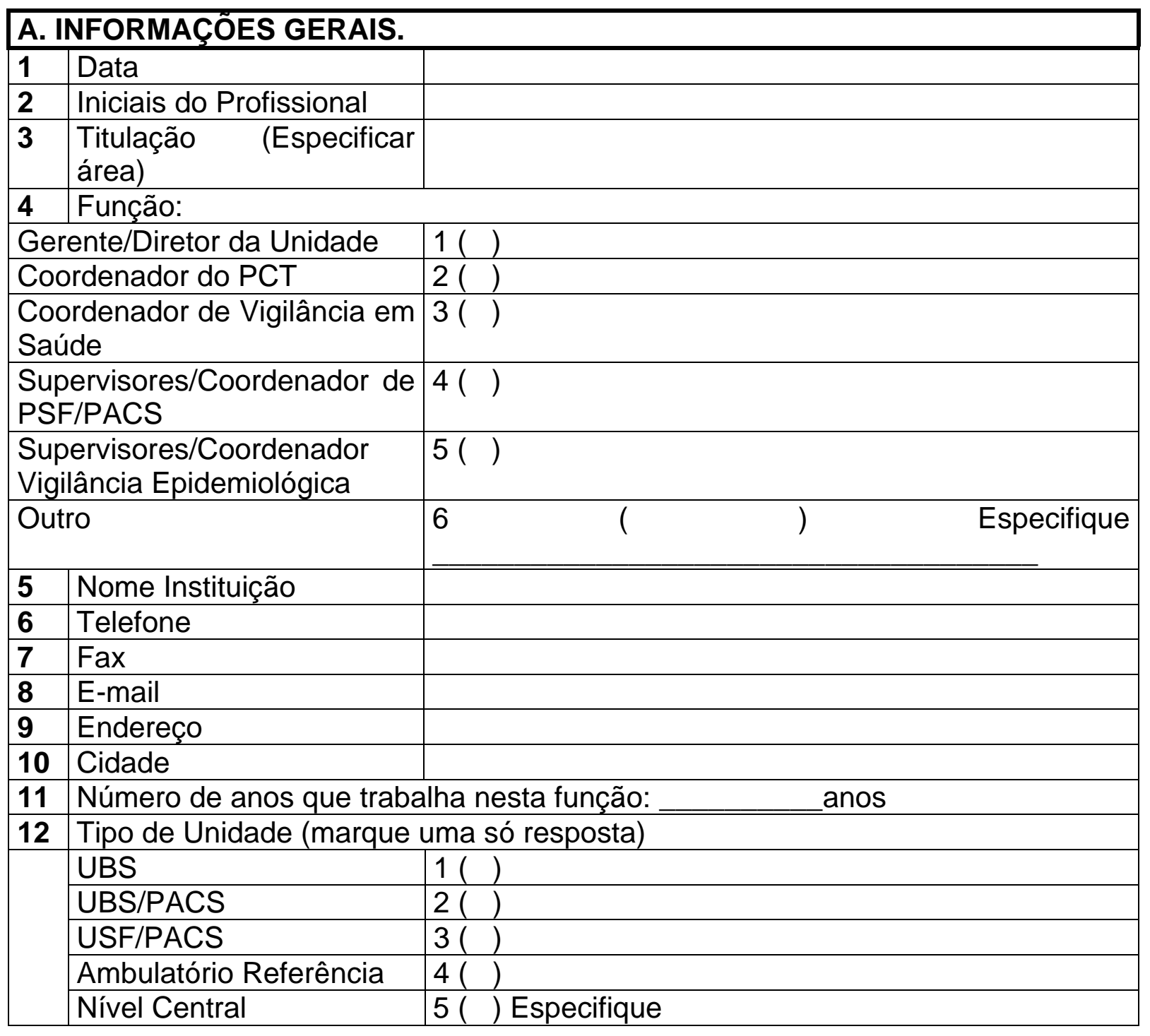

\section{\begin{tabular}{lllllllll}
\hline OBS: MOSTRAR & $E$ & EXPLICAR & AO & ENTREVISTADO & $O$ & CARTÃO & DE
\end{tabular} RESPOSTAS: A-B-C}

\section{B. A TB NA AGENDA MUNICIPAL}

\begin{tabular}{|l|l|c|c|c|c|c|}
\hline \multicolumn{2}{|c|}{ CARTÃo C } & Nunca & $\begin{array}{c}\text { Quase } \\
\text { Nunca }\end{array}$ & Às Vezes & $\begin{array}{c}\text { Quase } \\
\text { Sempre }\end{array}$ & Sempre \\
\cline { 2 - 6 } & 1 & 2 & 3 & 4 & 5 \\
\hline 13 & $\begin{array}{l}\text { A TB é considerada } \\
\text { como uma doença } \\
\text { prioritária no quadro } \\
\text { sanitário do município? }\end{array}$ & & & & & \\
\hline 14 & $\begin{array}{l}\text { A distribuição de } \\
\text { recursos para TB, é } \\
\text { realizada com base nas } \\
\text { necessidades da } \\
\text { população a ser } \\
\text { atendida? }\end{array}$ & & & & \\
\hline
\end{tabular}




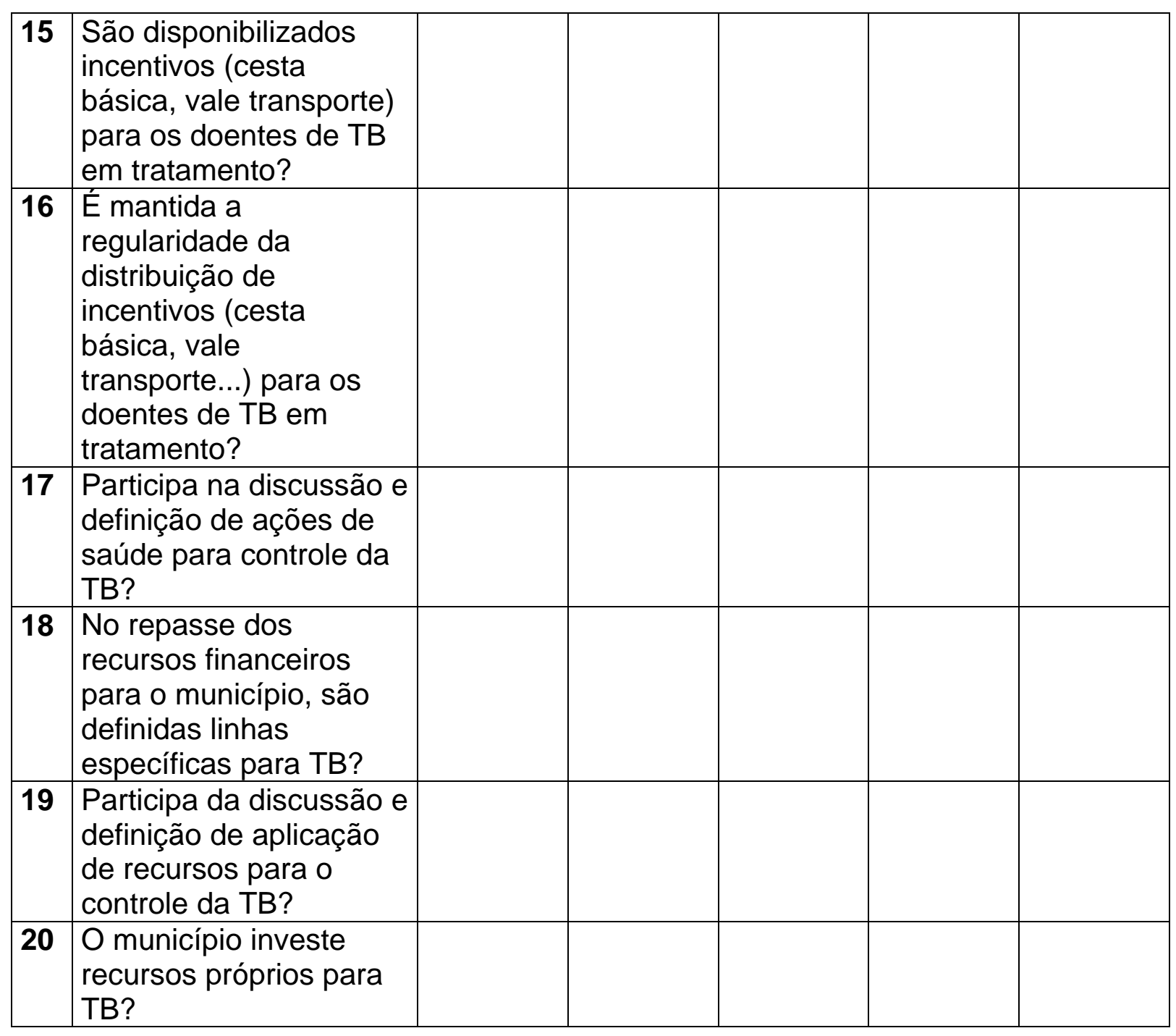

C. PORTA DE ENTRADA

\begin{tabular}{|c|c|c|c|c|c|c|}
\hline \multirow{2}{*}{\multicolumn{2}{|c|}{ CARTÃO C }} & Nunca & $\begin{array}{l}\text { Quase } \\
\text { Nunca }\end{array}$ & Às Vezes & $\begin{array}{l}\text { Quase } \\
\text { Sempre }\end{array}$ & Sempre \\
\hline & & 1 & 2 & 3 & 4 & 5 \\
\hline 21 & $\begin{array}{l}\text { Os recursos (potes, } \\
\text { viatura, motorista, } \\
\text { combustível, material de } \\
\text { laboratório,...) são } \\
\text { suficientes para atender } \\
\text { as necessidades de } \\
\text { controle da TB? }\end{array}$ & & & & & \\
\hline
\end{tabular}

\begin{tabular}{|c|c|c|c|c|c|}
\hline \multirow{2}{*}{ CARTÃo B } & Sempre & $\begin{array}{c}\text { Quase } \\
\text { Sempre }\end{array}$ & Às Vezes & $\begin{array}{c}\text { Quase } \\
\text { Nunca }\end{array}$ & Nunca \\
\cline { 2 - 6 } & 1 & 2 & 3 & 4 & 5 \\
\hline
\end{tabular}




\begin{tabular}{|l|l|l|l|l|l|}
\hline 22 & $\begin{array}{l}\text { Os recursos financeiros } \\
\text { destinados à TB são } \\
\text { aplicados em outros } \\
\text { programas/necessidades } \\
\text { de saúde? }\end{array}$ & & & & \\
\hline
\end{tabular}

\begin{tabular}{|c|c|c|c|c|c|c|}
\hline \multirow{2}{*}{\multicolumn{2}{|c|}{ CARTÃO C }} & Nunca & $\begin{array}{l}\text { Quase } \\
\text { Nunca } \\
\end{array}$ & Às Vezes & $\begin{array}{c}\text { Quase } \\
\text { Sempre }\end{array}$ & Sempre \\
\hline & & 1 & 2 & 3 & 4 & 5 \\
\hline 23 & \begin{tabular}{lrr} 
Quando & os & usuários \\
precisam & de & algum \\
controle de & saúde \\
preventivo & \multicolumn{2}{c}{ (vacinar } \\
BCG, exames de \\
escarro), vão ao ao \\
posto/centro/unidade de \\
saúde? \\
\end{tabular} & & & & & \\
\hline 24 & $\begin{array}{l}\text { Quando os usuários } \\
\text { apresentam } \\
\text { sinais/sintomas de TB } \\
\text { procuram primeiro o } \\
\text { posto/centro/unidade de } \\
\text { saúde? }\end{array}$ & & & & & \\
\hline 25 & $\begin{array}{l}\text { Quando os usuários } \\
\text { apresentam } \\
\text { sinais/sintomas de TB, } \\
\text { procuram primeiro o } \\
\text { pronto socorro/hospital? }\end{array}$ & & & & & \\
\hline 26 & $\begin{array}{l}\text { Quando os usuários } \\
\text { precisam de uma } \\
\text { consulta com algum } \\
\text { especialista, primeiro } \\
\text { procuram o } \\
\text { posto/centro/unidade de } \\
\text { saúde que realiza o } \\
\text { tratamento de TB, para } \\
\text { ser encaminhado? }\end{array}$ & & & & & \\
\hline
\end{tabular}

\section{ACESSO}

\begin{tabular}{|l|l|c|c|c|c|c|}
\hline \multicolumn{2}{|c|}{ CARTÃO B } & Sempre & $\begin{array}{c}\text { Quase } \\
\text { Sempre }\end{array}$ & Às Vezes & $\begin{array}{c}\text { Quase } \\
\text { Nunca }\end{array}$ & Nunca \\
\cline { 2 - 6 } & 1 & 2 & 3 & 4 & 5 \\
\hline 27 & $\begin{array}{l}\text { Quando os usuários } \\
\text { apresentam } \\
\text { sinais/sintomas de TB, } \\
\text { têm dificuldade para se } \\
\text { deslocarem até ao } \\
\text { posto/centro/unidade de } \\
\text { saúde? }\end{array}$ & & & & & \\
\hline
\end{tabular}




\begin{tabular}{|l|l|c|c|c|c|c|}
\hline \multicolumn{2}{|c|}{ CARTÃo C } & Nunca & $\begin{array}{c}\text { Quase } \\
\text { Nunca }\end{array}$ & Às Vezes & $\begin{array}{c}\text { Quase } \\
\text { Sempre }\end{array}$ & Sempre \\
\cline { 2 - 6 } & 1 & 2 & 3 & 4 & 5 \\
\hline 28 & $\begin{array}{l}\text { Quando os usuários } \\
\text { procuram om } \\
\text { posto/centro/unidade de } \\
\text { saúde com } \\
\text { sinais/sintomas de TB } \\
\text { conseguem consulta no } \\
\text { prazo de 24 horas? }\end{array}$ & & & & & \\
\hline
\end{tabular}

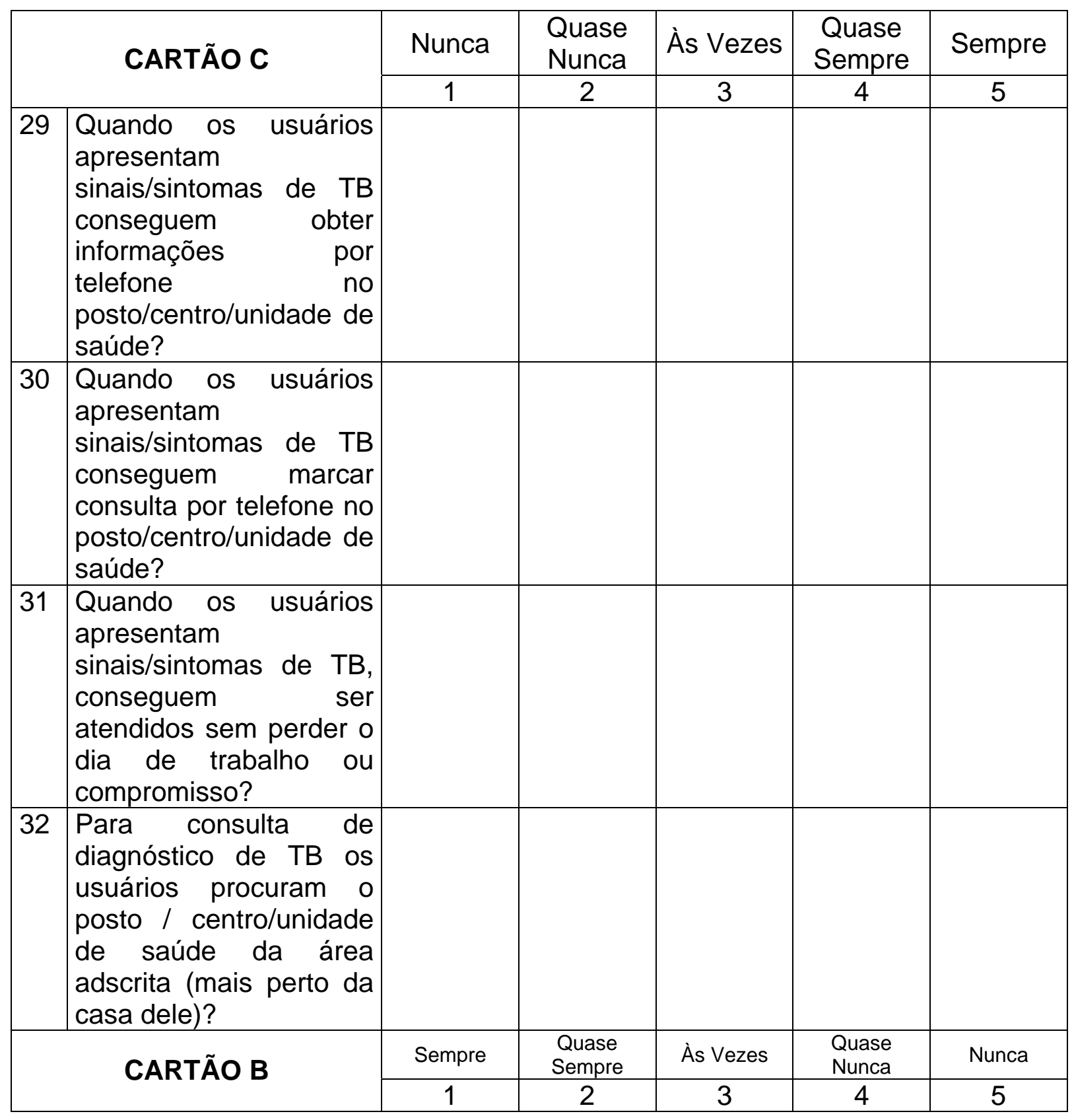




\begin{tabular}{|l|l|l|l|l|}
\hline 33 & $\begin{array}{l}\text { Para consulta de } \\
\text { diagnóstico de TB os } \\
\text { usuários precisam } \\
\text { utilizar algum tipo de } \\
\text { transporte motorizado } \\
\text { para ir ao } \\
\text { posto/centro/unidade de } \\
\text { saúde? }\end{array}$ & & & \\
\hline 34 & $\begin{array}{l}\text { Durante as consultas } \\
\text { para diagnóstico da TB } \\
\text { os usuários gastam } \\
\text { dinheiro com transporte } \\
\text { para ir ao } \\
\text { posto/centro/unidade de } \\
\text { saúde? }\end{array}$ & & & \\
\hline 35 & $\begin{array}{l}\text { Quando os usuários } \\
\text { apresentam os } \\
\text { sinais/sintomas da TB, } \\
\text { têm que esperar mais } \\
\text { de 60 minutos no } \\
\text { posto/centro/unidade de } \\
\text { saúde para serem } \\
\text { atendidos? }\end{array}$ & & \\
\hline
\end{tabular}

D 2. ACESSO AO TRATAMENTO.

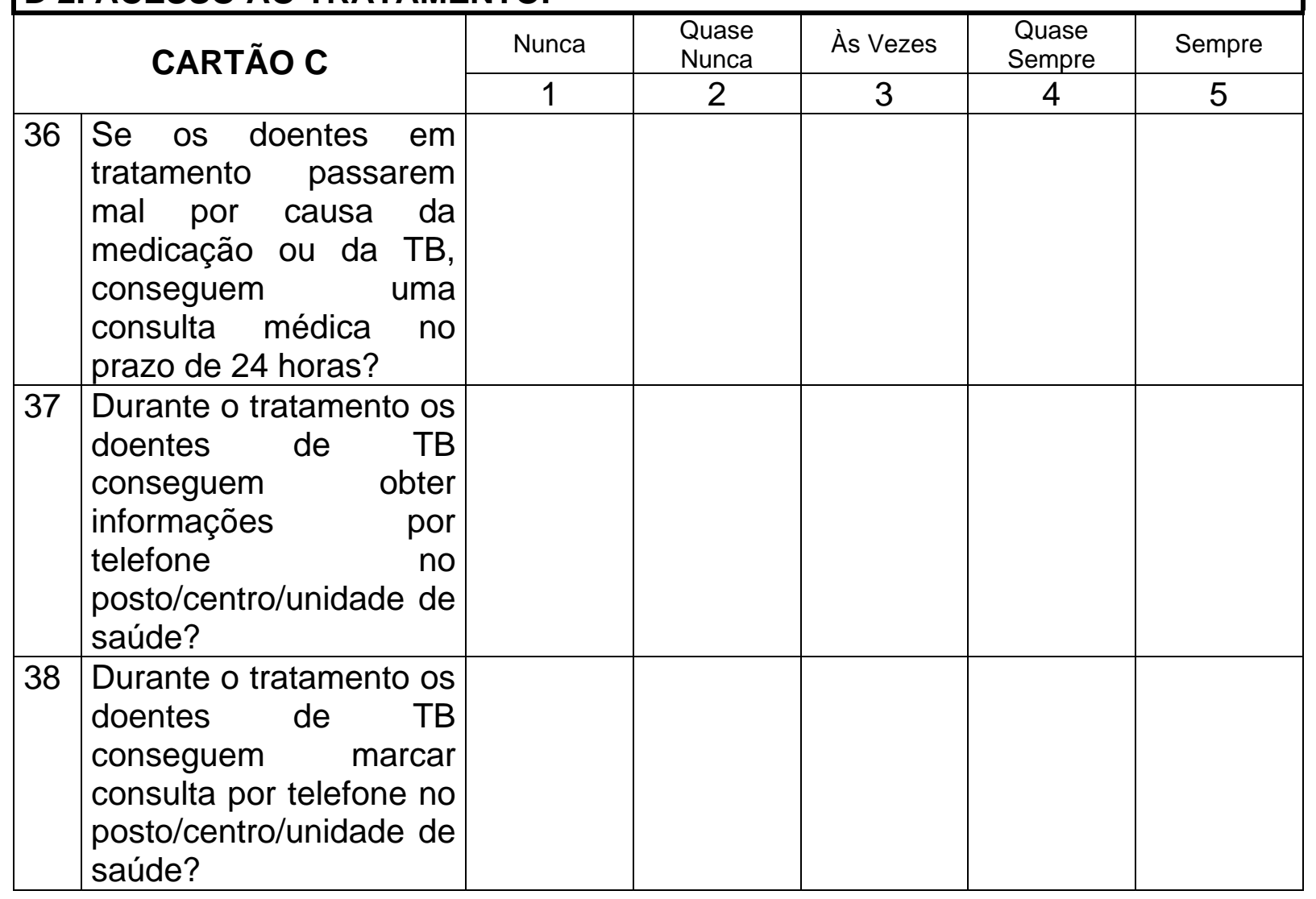




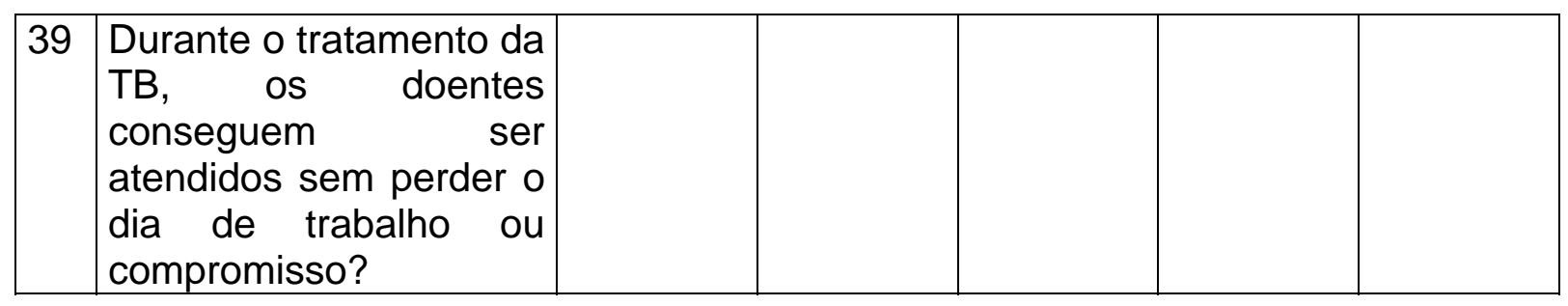

\begin{tabular}{|c|c|c|c|c|c|c|}
\hline \multirow{2}{*}{\multicolumn{2}{|c|}{ CARTÃO B }} & Sempre & $\begin{array}{l}\text { Quase } \\
\text { Sempre }\end{array}$ & Às Vezes & $\begin{array}{l}\text { Quase } \\
\text { Nunca }\end{array}$ & Nunca \\
\hline & & 1 & 2 & 3 & 4 & 5 \\
\hline 40 & $\begin{array}{l}\text { Os doentes de TB têm } \\
\text { que utilizar algum tipo } \\
\text { de transporte } \\
\text { motorizado para ir ao } \\
\text { posto/centro/unidade de } \\
\text { saúde? }\end{array}$ & & & & & \\
\hline 41 & $\begin{array}{l}\text { Os doentes de TB têm } \\
\text { que pagar pelo } \\
\text { transporte para ir ao } \\
\text { posto/centro/unidade de } \\
\text { saúde }\end{array}$ & & & & & \\
\hline 42 & $\begin{array}{l}\text { Durante os últimos } 12 \\
\text { meses, houve falta de } \\
\text { medicamentos para } \\
\text { TB? }\end{array}$ & & & & & \\
\hline 43 & $\begin{array}{lll}\text { Os doentes de } & \text { TB } \\
\text { esperam mais de } & 60 \\
\text { minutos } & & \text { no } \\
\text { posto/centro/unidade de } \\
\text { saúde para r serem } \\
\text { atendidos? }\end{array}$ & & & & & \\
\hline & & Nunca & $\begin{array}{l}\text { Quase } \\
\text { Nunca } \\
\end{array}$ & Às Vezes & $\begin{array}{c}\text { Quase } \\
\text { Sempre }\end{array}$ & Sempre \\
\hline & & 1 & 2 & 3 & 4 & 5 \\
\hline 44 & $\begin{array}{ll}\text { Os profissionais do } \\
\text { posto/centro/unidade de } \\
\text { saúde realizam visitas } \\
\text { domiciliares aos } \\
\text { doentes de TB? }\end{array}$ & & & & & \\
\hline 45 & $\begin{array}{l}\text { Todos os doentes de } \\
\text { TB tratados no } \\
\text { posto/centro/unidade de } \\
\text { saúde pertencem à área } \\
\text { adscrita? }\end{array}$ & & & & & \\
\hline
\end{tabular}

E. VíNCULO.

CARTÃO C

\begin{tabular}{|c|c|c|c|c|}
\hline Nunca & $\begin{array}{c}\text { Quase } \\
\text { Nunca }\end{array}$ & Às Vezes & $\begin{array}{c}\text { Quase } \\
\text { Sempre }\end{array}$ & Sempre \\
\hline 1 & 2 & 3 & 4 & 5 \\
\hline
\end{tabular}




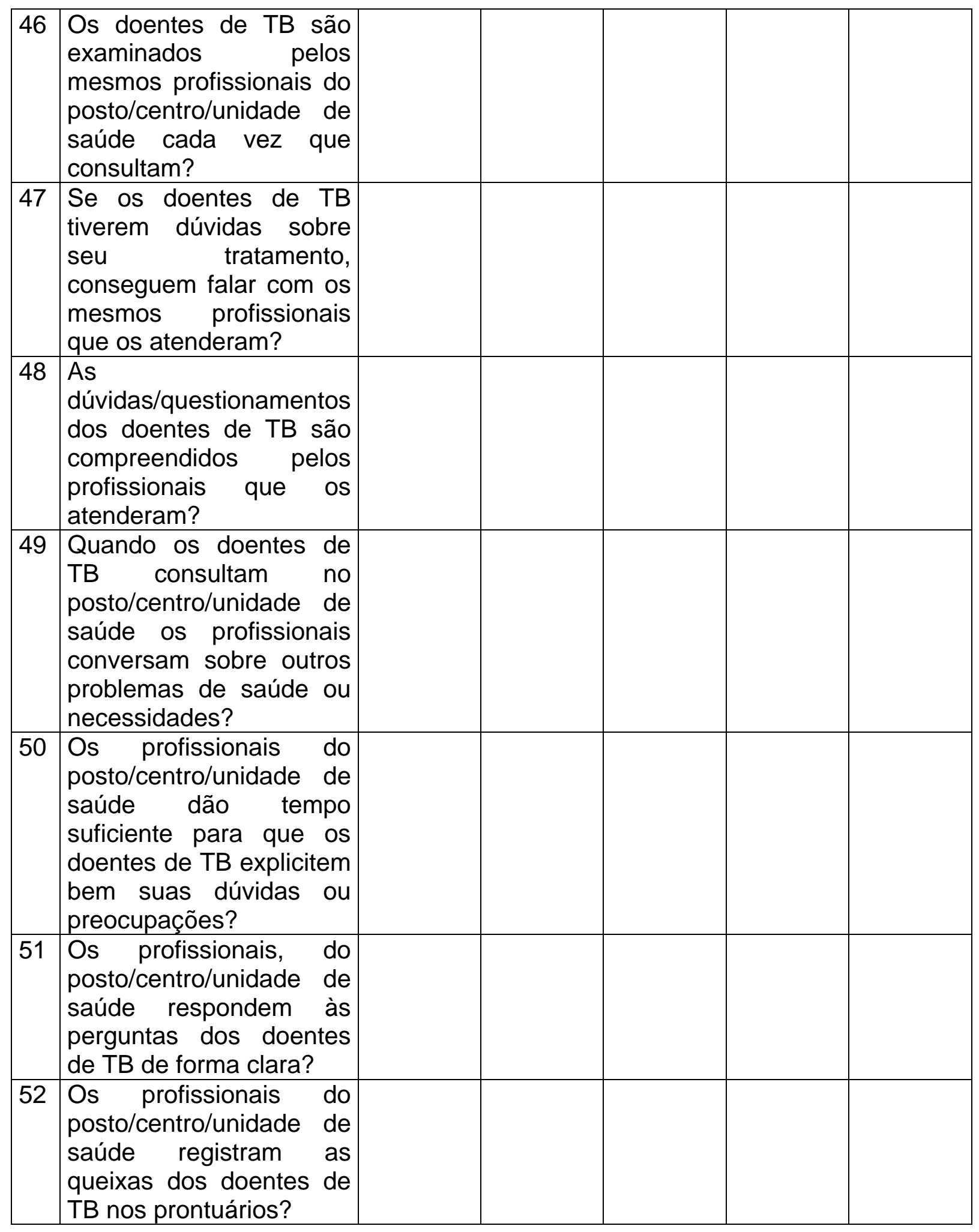




\begin{tabular}{|c|c|c|c|c|c|c|}
\hline \multirow{2}{*}{\multicolumn{2}{|c|}{ CARTÃO C }} & Nunca & $\begin{array}{l}\text { Quase } \\
\text { Nunca }\end{array}$ & Às Vezes & $\begin{array}{c}\text { Quase } \\
\text { Sempre }\end{array}$ & Sempre \\
\hline & & 1 & 2 & 3 & 4 & 5 \\
\hline 53 & $\begin{array}{l}\text { Os profissionais do } \\
\text { posto/centro/unidade de } \\
\text { saúde informam aos } \\
\text { doentes de TB sobre os } \\
\text { medicamentos } \\
\text { utilizados para o } \\
\text { tratamento da doença? }\end{array}$ & & & & & \\
\hline 54 & $\begin{array}{lr}\text { Os profissionais do } \\
\text { posto/centro/unidade de } \\
\text { saúderrander, solicitam } \\
\text { informaçores, sobre } \\
\text { todos os medicamentos } \\
\text { utilizados pelos doentes } \\
\text { de TB? }\end{array}$ & & & & & \\
\hline 55 & \multicolumn{6}{|c|}{$\begin{array}{l}\text { Na sua experiência, quando os doentes de TB têm algum problema de saúde ou } \\
\text { outras necessidades (cesta básica, vale transporte...), com que freqüência } \\
\text { procuram os seguintes profissionais? }\end{array}$} \\
\hline \multirow{2}{*}{\multicolumn{2}{|c|}{ CARTÃO C }} & Nunca & $\begin{array}{l}\text { Quase } \\
\text { Nunca }\end{array}$ & Às Vezes & $\begin{array}{l}\text { Quase } \\
\text { Sempre }\end{array}$ & Sempre \\
\hline & & 1 & 2 & 3 & 4 & 5 \\
\hline $\begin{array}{l}55 \\
a\end{array}$ & Médico & & & & & \\
\hline $\begin{array}{l}55 \\
b\end{array}$ & Enfermeiro & & & & & \\
\hline $\begin{array}{l}55 \\
c\end{array}$ & Auxiliar de Enfermagem & & & & & \\
\hline $\begin{array}{l}55 \\
d\end{array}$ & $\begin{array}{l}\text { Ag. Comunitários de } \\
\text { Saúde/ACS }\end{array}$ & & & & & \\
\hline $\begin{array}{l}55 \\
\mathrm{e}\end{array}$ & Outros Profissionais & & & & & \\
\hline \multicolumn{7}{|c|}{\begin{tabular}{l|l}
56 & $\begin{array}{l}\text { O tratamento é aceito } \\
\text { pelos doentes de TB? }\end{array}$
\end{tabular}} \\
\hline \multirow{2}{*}{\multicolumn{2}{|c|}{ CARTÃO A }} & $\begin{array}{l}\text { Muito } \\
\text { Ruim }\end{array}$ & Ruim & Regular & Bom & $\begin{array}{l}\text { Muito } \\
\text { Bom }\end{array}$ \\
\hline & & 1 & 2 & 3 & 4 & 5 \\
\hline 57 & $\begin{array}{llr}\text { Como o(a) Sr.(a) } \\
\text { considera } & \text { o } \\
\text { atendimento da equipe } \\
\text { de saúde aos doentes } \\
\text { de } \quad \text { TB r do } \\
\text { posto/centro/unidade de } \\
\text { saúde? }\end{array}$ & & & & & \\
\hline
\end{tabular}

\section{F. ELENCO DE SERVIÇOS.}

Com que freqüência o seu posto/centro/unidade de saúde oferece os seguintes serviços?

\begin{tabular}{|l|c|c|c|c|c|}
\hline CARTÃO C & Nunca & $\begin{array}{c}\text { Quase } \\
\text { Nunca }\end{array}$ & Às Vezes & $\begin{array}{c}\text { Quase } \\
\text { Sempre }\end{array}$ & Sempre \\
\hline
\end{tabular}




\begin{tabular}{|c|c|c|c|c|c|c|}
\hline & & 1 & 2 & 3 & 4 & 5 \\
\hline 58 & \begin{tabular}{|l} 
Pote para exame de \\
escarro \\
diagnóstico?
\end{tabular} & & & & & \\
\hline 59 & Exame para HIVIAIDS? & & & & & \\
\hline 60 & $\begin{array}{l}\text { Teste da pele (prova } \\
\text { tuberculínica)? }\end{array}$ & & & & & \\
\hline 61 & $\begin{array}{l}\text { Pote para exame de } \\
\text { escarro para controle }\end{array}$ & & & & & \\
\hline 62 & $\begin{array}{l}\text { Consulta de controle } \\
\text { para o tratamento da } \\
\text { TB? }\end{array}$ & & & & & \\
\hline 63 & $\begin{array}{|lrr|}\text { Entrega de } & \text { cestas } \\
\text { básicas } & \text { ou } & \text { vale } \\
\text { alimentação? } & \end{array}$ & & & & & \\
\hline 64 & $\begin{array}{l}\text { Entrega de } \\
\text { transporte? }\end{array}$ & & & & & \\
\hline 65 & $\begin{array}{l}\text { Informação sobre a TB } \\
\text { e seu tratamento? }\end{array}$ & & & & & \\
\hline 66 & 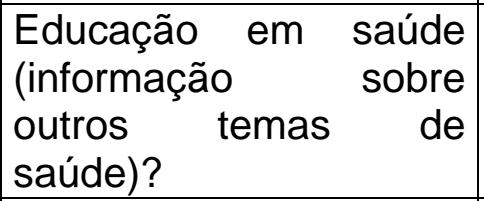 & & & & & \\
\hline 67 & \begin{tabular}{|l|} 
Visitas domiciliares \\
durante o tratamento?
\end{tabular} & & & & & \\
\hline 68 & $\begin{array}{l}\text { Visitas domiciliares por } \\
\text { outros motivos além da } \\
\text { TB? }\end{array}$ & & & & & \\
\hline 69 & $\begin{array}{l}\text { Formação de grupos de } \\
\text { doentes de TB no } \\
\text { posto/centro/unidade de } \\
\text { saúde? }\end{array}$ & & & & & \\
\hline 70 & $\begin{array}{l}\text { Tratamento } \\
\text { Supervisionado? * }\end{array}$ & & & & & \\
\hline \multicolumn{7}{|c|}{$\begin{array}{l}\text { * Obs.: Considerar Nunca (Auto - administrado); Quase nunca (A cada } 15 \text { ou } 30 \\
\text { dias); Âs vezes (1-2 vezes/ semana); Quase Sempre (3-4 vezes/ semana); Sempre } \\
\text { (Todos os dias úteis da semana) }\end{array}$} \\
\hline
\end{tabular}

\section{G. COORDENAÇÃO.}

\begin{tabular}{|c|c|c|c|c|c|c|}
\hline \multirow{2}{*}{\multicolumn{2}{|c|}{ CARTÃO C }} & Nunca & $\begin{array}{l}\text { Quase } \\
\text { Nunca }\end{array}$ & Às Vezes & $\begin{array}{c}\text { Quase } \\
\text { Sempre }\end{array}$ & Sempre \\
\hline & & 1 & 2 & 3 & 4 & 5 \\
\hline 71 & $\begin{array}{l}\text { Os profissionais do } \\
\text { posto/centro/unidade de } \\
\text { saúde utilizam os } \\
\text { prontuários quando } \\
\text { estão examinando os } \\
\text { doentes de TB? }\end{array}$ & & & & & \\
\hline
\end{tabular}




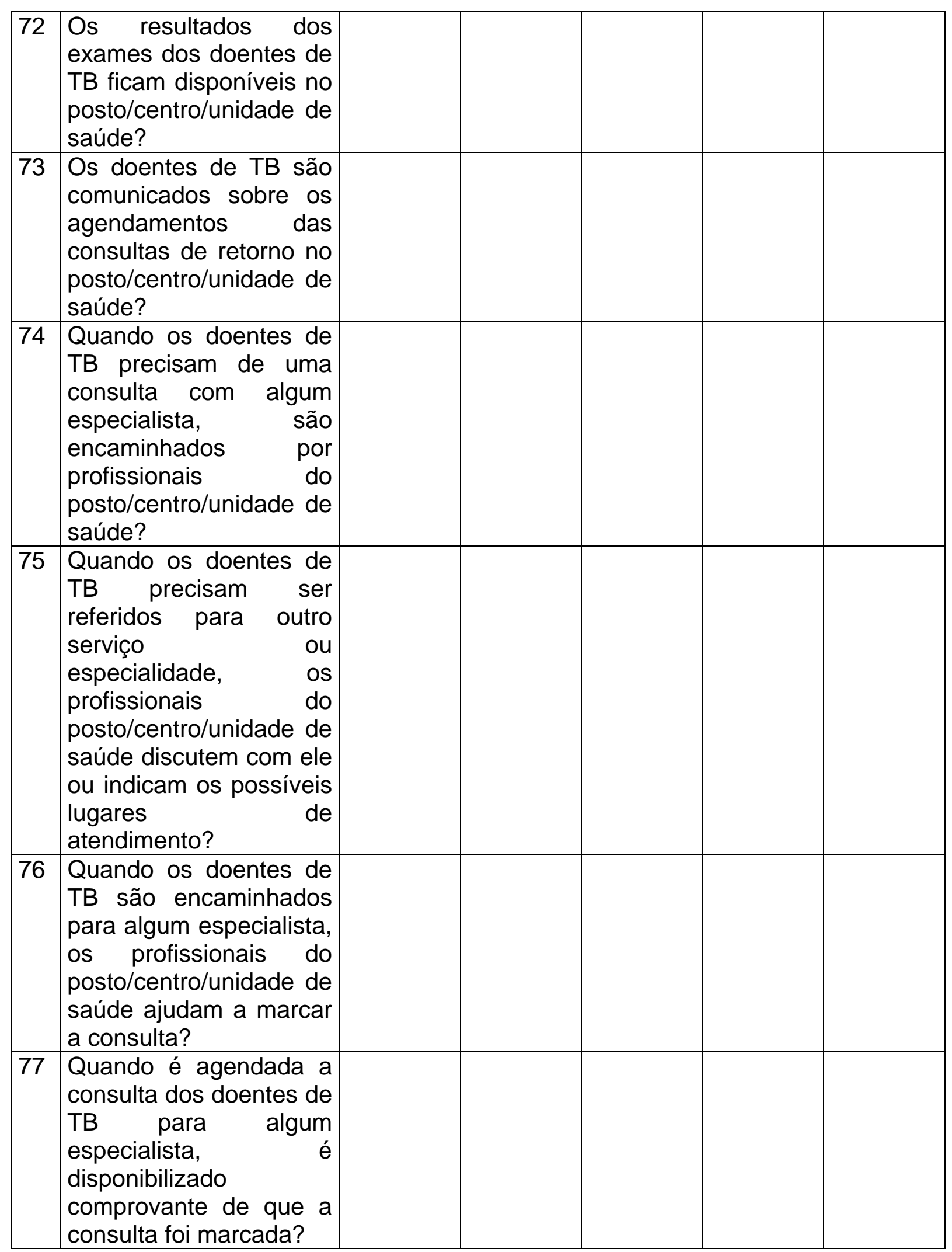




\begin{tabular}{|l|l|l|l|l|l|}
\hline 78 & $\begin{array}{l}\text { Quando os doentes de } \\
\text { TB são referidos para } \\
\text { outros serviços ou } \\
\text { especialidades, os } \\
\text { profissionais do } \\
\text { posto/centro/unidade de } \\
\text { saúder fornecem } \\
\text { informações escritas } \\
\text { para entregar ao serviço } \\
\text { referido? }\end{array}$ & & & & \\
\hline 79 & $\begin{array}{l}\text { Quando os doentes de } \\
\text { TB retornam ao } \\
\text { posto/centro/unidade de } \\
\text { saúde após a consulta } \\
\text { com om especialista, } \\
\text { trazem informações } \\
\text { escritas sobre os } \\
\text { resultados? }\end{array}$ & & & \\
\hline 80 & $\begin{array}{l}\text { Os profissionais do } \\
\text { posto/centro/unidade de } \\
\text { saúde discutem com os } \\
\text { doentes de TB sobre as } \\
\text { consultas realizadas } \\
\text { com os especialistas? }\end{array}$ & & & \\
\hline 81 & $\begin{array}{l}\text { Os profissionais do } \\
\text { posto/centro/unidade de } \\
\text { saúde se preocupam } \\
\text { com a assistência } \\
\text { prestada pelos } \\
\text { especialistas aos } \\
\text { doentes de TB? }\end{array}$ & & & \\
\hline
\end{tabular}

H. ENFOQUE NA FAMÍLIA.

\begin{tabular}{|c|c|c|c|c|c|c|}
\hline \multirow{2}{*}{\multicolumn{2}{|c|}{ CARTÃO C }} & Nunca & $\begin{array}{l}\text { Quase } \\
\text { Nunca }\end{array}$ & Às Vezes & $\begin{array}{l}\text { Quase } \\
\text { Sempre }\end{array}$ & Sempre \\
\hline & & 1 & 2 & 3 & 4 & 5 \\
\hline 82 & $\begin{array}{l}\text { Durante as consultas os } \\
\text { profissionais do } \\
\text { posto/centro/unidade de } \\
\text { saúde perguntam sobre } \\
\text { as condições de vida } \\
\text { dos doentes de TB e } \\
\text { família (emprego, } \\
\text { disponibilidade de água } \\
\text { potável, saneamento } \\
\text { básico...)? }\end{array}$ & & & & & \\
\hline
\end{tabular}




\begin{tabular}{|l|l|l|l|l|}
\hline 83 & $\begin{array}{l}\text { Durante as consultas os } \\
\text { profissionais do } \\
\text { posto/centro/unidade de } \\
\text { saúde, pedem } \\
\text { informações sobre } \\
\text { enfermidades das } \\
\text { pessoas que moram } \\
\text { com os doentes de TB? }\end{array}$ & & & \\
\hline 84 & $\begin{array}{l}\text { Os profissionais do } \\
\text { posto/centro/unidade de } \\
\text { saúde realizam } \\
\text { consultas nas pessoas } \\
\text { que moram com os } \\
\text { doentes de TB? }\end{array}$ & & & \\
\hline 85 & $\begin{array}{l}\text { Os profissionais do } \\
\text { posto/centro/unidade de } \\
\text { saúde realizam exames } \\
\text { para investigação da } \\
\text { doença nas pessoas } \\
\text { que moram com os } \\
\text { doentes de TB? }\end{array}$ & & \\
\hline 86 & $\begin{array}{l}\text { Os profissionais do } \\
\text { posto/centro/unidade de } \\
\text { saúde conhecem as } \\
\text { pessoas que moram } \\
\text { com os doentes de TB? }\end{array}$ & & \\
\hline 87 & $\begin{array}{l} \\
\text { Os profissionais do } \\
\text { posto/centro/unidade de } \\
\text { saúde conversam com } \\
\text { a família sobre o } \\
\text { problema de saúde dos } \\
\text { doentes de TB? }\end{array}$ & & \\
\hline 88 & $\begin{array}{l}\text { Os profissionais do } \\
\text { posto/centro/unidade de } \\
\text { saúde falam com a } \\
\text { família dos doentes de } \\
\text { TB sobrea doença? }\end{array}$ & & \\
\hline 89 & $\begin{array}{l} \\
\text { Os profissionais do } \\
\text { posto/centro/unidade de } \\
\text { saúde conversam com } \\
\text { a família dos doentes } \\
\text { de TB sobre o } \\
\text { tratamento da doença? }\end{array}$ & & \\
\hline 90 & $\begin{array}{l}\text { Os profissionais do } \\
\text { posto/centro/unidade de } \\
\text { saúde conversam com } \\
\text { a família dos doentes } \\
\text { problemas de saúde? }\end{array}$ & & \\
\hline
\end{tabular}




\begin{tabular}{|c|c|c|c|c|c|c|}
\hline \multicolumn{7}{|c|}{ I. ORIENTAÇÃO PARA COMUNIDADE. } \\
\hline \multirow{2}{*}{\multicolumn{2}{|c|}{ CARTÃO C }} & Nunca & $\begin{array}{l}\text { Quase } \\
\text { Nunca }\end{array}$ & Às Vezes & $\begin{array}{c}\text { Quase } \\
\text { Sempre }\end{array}$ & Sempre \\
\hline & & 1 & 2 & 3 & 4 & 5 \\
\hline 91 & $\begin{array}{l}\text { Os profissionais do } \\
\text { posto/centro/unidade de } \\
\text { saúde realizam } \\
\text { entrevistas com os } \\
\text { doentes de } \\
\text { atendidos para saber se } \\
\text { os serviços oferecidos } \\
\text { estão respondendo às } \\
\text { suas necessidades de } \\
\text { saúde? }\end{array}$ & & & & & \\
\hline
\end{tabular}

\begin{tabular}{|c|c|c|c|c|c|c|}
\hline \multirow{2}{*}{\multicolumn{2}{|c|}{ CARTÃO C }} & Nunca & $\begin{array}{l}\text { Quase } \\
\text { Nunca }\end{array}$ & Às Vezes & $\begin{array}{c}\text { Quase } \\
\text { Sempre }\end{array}$ & Sempre \\
\hline & & 1 & 2 & 3 & 4 & 5 \\
\hline 92 & $\begin{array}{l}\text { Os profissionais do } \\
\text { posto/centro/unidade de saúde } \\
\text { realizam } \\
\text { propagandas/campanhas/trabalhos } \\
\text { educativos, para informar a } \\
\text { comunidade sobre TB? }\end{array}$ & & & & & \\
\hline 93 & $\begin{array}{l}\text { Os profissionais do } \\
\text { posto/centro/unidade de saúde } \\
\text { trabalham em parceria com outras } \\
\text { instituições (igreja, associações de } \\
\text { bairro, abrigos...) para identificar } \\
\text { sintomáticos respiratórios? }\end{array}$ & & & & & \\
\hline 94 & $\begin{array}{l}\text { Os profissionais do } \\
\text { posto/centro/unidade de saúde } \\
\text { realizam busca de sintomáticos } \\
\text { respiratórios na comunidade? }\end{array}$ & & & & & \\
\hline 95 & $\begin{array}{l}\text { Os profissionais } \\
\text { posto/centro/unidade de saúde } \\
\text { solicitam a participação de um } \\
\text { representante da comunidade para } \\
\text { discutir o problema da TB? }\end{array}$ & & & & & \\
\hline
\end{tabular}

\section{J. FORMAÇÃO PROFISSIONAL.}

\begin{tabular}{|l|l|c|c|c|c|c|}
\hline \multicolumn{2}{|c|}{ CARTÃo C } & Nunca & $\begin{array}{c}\text { Quase } \\
\text { Nunca }\end{array}$ & Às Vezes & $\begin{array}{c}\text { Quase } \\
\text { Sempre }\end{array}$ & Sempre \\
\cline { 2 - 6 } & 1 & 2 & 3 & 4 & 5 \\
\hline 96 & $\begin{array}{l}\text { Os doentes de TB } \\
\text { encontram um profissional } \\
\text { no posto/centro/unidade } \\
\text { de saúde para atendê-los } \\
\text { em dias úteis da semana? }\end{array}$ & & & & & \\
\hline
\end{tabular}




\begin{tabular}{|c|c|c|c|c|c|c|}
\hline 97 & \begin{tabular}{|lr} 
Os doentes de & TB \\
atendidos & pelos \\
profissionais & do \\
posto/centro/unidade de & daúde recomendariam o \\
saso do serviço para um \\
amigo ser atendido?
\end{tabular} & & & & & \\
\hline 98 & 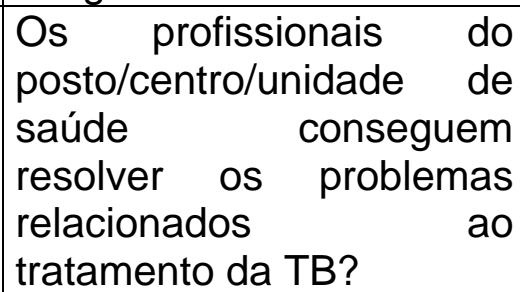 & & & & & \\
\hline 99 & $\begin{array}{l}\text { Os profissionais do do } \\
\text { posto/centro/unidade de } \\
\text { saúde conseguem } \\
\text { resolver os problemas de } \\
\text { saúde dos doentes de TB } \\
\text { e família? }\end{array}$ & & & & & \\
\hline \multirow{2}{*}{\multicolumn{2}{|c|}{ CARTÃO B }} & Sempre & $\begin{array}{c}\text { Quase } \\
\text { Sempre }\end{array}$ & Às Vezes & $\begin{array}{l}\text { Quase } \\
\text { Nunca }\end{array}$ & Nunca \\
\hline & & 1 & 2 & 3 & 4 & 5 \\
\hline 100 & $\begin{array}{l}\text { Os doentes de TB sofrem } \\
\text { discriminaçãor pelos } \\
\text { profissionais/trabalhadores } \\
\text { do posto/centro/unidade } \\
\text { de saúde por causa da } \\
\text { doença? }\end{array}$ & & & & & \\
\hline 101 & $\begin{array}{l}\text { Os doentes de TB mudam } \\
\text { de posto/centro/unidade } \\
\text { de saúde por causa dos } \\
\text { profissionais que os } \\
\text { atendem? }\end{array}$ & & & & & \\
\hline
\end{tabular}

\begin{tabular}{|l|l|c|c|c|c|c|}
\hline \multicolumn{2}{|c|}{ CARTÃo C } & Nunca & $\begin{array}{c}\text { Quase } \\
\text { Nunca }\end{array}$ & Às Vezes & $\begin{array}{c}\text { Quase } \\
\text { Sempre }\end{array}$ & Sempre \\
\cline { 2 - 6 } & 1 & 2 & 3 & 4 & 5 \\
\hline 102 & $\begin{array}{l}\text { Os profissionais do } \\
\text { posto/centro/unidade de } \\
\text { saúder foram } \\
\text { qualificados para } \\
\text { atender TB? }\end{array}$ & & & & \\
\hline 103 & $\begin{array}{l}\text { Os profissionais do } \\
\text { posto/centro/unidade de } \\
\text { saúde foram } \\
\text { qualificados para atuar } \\
\text { segundo a diversidade } \\
\text { cultural da } \\
\text { comunidade? }\end{array}$ & & & & \\
\hline
\end{tabular}




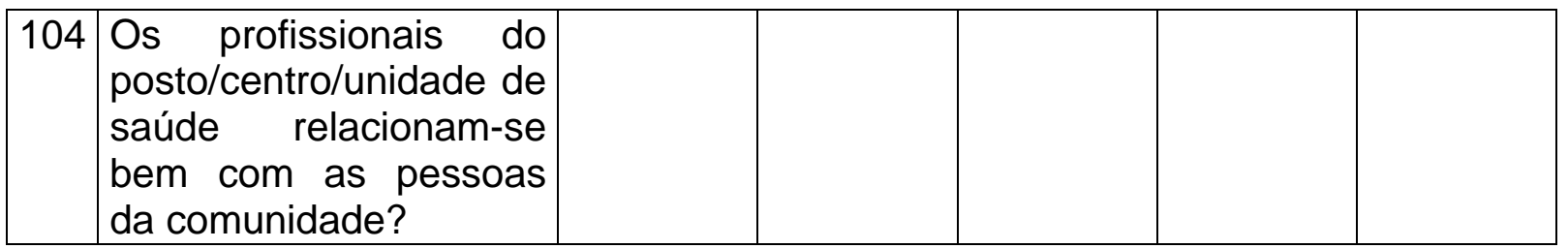

Suas sugestões, comentários, e /ou dúvidas.

Agradecimento pela participação!

Observações do entrevistador 

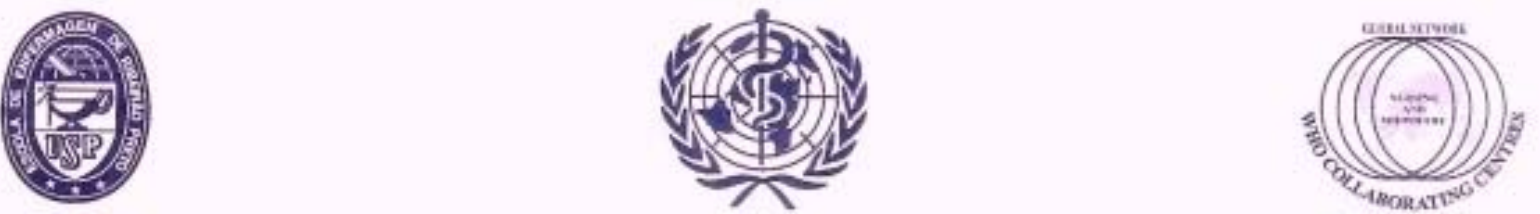

ESCOLA DE ENFERMAGEM DE RIBEIRÃO PRETO - UNIVERSIDADE DE SÃO PAULO

CENTRO COLABORADOR DA ORGANIZAÇĀO MUNDIAL DA SAÚDE PARA

O DESENVOLVIMENTO DA PESQUISA EM ENFERMAGEM

Avenida Bandeirantes, 3900 - Campus Univerșitário - Ribeirào Preto - CEP 14040-902 - Sĩo Paulo - Brasil FAX: (55) - 16 - 3633-3271/3602-4419 / TELEFONE: $(55)-16-3602-3382$

\section{COMITÊ DE ÉTICA EM PESQUISA DA EERP/USP}

Of.CEP-EERP/USP - 054/2007

Ribeirāo Preto, 22 de março de 2007

Prezada Senhora,

Comunicamos que o projeto de pesquisa, abaixo especificado, foi analisado e considerado APROVADO, pelo Comitê de Ética em Pesquisa da Escola de Enfermagem de Ribeirăo Preto da Universidade de Sāo Paulo, em sua

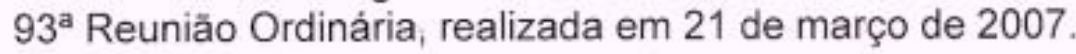

Protocolo: $n^{0} 0762 / 2007$

Projeto: AVALIAÇÃO DAS DIMENSÖES ORGANIZACIONAIS E DE DESEMPENHO DOS SERVIÇOS DE ATENÇĀO BASICA NO CONTROLE DA TB EM CENTROS URBANOS DE DIFERENTES REGIŌES DO BRASIL.

Pesquisador: Tereza Cristina Scatena Villa

Em atendimento à Resolução 196/96, deverá ser encaminhado ao CEP o relatório final da pesquisa e a publicação de seus resultados, para acompanhamento, bem como comunicada qualquer intercorrência ou a sua interrupção.

Atenciosamente,

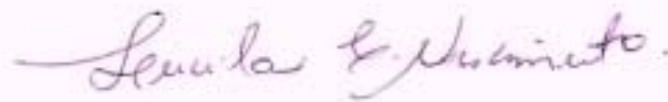

Prof ${ }^{\mathrm{a}} \mathrm{Dr}^{\mathrm{a}}$ Lucila Castanheira Nascimento

Coordenadora do CEP-EERP/USP

IIma. Sra.

Prof ${ }^{\mathrm{D}} \mathrm{r}^{\mathrm{a}}$ Tereza Cristina Scatena Villa

Dept $^{\circ}$ de Enfermagem Materno-Infantil e Saúde Pública

Escola de Enfermagem de Ribeirăo Preto - USP 